University of Montana

ScholarWorks at University of Montana

Graduate Student Theses, Dissertations, \&

Professional Papers

2020

\title{
MICROSEISMIC EVIDENCE FOR BOOKSHELF FAULTING IN WESTERN MONTANA
}

Ellen McGough Smith

Follow this and additional works at: https://scholarworks.umt.edu/etd

Part of the Geophysics and Seismology Commons

Let us know how access to this document benefits you.

\section{Recommended Citation}

Smith, Ellen M. "MICROSEISMIC EVIDENCE FOR BOOKSHELF FAULTING IN WESTERN MONTANA" (2020). Graduate Student Theses, Dissertations, \& Professional Papers. 12575 https://scholarworks.umt.edu/etd/ 12575

This Thesis is brought to you for free and open access by the Graduate School at ScholarWorks at University of Montana. It has been accepted for inclusion in Graduate Student Theses, Dissertations, \& Professional Papers by an authorized administrator of ScholarWorks at University of Montana. For more information, please contact scholarworks@mso.umt.edu. 


\title{
MICROSEISMIC EVIDENCE FOR BOOKSHELF FAULTING IN WESTERN MONTANA
}

By

\section{ELLEN MCGOUGH SMITH}

Bachelor of Arts in Geology, Colorado College, Colorado Springs, Colorado, 2016

\author{
Thesis \\ Presented in partial fulfillment of the requirements \\ for the degree of \\ Master of Science \\ in Geosciences \\ The University of Montana \\ Missoula, MT \\ January 2020 \\ Approved by: \\ Scott Whittenburg, Dean of the Graduate School \\ Graduate School \\ Dr. Hilary Martens, Chair \\ Geosciences \\ Dr. Rebecca Bendick \\ Geosciences \\ Dr. Paul Janzen \\ Physics \\ Dr. Michael Stickney \\ Director of Earthquake Studies at Montana Bureau of Mines and Geology
}


Microseismic Evidence for Bookshelf Faulting in Western Montana

Chairperson: Dr. Hilary Martens

One of the most seismically active regions in the western United States, far from any major plate boundary, is the Intermountain Seismic Belt (ISB). On 6 July 2017, a M5.8 earthquake occurred $11 \mathrm{~km}$ southeast of Lincoln, Montana within the ISB. This was the largest earthquake to occur in the state of Montana since the 1959 M7.3 Hebgen Lake earthquake. Data from the University of Montana Seismic Network (UMSN), the Montana Regional Seismic Network (MRSN), and the United States Geological Survey (USGS) were used to investigate the aftershock sequences following the M5.8 Lincoln event. We have manually picked P- and Swave arrival times, computed hypocenter locations and double difference re-locations, and generated focal mechanisms for hundreds of aftershocks in the two years following the main shock. We characterize the spatial and temporal evolution of the aftershock sequence, identify seismogenic faults, and characterize the local stress field. The main shock focal mechanism together with aftershock patterns indicate left-lateral slip on a NNE-trending fault plane for the main shock. Most aftershocks concentrate near the main shock but smaller clusters of hypocenters form north-south trending clusters to the west of the main shock. We suggest that faults identified oblique to the prominent WNW trending Lewis and Clark Line (LCL) faults may indicate a bookshelf faulting mechanism that accommodates differential extension rates in terrains north and south of the LCL. 


\section{Table of Contents}

Background, Motivation and Research Objectives...........................................1

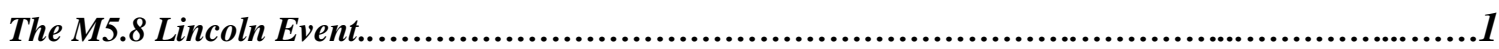

The Study from McMahon et al. (2019)...................................................2

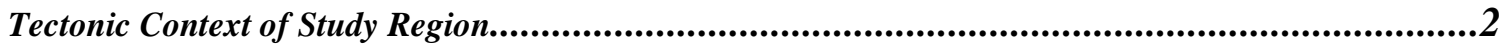

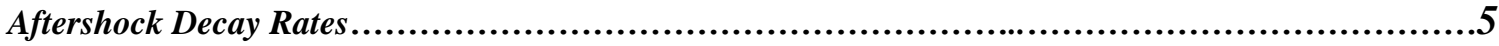

Historical Events in Montana, Seismic Networks, and Research Objectives...............................6

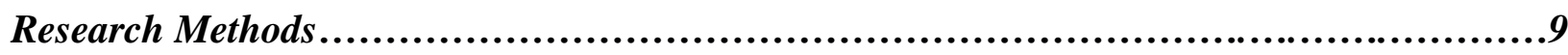

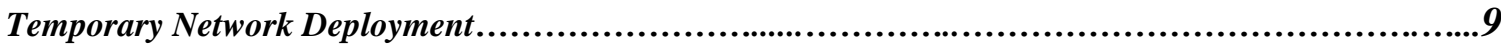

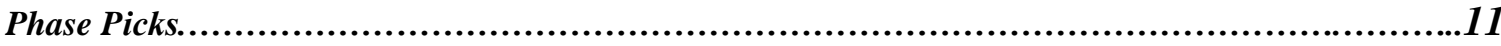

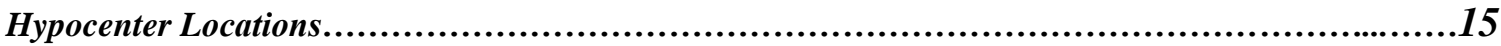

Double Difference Relocations..........................................................................17

Focal Mechanism Solutions...........................................................................19

Results..............................................................................................23

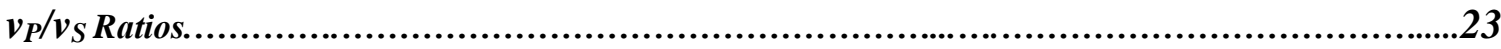

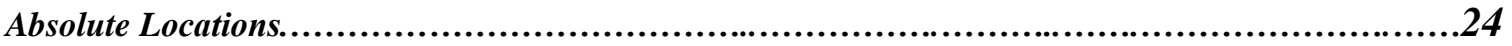

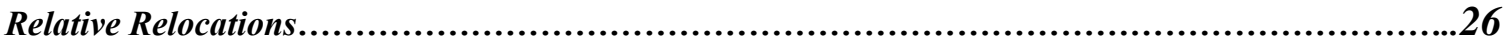

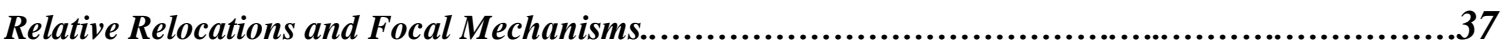

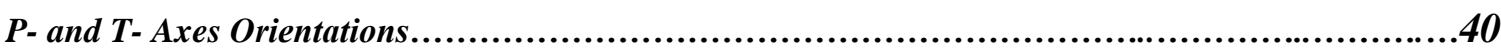

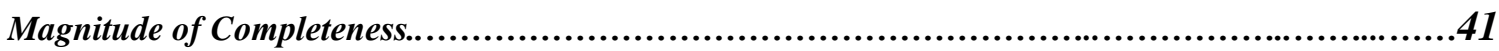

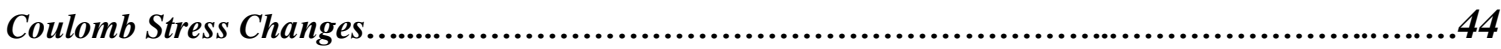

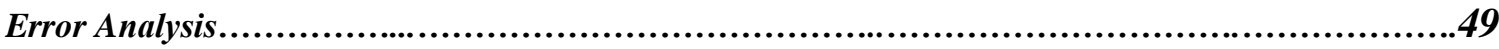

Discussion and Interpretation.....................................................................52

Why did the Lincoln Mainshock Rupture as a Left-lateral Strike Slip Fault?...............................52

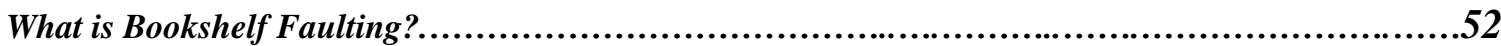

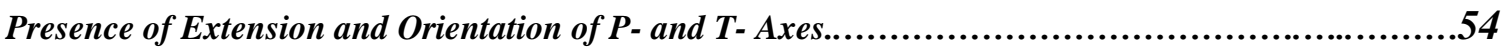

GPS Surface Velocities, Extension, and Right Lateral Motion .....................................56

Fault Plane Solutions and Aftershock Alignment......................................................57

The Temporal Evolution of the Lincoln Aftershock Sequence ...............................................58

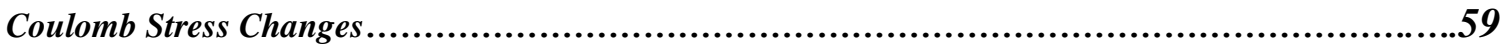

Spacing of Bookshelf Faulting Mechanisms .........................................................60

Presence of Parallel Faults .........................................................................61

Summary of Bookshelf Faulting Observed in Montana, Iceland, Ethiopia, and Nicaragua.............61

Is Shear or Extension the primary form of Deformation in Montana?.......................................................63

Conclusions................................................................................64

References.....................................................................................65

Appendices....................................................................................69 
Appendix A. Loading Data, Picking Phases, and Exporting Picks/catalogs from Jiggle .................69

Appendix B. Emergent and Impulsive Phase Arrivals...................................................69

Appendix C. Example HypoDD Input and Output Files.............................................70

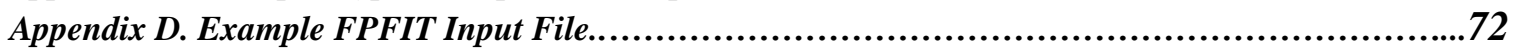

Appendix E. Events Filtered by Magnitude and OBSCT Parameter......................................73

Appendix F. All Focal Mechanism Solutions..........................................................79 


\section{Background, Motivation and Research Objectives}

The M5.8 Lincoln Event

On 6 July 2017, a magnitude 5.8 earthquake occurred 11 kilometers southeast of Lincoln, Montana. The Lincoln earthquake was the largest earthquake recorded within the Intermountain Seismic Belt (ISB) during the past 58 years, and the event was widely felt out to distances of about 800 kilometers away from the epicenter (USGS, 2018). The Lincoln earthquake sequence is a classic mainshock-aftershock sequence. Figure 1 shows the general pattern of the ISB and Centennial Tectonic Belt (CTB) seismicity and focal mechanism solutions from the Global CMT catalogue from 1976 - 2019, which show a combination of strike slip and normal faulting throughout the region. The black box and upper right portion of Figure 1 represents the Lincoln region. The Montana Bureau of Mines and Geology has located and contributed more than 3500 events to the USGS Comprehensive Catalog for the Lincoln region since the main shock (Figure 1). Figure 1 also includes mining blasts (clusters of shallow events in eastern Wyoming and eastern Montana). Seismic event data shown in Figure 1 comes from the USGS comprehensive earthquake catalog (https://earthquake.usgs.gov/earthquakes/search/). 


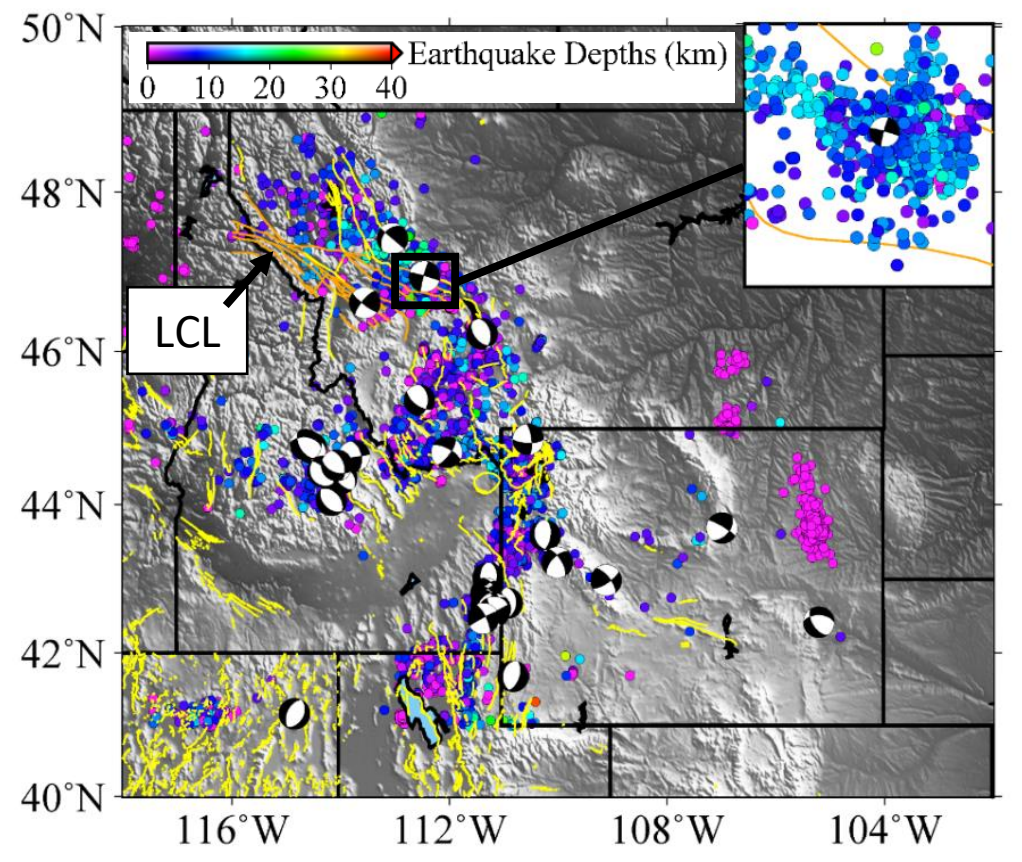

Figure 1. A topographic map of the Northern Rocky Mountains. The circles represent all events from July 6, 2017 through May 15, 2019, colored by hypocenter depth (USGS catalog). Note that most events occur outside of my specific study site, the Lincoln region, indicated by the black box. More than 3500 events have been located in the Lincoln region. The orange lines represent Lewis and Clark Line Faults (LCL). The yellow lines represent younger, Quaternary Faults. The fault plane solution in the inset shows the location of the M5.8 Lincoln event from July 6, 2017.

The Study from McMahon et al. (2019)

McMahon et al. (2019) determined that the Lincoln mainshock occurred on a previously unmapped NNE-SSW trending left-lateral, strike slip fault, which is approximately perpendicular to the trend of the principal Lewis and Clark Line (LCL) faults in the region. The study from McMahon et al. (2019) focused on the shorter-term aftershock sequence. We investigate the shorter and longer-term spatial and temporal evolution of the aftershock sequence and provide a plausible explanation for why the Lincoln main shock ruptured as a left-lateral strike slip fault. We hypothesize that left-lateral strike slip motion in the Lincoln region is consistent with a bookshelf faulting mechanism that accommodates regional extension via crustal block rotations.

\section{Tectonic Context of Study Region}

Flesch et al. (2007) shows strain rates inferred from the long-term GPS velocity field (Figs. 8a and 8b) for western North America. Higher strain rates occur along the western coast of 
North America because this region is located along major plate boundaries. Deformation also occurs in Montana, which is located in an intraplate setting with diffuse deformation. Although Montana is more than $500 \mathrm{~km}$ away from a major tectonic boundary, Montana is a complex and actively deforming region as evidenced by geodetic and seismic observations of the interior of the northwestern portion of the United States (Schmeelk et al., 2017; Stickney, 2015; Payne et al., 2012). We aim to explore whether extension or shear forces are the primary drivers of deformation in the Lincoln region.

The key features in the Lincoln, Montana region include the ISB, the LCL, and the Basin and Range Province. The ISB is defined by seismicity, and is a $100 \mathrm{~km}$ wide belt that extends from southwestern Utah to northwest Montana (Smith and Sbar, 1974; Stickney and Bartholomew, 1987). Several earthquakes occur within the ISB annually, which makes Montana one of the most seismically active states in the United States (Fig. 1) (McMahon et al., 2019; Stickney, 2015). The M5.8 Lincoln event is an excellent opportunity to study a large magnitude event that occurred within the ISB (an intraplate setting), especially given that large magnitude events do occur within the ISB and can cause significant damage. Most of the events are shallower than 15 kilometers in depth (Figure 2) and the region is characterized by clustered seismic activity with interspersed areas of infrequent seismicity (Stickney, 2015). The LCL (orange lines in Fig. 1) is a 40 to 80 -kilometer-wide and 400-kilometer-long, WNW-trending fault and fold zone that contains at least 12 major faults (Wallace et al., 1990; Sears and Hendrix, 2004). 


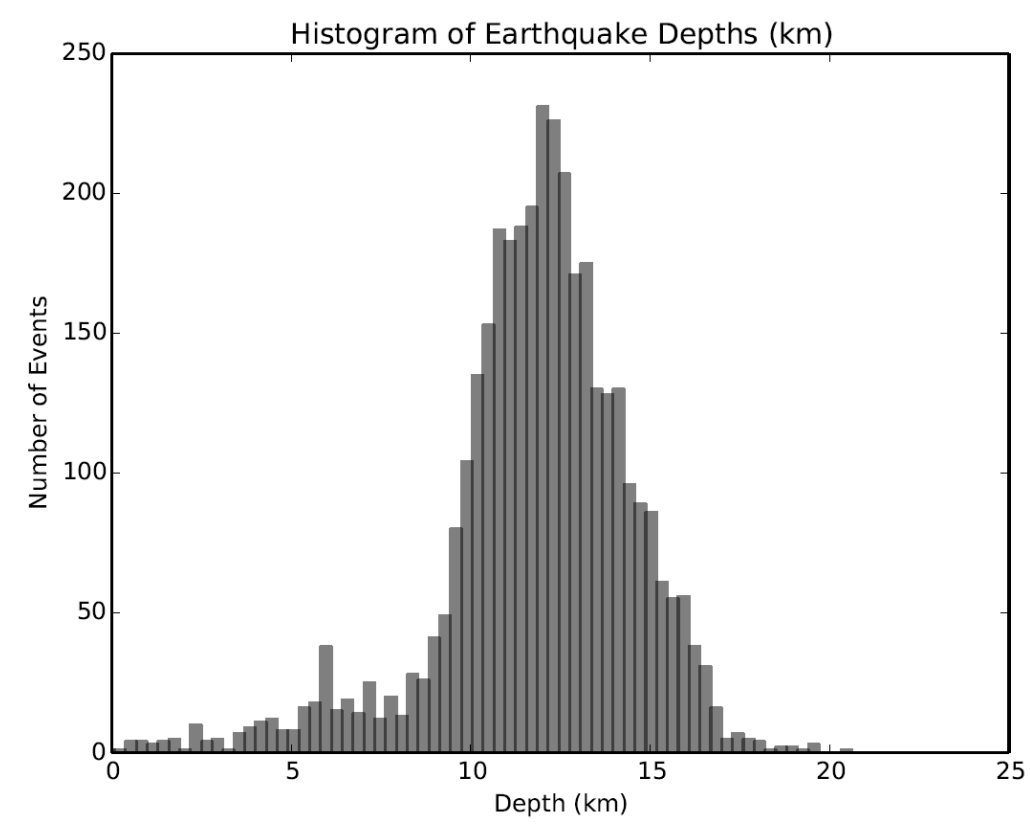

Figure 2. Depth distribution of aftershock events following the M5.8 Lincoln, Montana earthquake. Depth is below sea level. The hypocenter depths are obtained from the Montana Regional Seismic Network catalog for the date range of 6 July 2017 - 31 May 2019 for all earthquakes that occurred within the inset of Fig. 1.

The LCL is a structural discontinuity that contains strike slip, oblique slip, and dip slip faults. Reynolds (1979) and Stickney and Bartholomew (1987) hypothesized the LCL serves as the northern boundary of the Basin and Range province. The Basin and Range Province is characterized by widespread block faulting that followed the Laramide Orogeny. This province is now undergoing crustal extension due to a variety of causes such as the migration of the Yellowstone Hotspot and associated crustal uplift, gravitational collapse, and back-arc extension (e.g. Schmeelk et al, 2017); Pierce and Morgan, 2009). Sears and Hendrix (2004) and Wallace et al. (1990) identified the LCL as a shear zone that accommodated up to approximately 11 to 28 $\mathrm{km}$ of dextral slip during the Late Cretaceous (over a time period of several million years) (Sears and Hendrix, 2004; Wallace et al., 1990). The M5.8 Lincoln event occurred at the intersection of the northwestern portion of the ISB and the LCL (Figure 1). 


\section{Aftershock Decay Rates}

It is common for aftershocks to occur following any moderate to large magnitude earthquake. The timing of aftershock events depends on the transfer of energy, and aftershock events often occur near the mainshock (Zhang and Shcherbakov, 2016). Overall, the aftershock decay rate for the Lincoln M5.8 event shows that more aftershocks occurred within the first few days following the mainshock while fewer events occurred several days after the mainshock. Larger magnitude events will have more and larger aftershock events than smaller magnitude events (USGS, 2019). Figure 3 shows the aftershock decay rate for the Lincoln M5.8 event. The number of aftershocks per day decays over time.

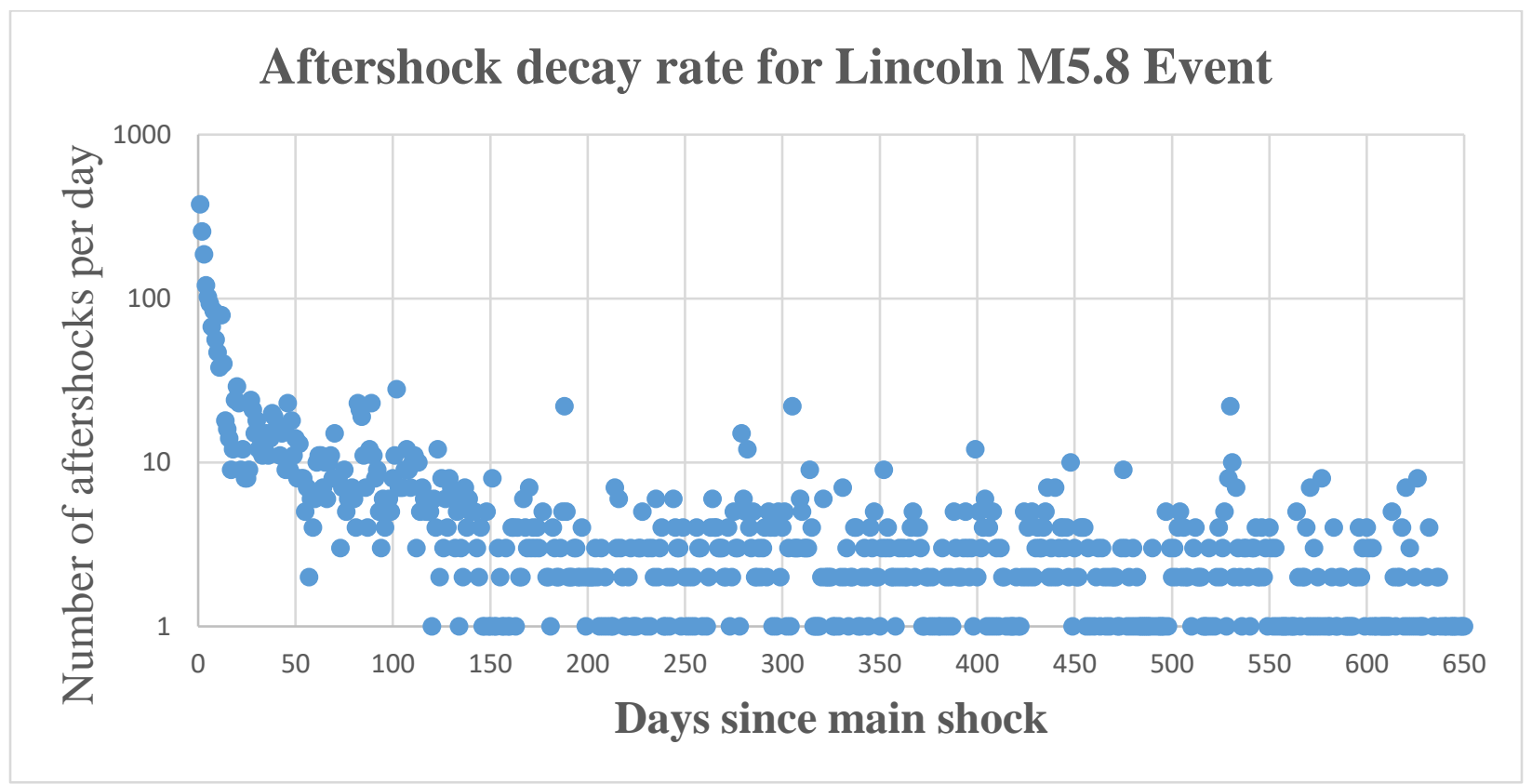

Figure 3. Figure showing number of days since mainshock versus number of aftershocks per day. The number of aftershocks per day has significantly decreased since the time of the mainshock. The number of aftershock per day is plotted on a logarithmic scale; the days since mainshock is plotted on a linear scale. 
Figure 4 shows that seismicity in Montana includes 23 earthquakes with magnitudes ranging from 5.0 to 7.3 since 1865 . All moderate-to-large historical events in Montana are poorly documented because they occurred prior to the existence of the Montana Regional Seismic Network (MRSN), which began producing an earthquake catalog in 1982 and currently includes 42 seismic stations in western Montana. The University of Montana Seismic Network (UMSN), consisting of 10 broadband stations, was deployed in August 2017 and 2018. Figure 5 shows the locations of additional stations from the UMSN. The UMSN, in conjunction with the MRSN network and a temporary United States Geological Survey (USGS) network deployed immediately after the Lincoln mainshock, provided the best set of data for an aftershock sequence in the state of Montana to date.

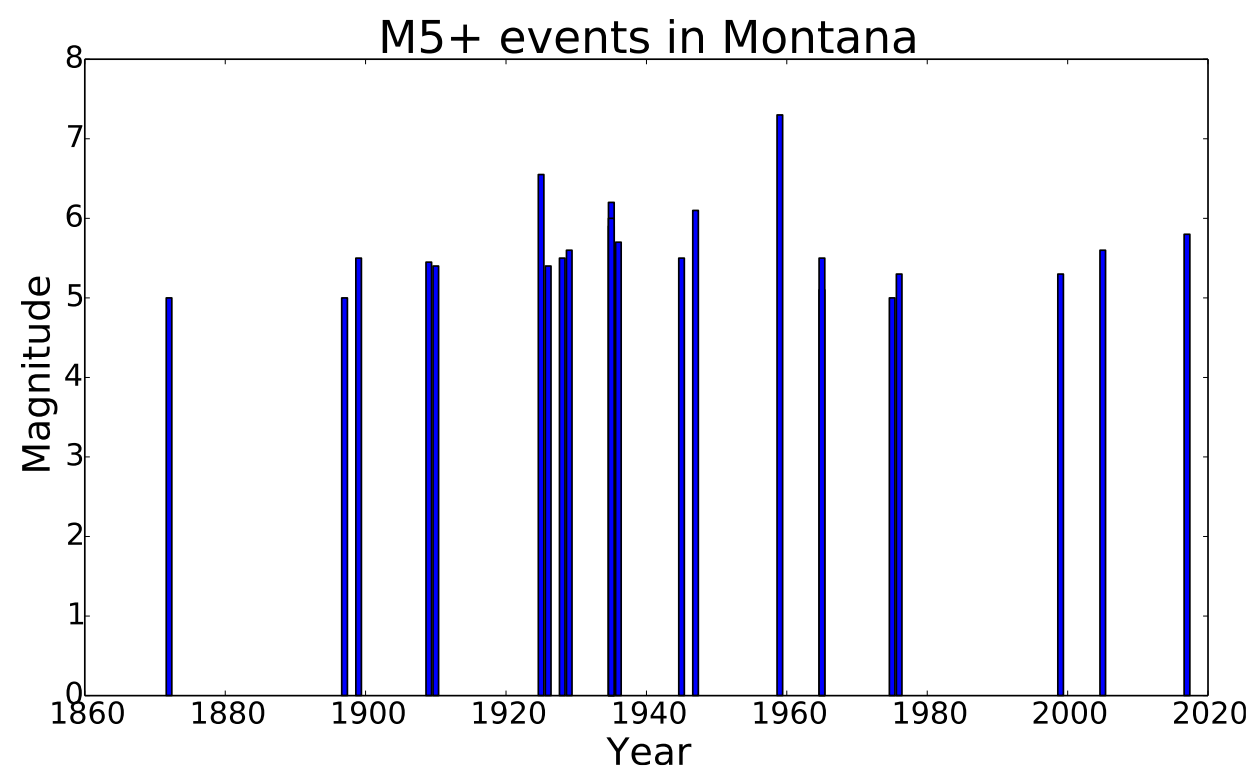

Figure 4. Figure showing earthquakes greater than magnitude 5 in Montana over the past 150 years. 


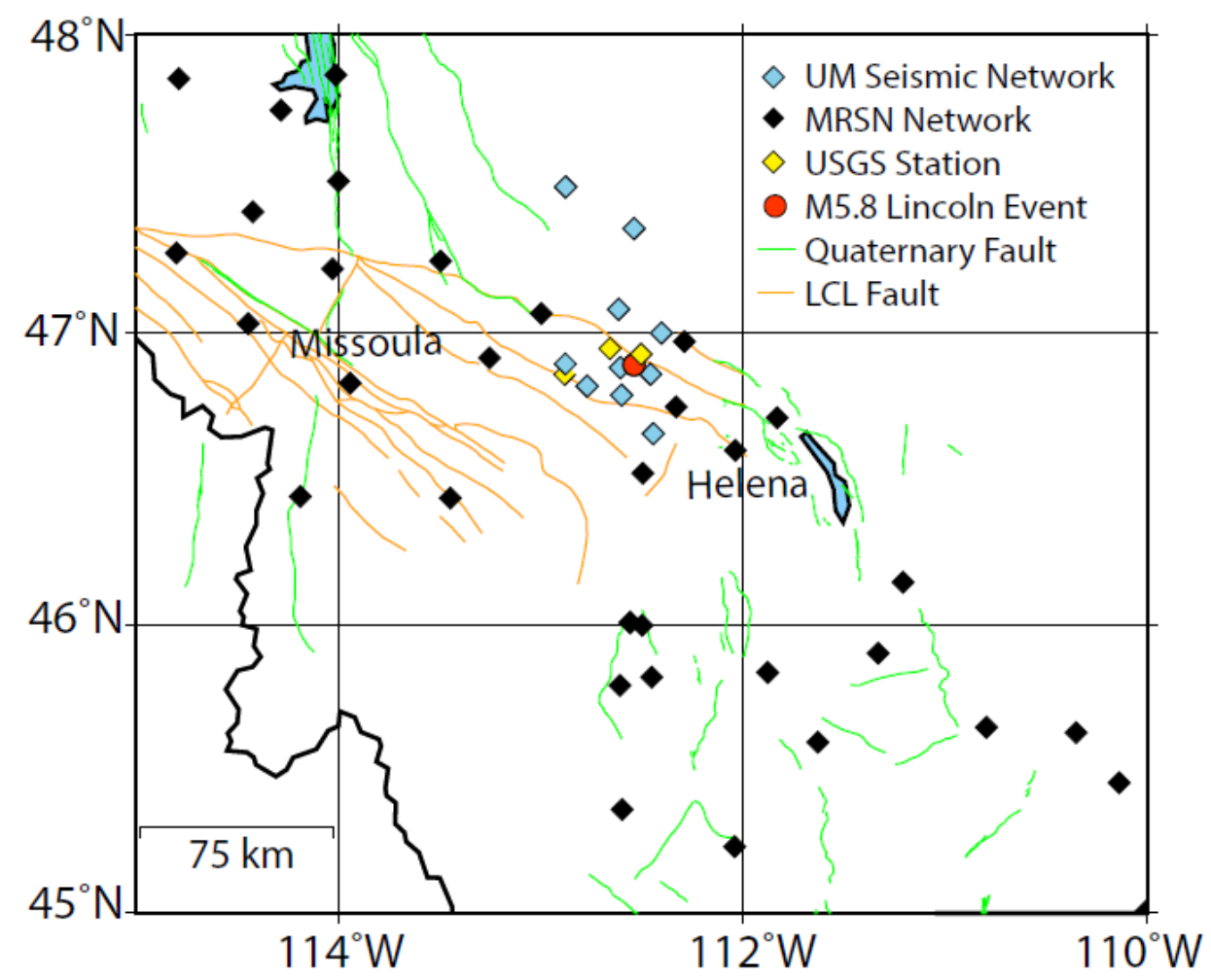

Figure 5. Study area location map. UM Seismic Network (UMSN) represented with black diamonds, Montana Regional Seismic Network (MRSN) stations represented with blue diamonds, and United States Geological Survey (USGS) temporary stations represented with yellow diamonds. Younger quaternary faults are shown in green and Lewis and Clark Line (LCL) faults are shown in orange. The location of the 2017 M5.8 Lincoln event is denoted by the red circle.

We use data from the UMSN, MRSN, and USGS seismic stations to test whether the apparent left-lateral motion exhibited by the mainshock may be indicative of crustal block rotations via a bookshelf faulting mechanism. Specifically, we make the following steps:

1. To explore the spatial and temporal evolution of the aftershock sequence, we generate precise hypocenter locations for aftershocks that occurred from July 6, 2017 to April 28, 2019 following the main M5.8 Lincoln event. The progression of the sequence can help us to infer the transfer and release of stress in the crust and to resolve distinct structural features, such as seismogenic fault planes. 
2. To identify outlying phase picks, to constrain the local lithologic properties, and to determine the S-wave velocity, we determine the P-wave-to-S-wave velocity ratios $\left(v_{\mathrm{P}} / v_{\mathrm{S}}\right)$ for the aftershock sequence and explore variations with depth (if any).

3. To determine the mode of fault slip, we will compute fault-plane solutions using P-wave first motions. Furthermore, we will explore the distributions of the axes of maximum and minimum compressive stress for all well-constrained events to characterize the ambient stress field in the region.

4. To assess how the mainshock imparted static stress changes to surrounding faults, we will compute Coulomb stress changes. The stress simulations allow us to estimate regions that were brought closer to, or further from, failure due to the mainshock rupture. We can then compare the aftershock distribution with regions of positive stress changes to infer the likelihood that stress changes from the mainshock triggered additional earthquakes.

5. To guide our interpretations of the aftershock sequence, we estimate uncertainties associated with the absolute hypocenter locations, double-difference relative relocations, and focalmechanism solutions.

6. We will use fault plane solutions, hypocenter distributions, and GPS surface velocities in the context of existing literature and prior studies to evaluate the bookshelf faulting hypothesis and to explore whether or not bookshelf faulting is a result of extension or shear, or a combination of both types of forcing. 


\section{Research Methods}

\section{Temporary Network Deployment}

Part 1 (Temporary network deployment): In collaboration with my research adviser, Dr. Hilary Martens, and the director of Montana's Earthquake Studies Office, Michael Stickney, we deployed ten Metrozet MBB-2 broadband seismometers with Kinemetrics Obsidian4X digitizers near Lincoln, Montana to supplement the MRSN. We deployed these instruments to investigate aftershock sequences from the magnitude 5.8 earthquake that occurred in the region in July 2017. Setting up the seismometers was a multi-step process. Prior to installing the stations, we selected deployment sites that were accessible (but out of human view to the extent possible), on south facing slopes with good exposure to sunlight, and away from hazards such as falling rocks. We also selected sites based on station distribution and aftershock locations. A primary purpose of a seismic network is to determine well-constrained earthquake locations and magnitudes. We deployed seismometers in locations that would best capture the focal sphere and locate the range of seismic events based on travel-time inversion methods for the Lincoln region. The MBB-2 seismometers are designed for direct burial installations (at least $0.25 \mathrm{~m}$ deep or deeper) and packed into position with soil to provide good coupling to the ground. We made sure the base of the hole for the seismometer was level and aligned the sensor with north. Figures 6 and 7 show how we connected the solar panel, batteries, and instruments/sensors/digitizer to the charge controller. We then connected the field laptop to the digitizer through the Ethernet port to access a Kinemetrics-specific web interface, which allowed us to set and confirm the configuration settings. Through a different Kinemetrics application, we could view the live waveforms to make sure instruments were operating correctly. 


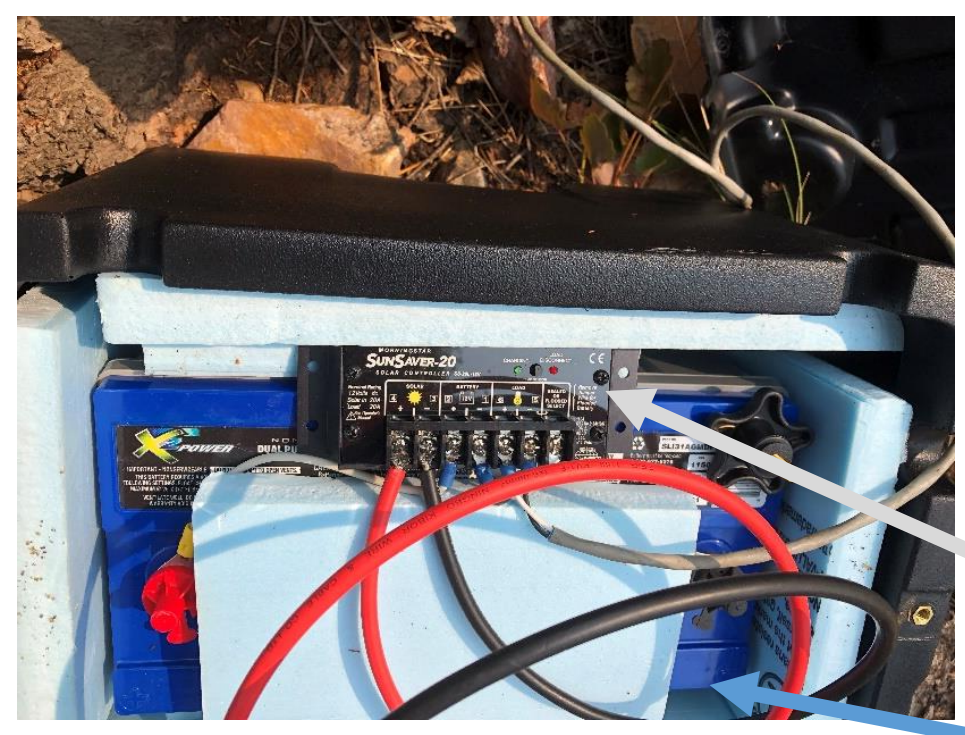

Figure 6. Wiring

connections from the

charge controller to the

solar panel, battery, and

load.

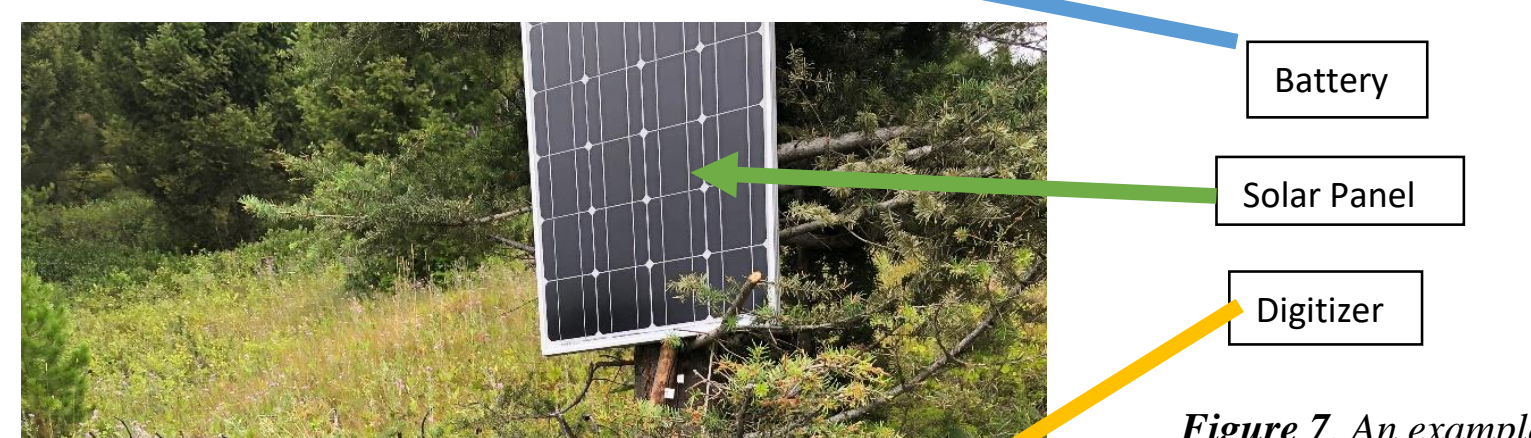

Figure 7. An example showing a complete station looks like. 
In conjunction with the existing MRSN and temporary USGS stations, the UMSN provides dense coverage around the Lincoln aftershocks (Figure 5), which has allowed us to determine both good hypocentral locations and well-constrained fault-plane solutions.

Part 2 (Collecting and Archiving Data): Because the new stations are not currently telemetered, we visited the stations every three to six months to download data and perform site maintenance. Continuous waveform data were archived on the IRIS website (https://ds.iris.edu/mda/UM) according to standard formats.

\section{Phase Picks}

We manually picked the times of $\mathrm{P}$ - and S-wave arrivals using the Advanced National Seismic System (ANSS) Jiggle software, which provides an interactive graphical interface for analyzing seismic data from multiple seismic networks. Earthquake events are initially identified by the Earthworm software using an automatic-detection algorithm. Arrival time picks were refined manually using Jiggle's interactive features. Jiggle is convenient to use because it is interactive and allows manipulation of a catalog that was initially created by Earthworm. Jiggle automatically generates an earthquake catalog with preliminary phase picks; sorts waveforms by distance from the epicenter; allows the user to view multiple waveforms in the same window; arranges events by location, error, and magnitude; and calculates root-mean-square (RMS) error, horizontal hypocenter-location error, vertical error, azimuthal gap, local magnitude, and time residuals at each station for each event. See Appendix A for how to load data, pick phases, and export picks/locations in Jiggle.

We used P- and S- wave arrival times for the UMSN from August 24, 2017 through April 27, 2019. August 24, 2017, marks the date that the first UM stations were deployed. The UMSN 
had three active stations from August 2017 through August 2018, and ten active stations thereafter. For Fall 2017, we have data from three UMSN stations (LGMT, NVMT, and GBMT) and three USGS temporary stations. A permanent USGS station was deployed on October 17, 2017 at the Lincoln Ranger Station, very close to the location of the temporary USGS site MT01 (Table 1). We have data from nine out of the ten UMSN stations from late-fall 2018 through spring 2019; the data from NVMT are only available until November 17, 2018 due to site disturbance. Table 1 provides a list of network and station names, deployment dates, decommission dates (as applicable), and location information for the USGS and UMSN stations. All stations are recorded at a $100 \mathrm{~Hz}$ sampling rate and are 3-component. Station MT04 uses a 3component Episensor accelerometer; the rest of the stations are broadband seismometers. Information for the MRSN and UMSN may be found online (https://www.fdsn.org/networks/detail/MB/ and https://www.fdsn.org/networks/detail/UM/). We made phase picks using all available data from the UMSN, MRSN, and USGS networks. Mike Stickney, Ellen Smith, and Andrew Wilson (a student at Montana Tech) made picks for events in the Lincoln region. We only included events with manually picked phase arrivals.

P-wave arrivals are given a four-character designation such as IPU0. S-wave arrivals only have a 3-character designation (no first motion). The first letter denotes whether the waveform is emergent (E) or impulsive (I). See Appendix B for an example of emergent and impulsive Pwave arrivals. The second letter denotes whether it is a P-wave or S-wave. The third letter (U or $\mathrm{D}$, or + or - ) specifies if the $\mathrm{P}$-wave first motion is up or down (compressional or dilatational). Pand S-waves are assigned a pick quality between zero and four. Zero represents a high-quality pick, while four represents a poor-quality pick. A pick weight of four is not used in the hypocenter locations but travel time residuals are computed. We typically assigned S-waves a 
pick weight between one and four and P-waves a pick weight between zero and four. S-waves are typically assigned three-quarter weight (1) because $S$-wave arrival onsets are usually more difficult to determine than the $\mathrm{P}$-wave arrivals. We picked $\mathrm{P}$-wave arrival times on the vertical component (HHZ), and S-wave arrival times on the horizontal components (HHE or HHN) when available. Some stations in the MRSN are only vertical component; in this case, we made both Pand S-wave picks on the vertical component. When we picked S-wave arrival times on one component stations (HNZ or EHZ), we typically assigned one-half weight (2). Figure 8 shows example waveforms from Jiggle for two of the UMSN stations (ESMT and OGMT).

Table 1. A list of network and station names, deployment dates, decommission dates, and location information for the USGS and UMSN stations.

\begin{tabular}{|c|c|c|c|c|c|c|}
\hline Network & Station & Start Recording Date & End Recording Date & latitude & longitude & elevation \\
\hline GS & MT01 & $7 / 8 / 17$ & $10 / 17 / 17$ & 46.95299 & -112.6566 & 1317.7 \\
\hline GS & MT02 & $7 / 10 / 17$ & $10 / 17 / 17$ & 46.85853 & -112.88047 & 1671.8 \\
\hline GS & МT03 & $7 / 9 / 17$ & $10 / 17 / 17$ & 46.91299 & -112.49753 & 2024.8 \\
\hline GS & MT04 & $10 / 17 / 17$ & present & 46.9554 & -112.656 & 1420 \\
\hline UM & GBMT & $8 / 24 / 17$ & present & 46.85293 & -112.4568 & 2235 \\
\hline UM & LGMT & $8 / 24 / 17$ & present & 46.88137 & -112.60508 & 1784 \\
\hline UM & NVMT & $8 / 25 / 17$ & $11 / 16 / 18$ & 46.78763 & -112.59965 & 1741 \\
\hline UM & OGMT & $8 / 24 / 18$ & present & 46.88643 & -112.88782 & 1620 \\
\hline UM & FPMT & $8 / 23 / 18$ & present & 46.99877 & -112.4025 & 1660 \\
\hline UM & ESMT & $8 / 21 / 18$ & present & 46.65665 & -112.4426 & 1742 \\
\hline UM & EKMT & $8 / 23 / 18$ & present & 47.35053 & -112.53827 & 1473 \\
\hline UM & COMT & $8 / 23 / 18$ & present & 47.07883 & -112.6144 & 1665 \\
\hline UM & CLMT & $8 / 21 / 18$ & present & 46.81868 & -112.76988 & 1616 \\
\hline UM & BMMT & $8 / 22 / 18$ & present & 47.49065 & -112.87633 & 1676 \\
\hline
\end{tabular}




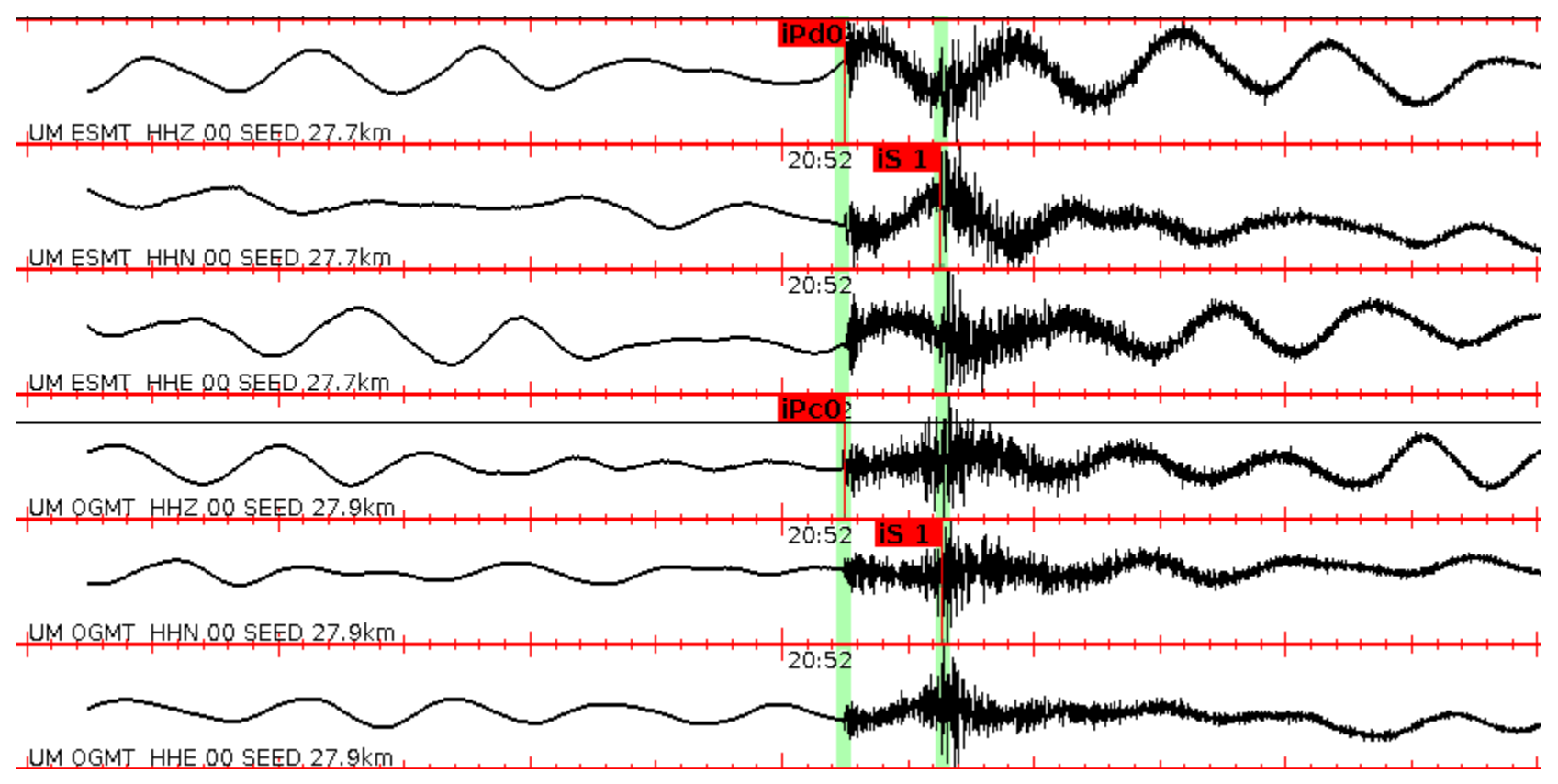

Figure 8. Example waveforms from Jiggle. We zoomed in on the waveforms for each station to make clean and precise pick arrivals. The first two letters (UM) denote the network code. The second four letters denote the station name. The HHZ, HHE, and HHN indicate the channel. P-and S-wave arrival times are assigned a three or four character code (I or E; P or S; U, D, or blank; and 0-4).

A Wadati plot shows the S-P interval time plotted against the P-arrival time (seconds). Pand S- wave travel times are used to plot Wadati diagrams. We plotted Wadati diagrams for each event to test phase-pick quality and to determine the $\mathrm{P}$ - to $\mathrm{S}$-wave velocity ratio. $\mathrm{P}$ - wave travel time $\left(t_{p}\right)$ is equal to the distance (D) divided by the p-wave velocity $(\alpha)$. S-wave travel time $\left(t_{s}\right)$ is defined by the distance (D) divided by the s-wave velocity $(\beta)$. Because distance and seismic velocities are not known a priori, we determined the ratio of P-wave to S-wave velocity by rearranging the travel times and performing a simple linear regression (Wadati 1933). The following equation defines the slope of the line and the $v_{\mathrm{P}} / v_{\mathrm{S}}$ ratio: 
$\mathrm{t}_{\mathrm{s}}-\mathrm{t}_{\mathrm{p}}=(\alpha / \beta-1)\left(\mathrm{t}_{\mathrm{p}}\right)$. Figure 9 shows an example Wadati Plot (Wadati 1933). The average $v_{\mathrm{P}} / v_{\mathrm{S}}$

from July 6, 2017 through October 10, 2017 and from August 23, 2018 through April 28, 2019 is

1.76, which is typical for an intraplate and crustal setting. We selected these data ranges because we had P- and S-wave travel times from multiple stations.

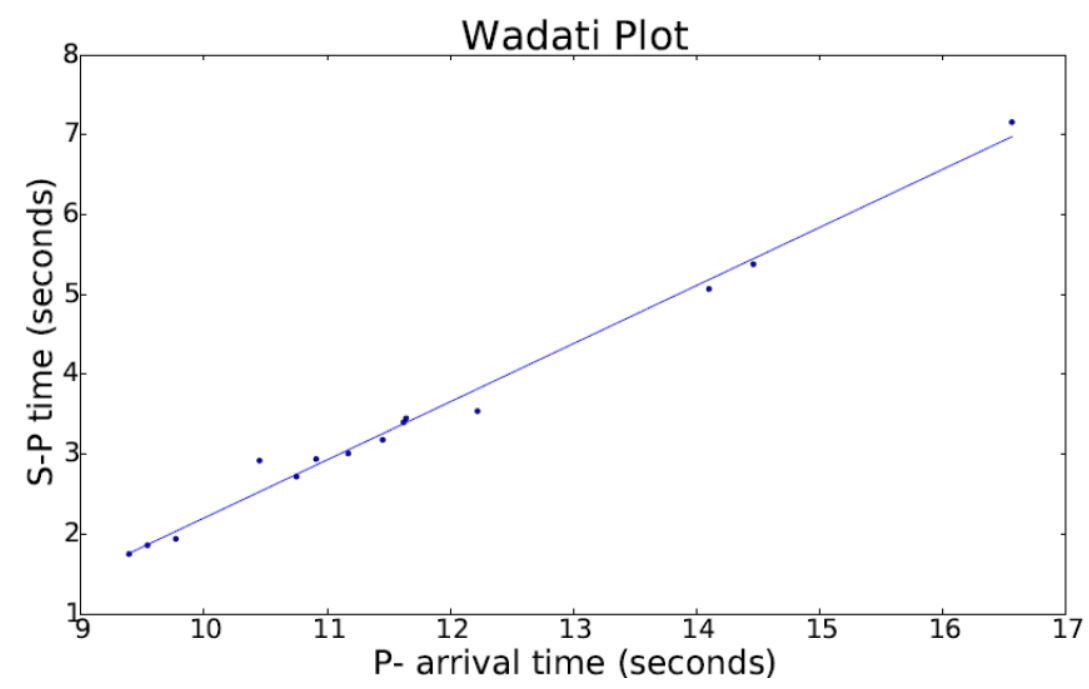

Figure 9. Example Wadati Plot. Pwave arrival time (seconds) on the $x$ axis and $S$-wave minus $P$-wave arrival time (seconds) on the y-axis.

\section{Hypocenter Locations}

Jiggle locates earthquakes using the HypoInverse-2000 software, which uses a 1D velocity model and P- and S-wave arrival times to invert for best-fit earthquake hypocenter locations. The magnitudes for all events determined by Jiggle are based on a local magnitude scale. The local magnitude is determined from peak-to-peak amplitudes derived from synthetic Wood-Anderson seismograms (Earthquake Process with Jiggle, 2018). The 1D velocity model (Zeiler et al., 2005), assumed to have uniform velocity within each layer was used to locate the hypocenters. The velocity model is provided in Table 2. 
Table 2. 1D velocity model (Zeiler et al., 2005).

\begin{tabular}{|l|l|l|}
\hline $\begin{array}{l}\text { Depth to } \\
\text { layer top } \\
(\mathrm{km})\end{array}$ & $\begin{array}{l}\text { P-wave } \\
\text { velocity } \\
(\mathrm{km} / \mathrm{s})\end{array}$ & $\begin{array}{l}\text { S-Wave } \\
\text { velocity } \\
(\mathrm{km} / \mathrm{s})\end{array}$ \\
\hline 0 & 4.58 & 2.60 \\
\hline 1.90 & 5.70 & 3.24 \\
\hline 5.80 & 6.12 & 3.46 \\
\hline 18.60 & 6.53 & 3.71 \\
\hline 38.50 & 8.00 & 4.54 \\
\hline
\end{tabular}

We initially downloaded phase picks and hypocenter locations that were determined using Jiggle. We then recalculated hypocenter locations directly using Hypoinverse-2000 (Klein 2002) in order to include station delays. Station delays can help compensate for the assumption of constant station elevation made by the software. We determined station delays by computing travel time differences between the actual elevation of each seismic station and a reference elevation of 1813 meters, which represents the average elevation of the four closest stations to the aftershock events. To begin the inversion, Hypoinverse-2000 initially assumes that the station closest to the event is the epicenter location and earthquake focal depth of $7 \mathrm{~km}$; the hypocenter location is then refined iteratively by calculating travel times from the trial hypocenter and comparing these to the observed arrival times, then adjusting the trial hypocenter to minimize these differences. We then computed the depths to be relative to sea level. See pages 97-99 in the HypoInverse manual for example Hypoinverse-2000 input and output files.

Locating earthquakes is a classic nonlinear inverse problem. It is nonlinear because some of the terms we wish to solve for (e.g. hypocenter location) appear non-linearly in the equation (Stein and Wysession, 2003); it is an inverse problem because we are using the data to infer a model rather than using a model to simulate the data. The time, latitude, longitude, and depth of each event represent the model parameters (time, $\mathrm{x}, \mathrm{y}, \mathrm{z}$ ) for which we are solving. The model 
operator identifies the predicted arrival times at each station based on the model parameters. The model operator depends on the given velocity model and on individual station locations. We solve for the model parameters that best-fit the data by minimizing the sum of squares of the residuals between observed and predicted travel times (i.e. by performing a least-squares inversion).

\section{Double Difference Relocations}

We further refined earthquake locations using the software HypoDD (Waldhauser 2001). HypoDD can help decrease errors in relative hypocenter locations by minimizing travel time residuals for pairs of earthquakes recorded at common stations. HypoDD assumes that the distance between two (or multiple) events is small compared to the event-to-station distance. Nearby events recorded at the same station are assumed to have nearly the same ray path from the source region to the station. Events are located relative to each other rather than independently located, thus reducing the error in hypocenter locations due to mismodeled velocity structure (Waldhauser and Ellsworth, 2000). In other words, HypoDD attempts to reduce the error in event locations by determining relative re-locations rather than absolute locations. We used HypoDD to sharpen earthquake cluster geometries and to identify fault planes. See Appendix C for example input and output files from HypoDD.

Using P- and S-phase arrival times as input, we used HypoDD to calculate the difference in travel time residuals for events recorded at the same stations. We used the built-in HypoDD program, $p h 2 d t$, to identify pairs of earthquakes close to each other (neighboring events). The number of degrees of freedom for a single event is 4 (one vertical component, two horizontal components, and time) and would therefore be 8 for two events. We used a value of 8 to define the minimum number of phase pairs recorded at common stations to define a "strongly linked" 
earthquake pair. We used a cutoff value of 5 for the minimum number of phase pairs required to define an earthquake pair (not necessarily strongly linked). Events linked with less than 5 phase pairs were not included in the dataset. We used values of 5 and 8 , instead of values of 8 and 8 , to increase the total number of events included in the analysis while still favoring stronger event pairs. We used a value of 80 for the maximum number of observations per event pair. We chose a value of 80 because we are using P- and S-wave arrivals and 40 is the total number of stations within $200 \mathrm{~km}$. We used a value of 8 to define the maximum number of strongly linked neighboring events to include within a given search radius. Linked events are selected using a nearest-neighbor approach, so events that are clustered closer together are prioritized over events that are further apart. We experimented with values of $5 \mathrm{~km}$ and $2 \mathrm{~km}$ for the search radius, or the maximum separation between event pairs (MAXSEP). Ultimately, a value of either $2 \mathrm{~km}$ or 5 $\mathrm{km}$ for the MAXSEP parameter gave similar results (Appendix E), indicating that we typically reach the maximum of 8 strongly linked event pairs within a distance of $2 \mathrm{~km}$. In choosing these parameters, we tried to find a balance between including as much data as possible while also providing a stable solution. For example, if we increased the maximum number of neighbors per event, we would have included more earthquake neighbors, but we also would have increased error since we would be including earthquakes from greater distances.

We then used HypoDD to compute the double-difference relocations using the differential travel time data computed by the $p h 2 d t$ program. We set the minimum number of links per event to a value of greater than or equal to 8 (degrees of freedom for an earthquake pair) with the intention to include only strongly linked event pairs. We experimented with values of 8,10 , and 12 for the minimum number of links per earthquake pair (Appendix E). The average distance between strongly linked events was $\sim 0.81 \mathrm{~km}$, so we used the value of $1 \mathrm{~km}$ for the 
distance-weighting parameter. If the distance-weighting parameter is set too high, then HypoDD will identify all events as one big cluster because more strongly linked event pairs will be included (or strongly weighted) in the solution. More events are likely to be included in an earthquake cluster if the distance-weighting parameter between event pairs (or the main event and neighboring events) is increased rather than decreased. Some of our stations are located very close to the aftershocks, so it is important to use a value where the distance weighting parameter can reduce the significance of phase pairs separated by greater distances. This study generally focuses on a small region spatially, so the event-to-event distance within earthquake clusters should be small (generally equal to or less than about $1 \mathrm{~km}$ ). If the distance-weighting parameter is set too low, then HypoDD will identify several small clusters with few events in each cluster.

We first located all earthquake clusters using the least squares (LSQR) inversion method because the singular-value decomposition (SVD) method only works for clusters with fewer than $\sim 100$ events. For clusters with more than 100 events, we used the LSQR method and damped the solution based on the recommended range of condition values in the HypoDD manual (page 12) in order to mitigate numerical instability (Waldhauser and Ellsworth, 2000).

\section{Focal Mechanism Solutions}

Additionally, we computed focal mechanism solutions using the FPFIT software (Reasenberg and Oppenheimer, 1985). Focal mechanisms represent a pair of potential fault planes and the type of movement on them. P-wave first motions recorded by seismic stations usually have an upward motion (indicating compression) or a downward motion (indicating dilatation). P-wave first motions are projected onto a lower hemisphere stereographic plot, an imaginary hemisphere that is arbitrarily defined around the hypocenter (Stein and Wysession, 2003). 
A P-wave can be thought of as traveling along a ray path from the hypocenter to a seismic station. The azimuth refers to the direction from a seismic source to the seismic station measured clockwise from north. The take-off angle is the angle between a vertical line extending through the lower focal hemisphere and the ray path as it emerges from the hypocenter (Stein and Wysession, 2003). Ray path takeoff angles depend on the velocity structure (Table 2) and the geometry of the earthquake hypocenter and the recording stations. Takeoff angles are computed by the software package HypoInverse-2000 (contained in the "archive"-type file) as part of the hypocenter location process. Figure 10 shows an example of phase takeoff angles (one piercing through the lower hemisphere and one leaving through the upper hemisphere). FPFIT plots the distribution of P-wave first motions on the lower hemisphere and determines the orientations of the two nodal planes. The two nodal planes, called the fault plane and auxiliary plane, are orthogonal to each other for double-couple mechanisms. There is ambiguity in terms of which nodal plane represents the fault plane. To determine which plane is the fault plane, we can use geologic knowledge of the region and/or the alignment of aftershocks. The auxiliary plane has no structural significance. The direction of maximum compressive stress, referred to as the P-axis in a double-couple focal mechanism, is located in the middle of the dilatational quadrant, and the direction of minimum compressive stress, referred to as the T-axis, is located in the middle of the compressional quadrant. $\mathrm{P}$ - and T-axes orientations may be used to infer the dominate style of faulting in the region and to estimate the mean directions of extension and compression in the region. 


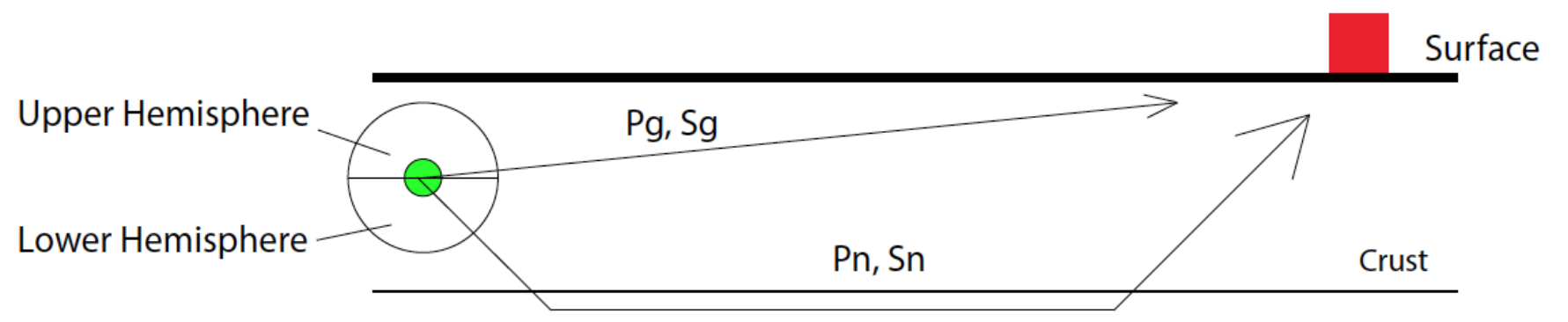

Mantle

Figure 10. Diagram showing ray paths leaving the hypocenter with an upward and downward angle of incidence in a plane layered crustal velocity model. Pn and Sn are refracted phases. Down-going waves (Pn) pierce the lower hemisphere and up-going ray $(P g)$ leave through the upper hemisphere and must be reprojected onto the lower hemisphere for fault plane solutions. A lower hemisphere projection is used for fault plane solutions. (Figure modified from http://gfzpublic.gfzpotsdam.de/pubman/item/escidoc:4005:5/component/escidoc:4006/Chapter_2_rev1.pdf

In order to use FPFIT to compute focal mechanisms, we had to first convert the file formats output by the HypoInverse-2000 software (i.e. from a Y2000 HypoInverse "archive" file format into a Pre-Y2000 HypoInverse "archive" file format), because FPFIT only accepts input files in the older format. We first converted the Y2000 archive file output from the Jiggle software into a traditional HypoInverse-2000 "phase" file, which contains phase-pick information. We then relocated all earthquake events using HypoInverse-2000, forcing the output to be in pre-Y2000 format. Then, we used the new output from HypoInverse-2000 (i.e. polarity picks and take-off angles in pre-Y2000 format) as input to FPFIT.

We experimented with different parameters to compute focal mechanisms (see Appendix D for example FPFIT input file and output files). For example, we experimented with adjusting the parameter that specifies the minimum number of $\mathrm{P}$-wave first motion polarities to include in each focal-mechanism computation. We determined focal mechanisms for events with $8,10,12$, 
15, and 20 polarities. We manually re-inspected (and adjusted as necessary) P- wave polarities for events with stations that were flagged as outliers, which means that the observed polarity was discrepant given the fault plane solution. For example, an upward P-wave first motion (+) may sometimes be located in one of the dilatational quadrants rather than a compressional quadrant. In general, focal mechanisms with the greatest number of polarity observations had the lowest error and best constrained focal-mechanism solutions. We chose a value of 12 for the minimum number of polarity observations so we would retain focal mechanism solutions for events occurring to the west of the mainshock, while still maintaining reasonably robust solutions. See Appendix $\mathrm{F}$ for all focal mechanisms with a minimum of 12 polarity observations. 


\section{Results}

$v_{P} / v_{S}$ Ratios

Figure 11 shows that the average $v_{P} / v_{S}$ ratio for the Lincoln, Montana region is 1.76 . We did not observe any changes to the $v_{P} / v_{S}$ ratios with depth. The $v_{P} / v_{S}$ ratio depends on different factors such as porosity, clay content, differential pressure, and pore geometry (Lee, 2003). Compressional and shear velocities $\left(v_{P}\right.$ and $\left.v_{S}\right)$ are defined by the following equations:

$v_{P}=\sqrt{\frac{\mathrm{k}+\frac{4}{3} \mu}{\rho}} ; \quad v_{S}=\sqrt{\frac{\mu}{\rho}}$

The variables, $\mathrm{k}, \mu$, and $\rho$, represent the bulk modulus, shear modulus, and density, respectively. The shear modulus describes the rigidity of a material. The bulk modulus describes the compressibility of a material (Stein and Wysession, 2003). P- and S-wave velocities also depend on the density of the material. Poisson's ratio, $v$, can be determined using $v_{P} / v_{S}$ ratios. Poisson's ratio is defined by the following equation:

$\mathrm{v}=\frac{1}{2}\left[1^{-} \frac{1}{\left(\frac{\mathrm{vp}}{\mathrm{vs}}\right)^{2}-1}\right]$

A value of 1.76 for the $v_{P} / v_{S}$ ratio results in a value of 0.26 for Poisson's ratio. A higher $v_{P} / v_{S}$ ratio $(>2.0)$ is characteristic of water saturated unconsolidated material, while a lower $v_{P} / v_{S}$ ratio $(<2.0)$ is indicative of well-consolidated material (Lee, 2003). A value of 1.76 for the $v_{P} / v_{S}$ ratio and a value of 0.26 for Poisson's ratio is characteristic of upper crystalline crust (Mjelde et al., 2015; Eunyoung and Tae-Kyung, 2013; Catchings, 1999). 


\section{Histogram of $v_{p} / v_{s}$ Ratios}

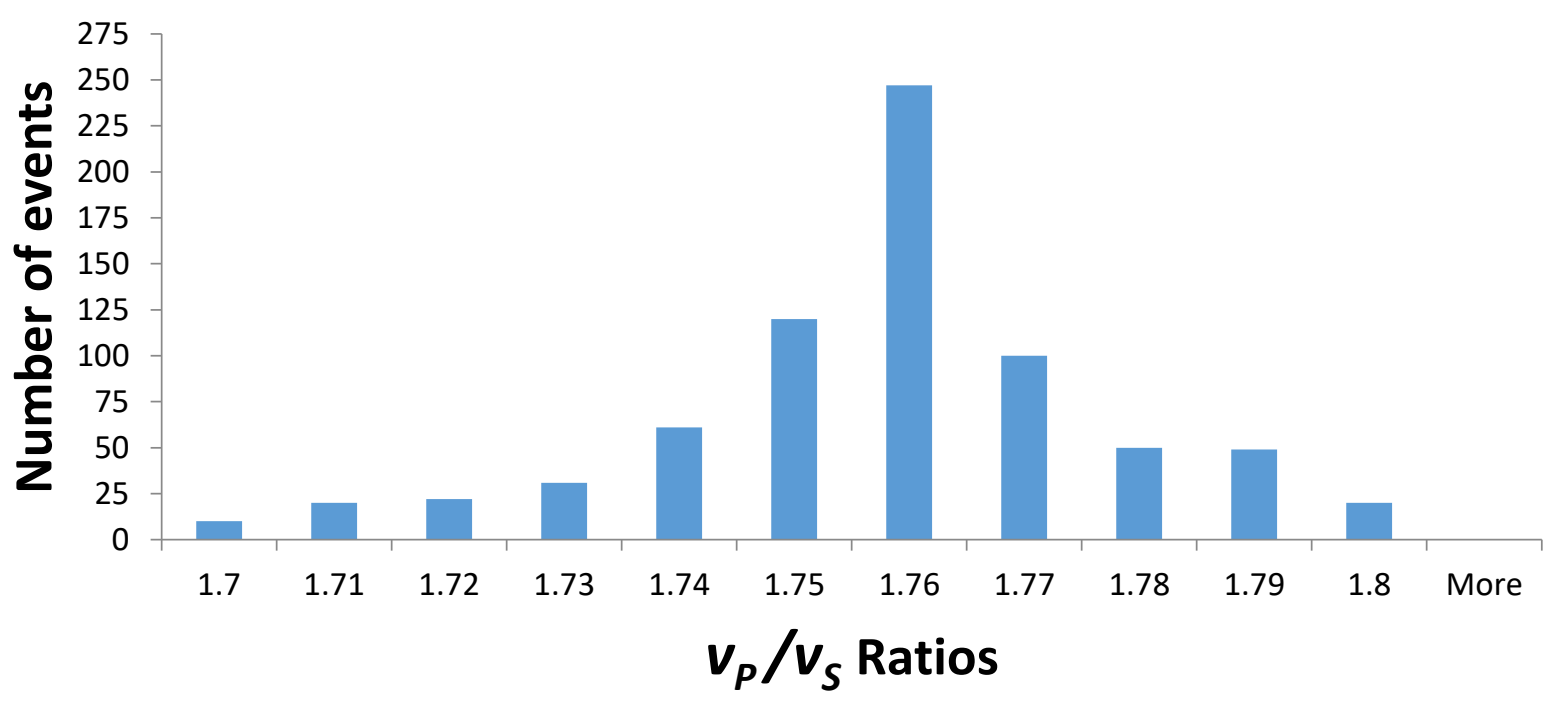

Figure 11. $v_{P} / v_{S}$ ratio distribution of aftershock events for 730 events following the M5.8 Lincoln, Montana earthquake. We computed $v_{P} / v_{S}$ ratios for events occurring from July 6 , 2017 through October 10, 2017 and from August 23, 2018 through April 28, 2019. The average $v_{P} / v_{S}$ ratio for the region is 1.76

\section{Absolute Locations}

Figure 12 shows all HypoInverse-2000 absolute hypocenter locations color-coded by time (days since mainshock until April 28, 2019). To depict the clusters in map view over their short spatial extents, we converted longitude and latitude into Universal Transverse Mercator (UTM) coordinates (easting and northing). HypoInverse-2000 absolute locations show that the majority of the aftershocks are within the same region as the main fault rupture $(\sim 384,5195 \mathrm{~km}$; UTM zone 12T). Most aftershocks occurred within a zone that is $~ 20 \mathrm{~km}$ by $15 \mathrm{~km}$; events are occurring throughout the study period (April 28, 2019 until April 28, 2019). Most of the aftershocks are occurring to the east of mainshock. Individual clusters with fewer events are 
primarily located to the west of the mainshock. Aftershock clusters are trending $\sim \mathrm{N}-\mathrm{S}$ or NNESSW.

\section{Hypolnverse Absolute Locations}

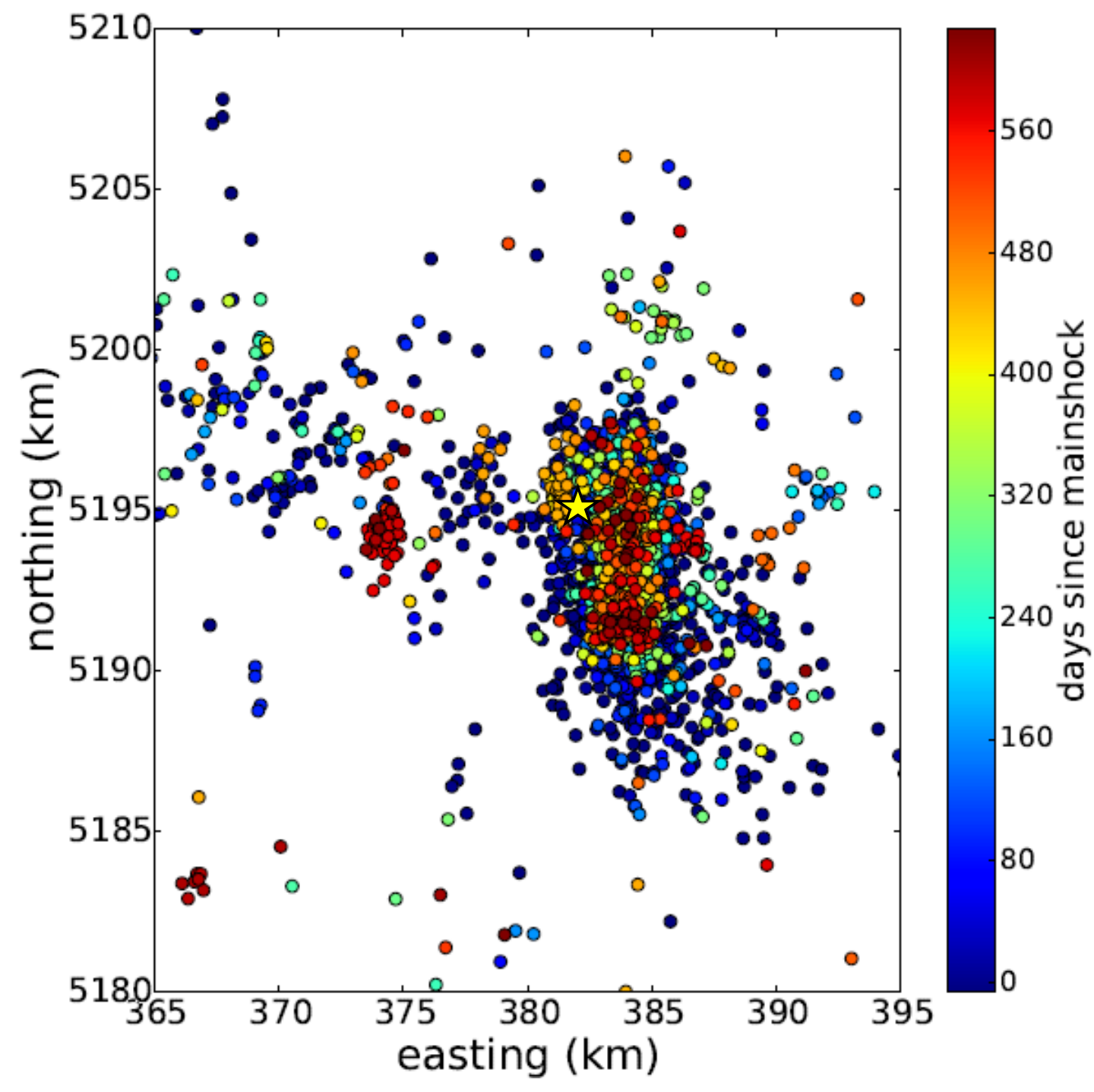

Figure 12. Absolute locations for all events since the Lincoln M5.8 event until April 28, 2019. Events are color coded by time (days since mainshock until April 28, 2019). Most aftershocks are located within the immediate vicinity $(<5 \mathrm{~km})$ of the main fault rupture at about $385 \mathrm{~km}, 5195 \mathrm{~km}$ (UTM Zone 12T). 


\section{Relative Relocations}

HypoDD retains and relocates events that are close in proximity and can be identified as a cluster, as defined in the methods section. Figure 13 shows a map of double difference relocations for events from the M5.8 mainshock until April 28, 2019 organized into distinct clusters. Events are plotted in map view. Double difference relocations are primarily concentrated in a $20 \times 15 \mathrm{~km}$ area. Table 3 shows the number of events, trend, distance from main shock (MS), depth range, and time range for each cluster.

Table 3. Number of events, trend, distance from mainshock (MS), depth range, and time range for each cluster.

\begin{tabular}{|l|l|l|l|l|l|l|}
\hline Cluster & \# of & Dimensions & Trend & Distance from & Depth & Date \\
\hline 1 & 2177 & $7.0 \times 9.0 \mathrm{~km}$ & $\mathrm{~N}-\mathrm{S}$ & $\mathrm{n} / \mathrm{a}$ & & \\
\hline 2 & 67 & $0.5 \times 1.0 \mathrm{~km}$ & NNE-SSW & $2 \mathrm{~km}(\mathrm{depth})$ & $8-10 \mathrm{~km}$ & $7 / 17-10 / 17$ \\
\hline 3 & 19 & $0.6 \times 0.4 \mathrm{~km}$ & NNE-SSW & $7.8 \mathrm{~km}$ SE of ms & $12-15 \mathrm{~km}$ & $7 / 17-10 / 17$ \\
\hline 4 & 5 & $0.1 \times 0.6 \mathrm{~km}$ & N-S & $7 \mathrm{~km} \mathrm{~N}$ of ms & $15-18 \mathrm{~km}$ & $5 / 18-6-18$ \\
\hline 5 & 6 & $0.2 \times 0.3 \mathrm{~km}$ & N-S & $5 \mathrm{~km} \mathrm{~W}$ of ms & $7-8 \mathrm{~km}$ & $10 / 18$ \\
\hline 6 & 5 & $0.3 \times 0.3 \mathrm{~km}$ & N-S & $15 \mathrm{~km}$ NW of ms & $11-13 \mathrm{~km}$ & $4 / 19$ \\
\hline 7 & 5 & $2.0 \times 2.0 \mathrm{~km}$ & NNE-SSW & $7 \mathrm{~km} \mathrm{~W}$ of ms & $16-18 \mathrm{~km}$ & $7 / 17-12 / 17$ \\
\hline 8 & 17 & $0.4 \times 0.9 \mathrm{~km}$ & N-S & $12 \mathrm{~km}$ W of ms & $12-15 \mathrm{~km}$ & $2 / 19-4 / 19$ \\
\hline 9 & 12 & $1.5 \times 1.8 \mathrm{~km}$ & N-S & $15 \mathrm{~km} \mathrm{~W}$ of ms & $15-17 \mathrm{~km}$ & $7 / 17-10 / 17$ \\
\hline 10 & 10 & $0.5 \times 1.3 \mathrm{~km}$ & NNW-SSE & $5 \mathrm{~km} \mathrm{SSE}$ of ms & $19-21 \mathrm{~km}$ & $7 / 17-8 / 17$ \\
\hline 12 & 6 & $0.2 \times 1.0 \mathrm{~km}$ & N-S & $5 \mathrm{~km}$ E of ms & $12-15 \mathrm{~km}$ & $11 / 17-5 / 18$ \\
\hline
\end{tabular}


Cluster 1 shows aftershocks along the main fault rupture and the remaining clusters show events located to the east or west of the mainshock. The Clusters are approximately parallel to one another and separated from each other by $\sim 1$ to $5 \mathrm{~km}$. Some of the individual clusters, such as Clusters 7, 9, 10, and 11, span N-S distances of up to $1 \mathrm{~km}$. 


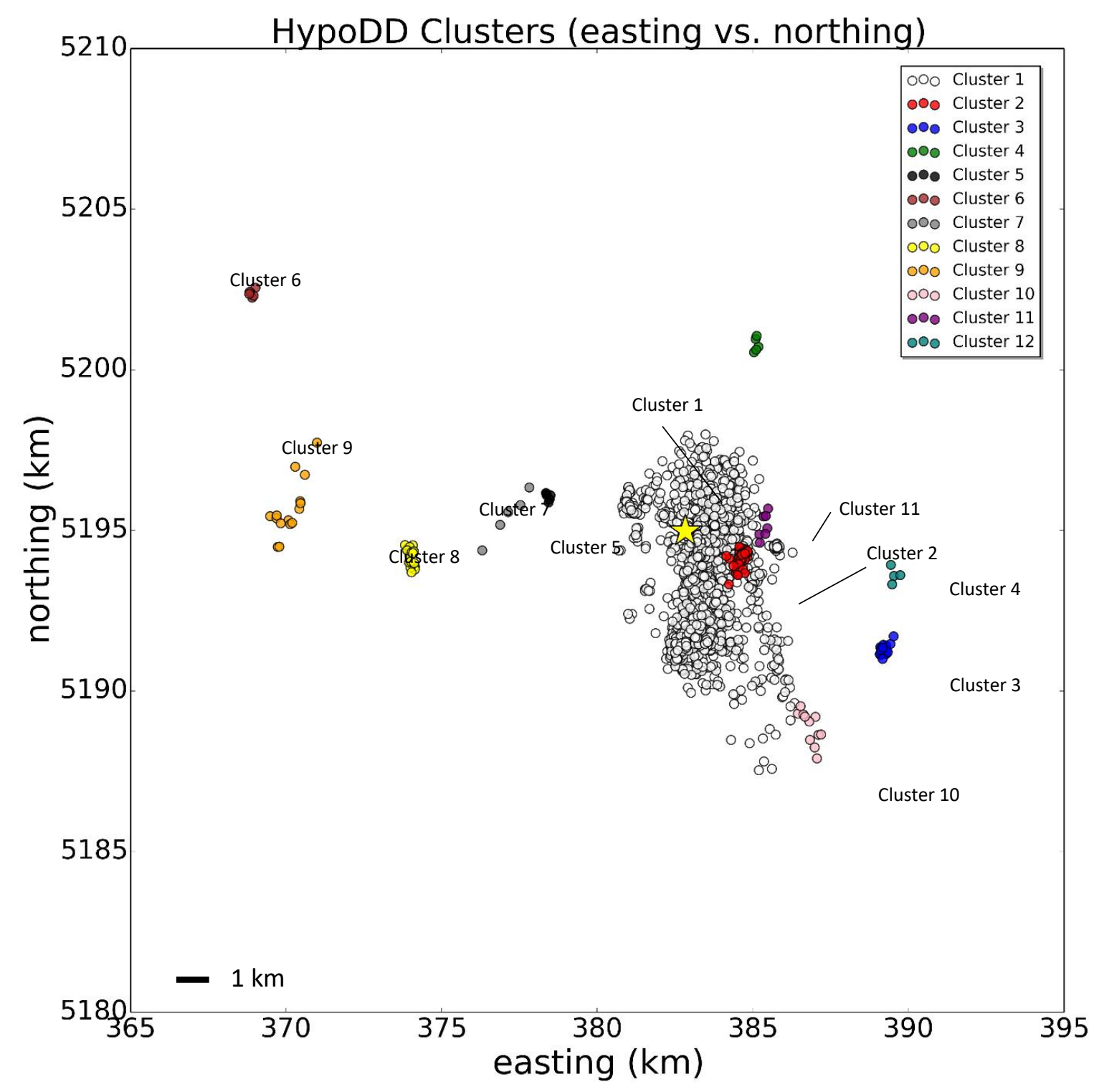

Figure 13. Double difference relocations for all events since the Lincoln M5.8 event until April 28, 2019. Events are color coded by cluster and plotted in UTM coordinates (easting $(\mathrm{km})$ versus northing $(\mathrm{km})$ ). Yellow star denotes location of M5.8 Lincoln event. The majority of double difference locations are located near the M5.8 Lincoln event. Clusters 5, 6, 7, 8, and 9 are to the west of the mainshock. Cluster 3 is to the east of the main shock. Cluster 2 represents a shallow earthquake cluster.

Figure 14 shows an east-west cross section of double difference relocations viewed to the north for all events since the Lincoln M5.8 event until April 28, 2019 in easting (km) versus 
depth below sea level $(\mathrm{km})$. We adjusted HypoInverse depths to depth below sea level by subtracting $1813 \mathrm{~m}$, the mean elevation of the closest four stations from the depths we have computed. Event hypocenters are plotted roughly along an east-west cross section of the main fault rupture. Events in Cluster 1 range from $\sim 10 \mathrm{~km}$ to $20 \mathrm{~km}$ in depth. In map view, events in Cluster 2 are located near events in Cluster 1. Cluster 2 is likely its own distinct cluster because events in Cluster 2 are located at shallower depths of $\sim 8$ to $10 \mathrm{~km}$ rather than depths of 10 to $20 \mathrm{~km}$ associated with the main aftershock cluster. Most earthquakes rupture between depths of $\sim 12-17 \mathrm{~km}$; events in Clusters 2 and 5 are distinctly shallower than the rest of the events. Events in Clusters 2 and 5 rupture between depths of $\sim 7-10 \mathrm{~km}$. See Table 3 for the depth range for each Cluster. 


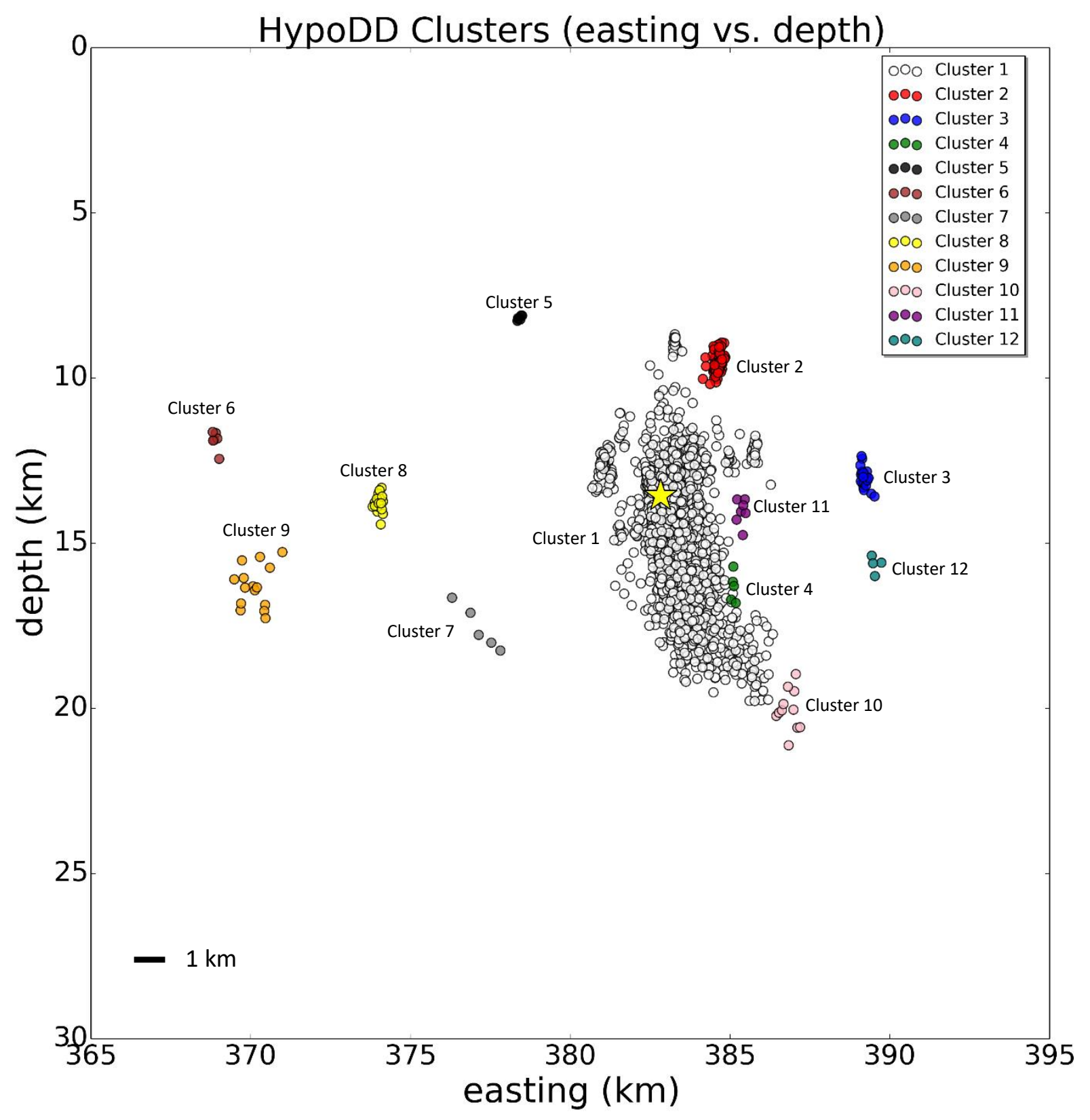

Figure 14. Double difference relocations for all events since the Lincoln M5.8 event until April 28, 2019. Events are color coded by cluster and plotted in UTM coordinates (easting $(\mathrm{km})$ versus depth below sea level $(\mathrm{km})$ ). Yellow star denotes location of M5.8 event. Cluster 2 is the shallow cluster located at a depth of $\sim 8 \mathrm{~km}$.

Figure 15 shows double difference relocations projected into a N-S cross section viewed to the west for all events since the Lincoln M5.8 event until April 28, 2019. Events are plotted 
roughly along the strike direction of the main fault rupture, color coded by cluster and plotted in UTM coordinates (northing $(\mathrm{km})$ versus depth below sea level $(\mathrm{km})$. Overall, clusters are distributed over a 10-km-wide band in northing.

More events are included in Figure 12 (Hypoinverse absolute locations) than in Figure 13 (double difference relocations) because HypoDD naturally decreases the amount of events included in the dataset. Both absolute locations and relative relocations to the west of the mainshock appear to be organized into distinct clusters. For example, the absolute locations that are located at $\sim 373 \mathrm{~km}$ (easting) and $5194 \mathrm{~km}$ (northing) likely correspond to events in Cluster 8 in Figures 13 through 15. Double difference relocations sharpen earthquake geometries (initially observed in absolute locations) and represent potential fault planes. 


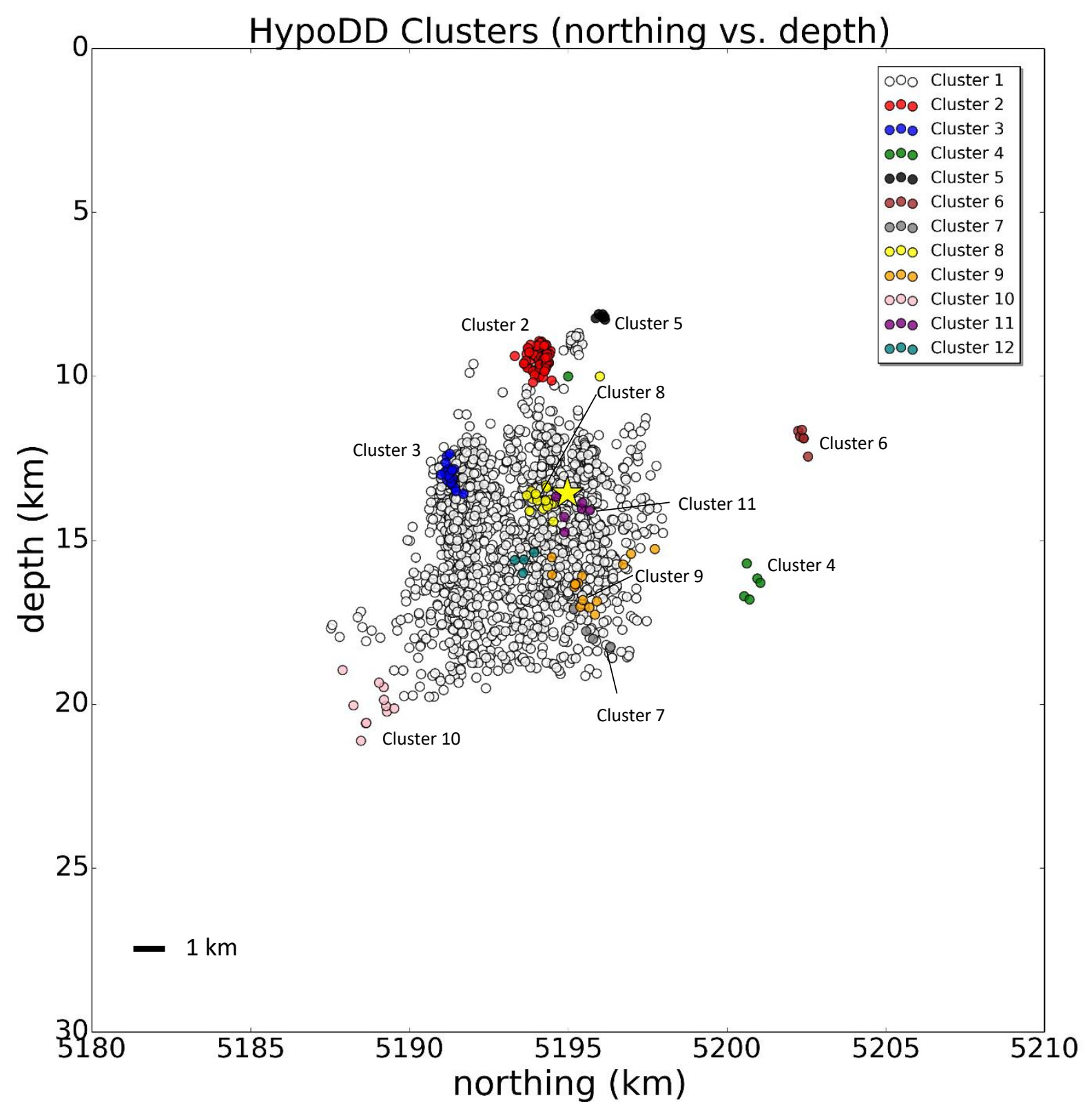

Figure 15. E-W cross-section of double difference relocations, viewed to the west, for all events since the Lincoln M5.8 event until April 28, 2019. Events are color coded by cluster and plotted in UTM coordinates (northing $(\mathrm{km})$ versus depth below sea level $(\mathrm{km})$ ). Yellow star denotes location of the M5.8 Lincoln event. 
To visualize how the aftershocks ruptured through time, we color coded each cluster by time (days since mainshock) up until April 28, 2019. Figures 16 through 18 reproduce Figs. 1315, but show double-difference relocations color coded by time. Earthquakes have continued to rupture along the inferred primary fault plane for the full two years of the study period. The remaining clusters are not rupturing systematically from east to west or from west to east; for example, Clusters 5 and 7 are located near to each other but events in Cluster 5 occurred over a year later than the events in Cluster 7. Clusters do not appear to rupture in any particular spatial sequence. 


\section{HypoDD Clusters (easting vs. northing)}

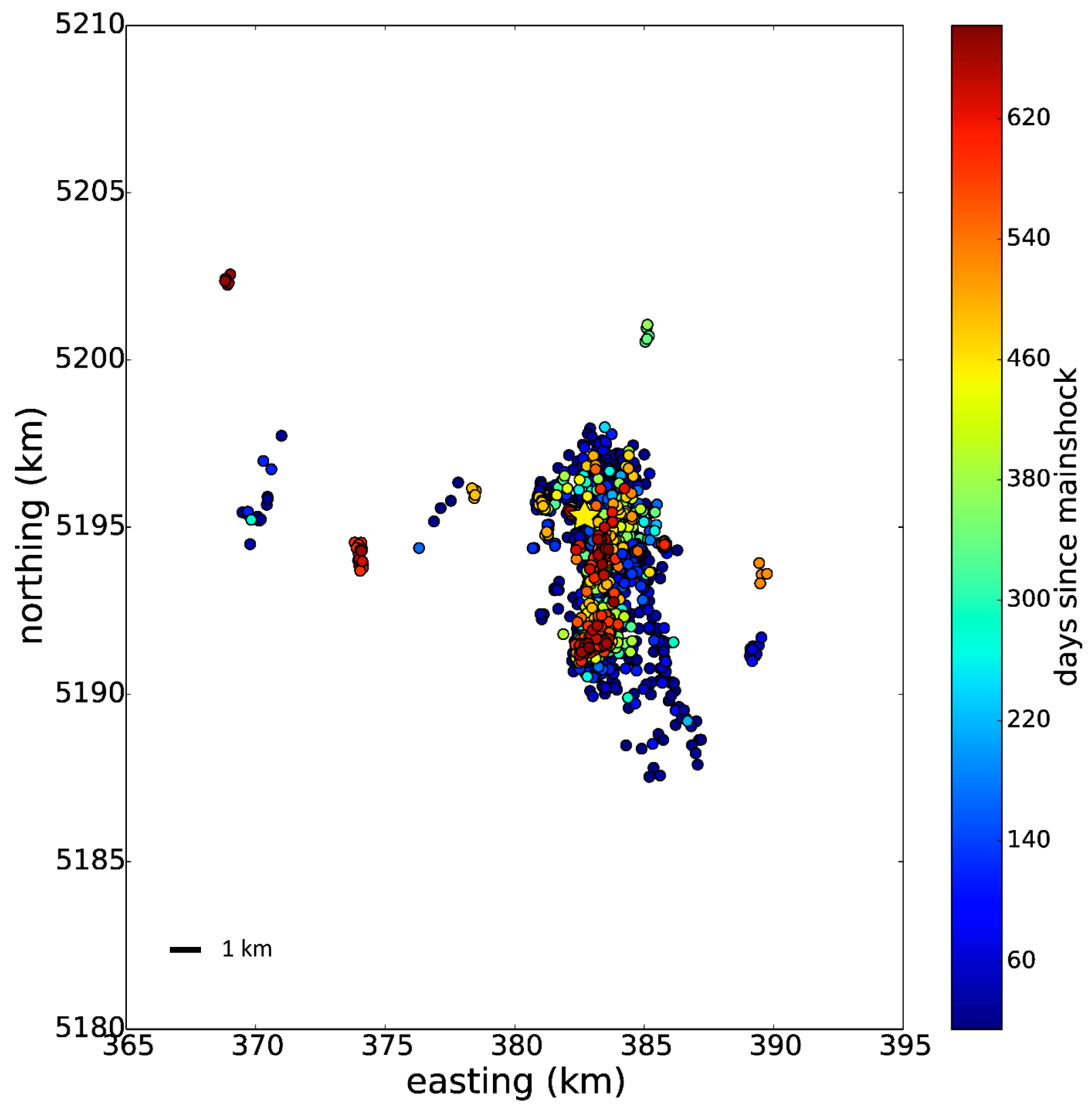

Figure 16. Double difference relocations for all events since the Lincoln M5.8 event until April 28, 2019. Events are color coded by time (days since mainshock) and plotted in UTM coordinates (easting $(\mathrm{km})$ versus northing $(\mathrm{km})$ ). The majority of the earthquake clusters are to the west of the Lincoln M5.8 event. Some of the earthquake clusters are more diffuse than others, but almost all of the earthquake clusters are spatially and temporally correlated. 
HypoDD Clusters (easting vs. depth)

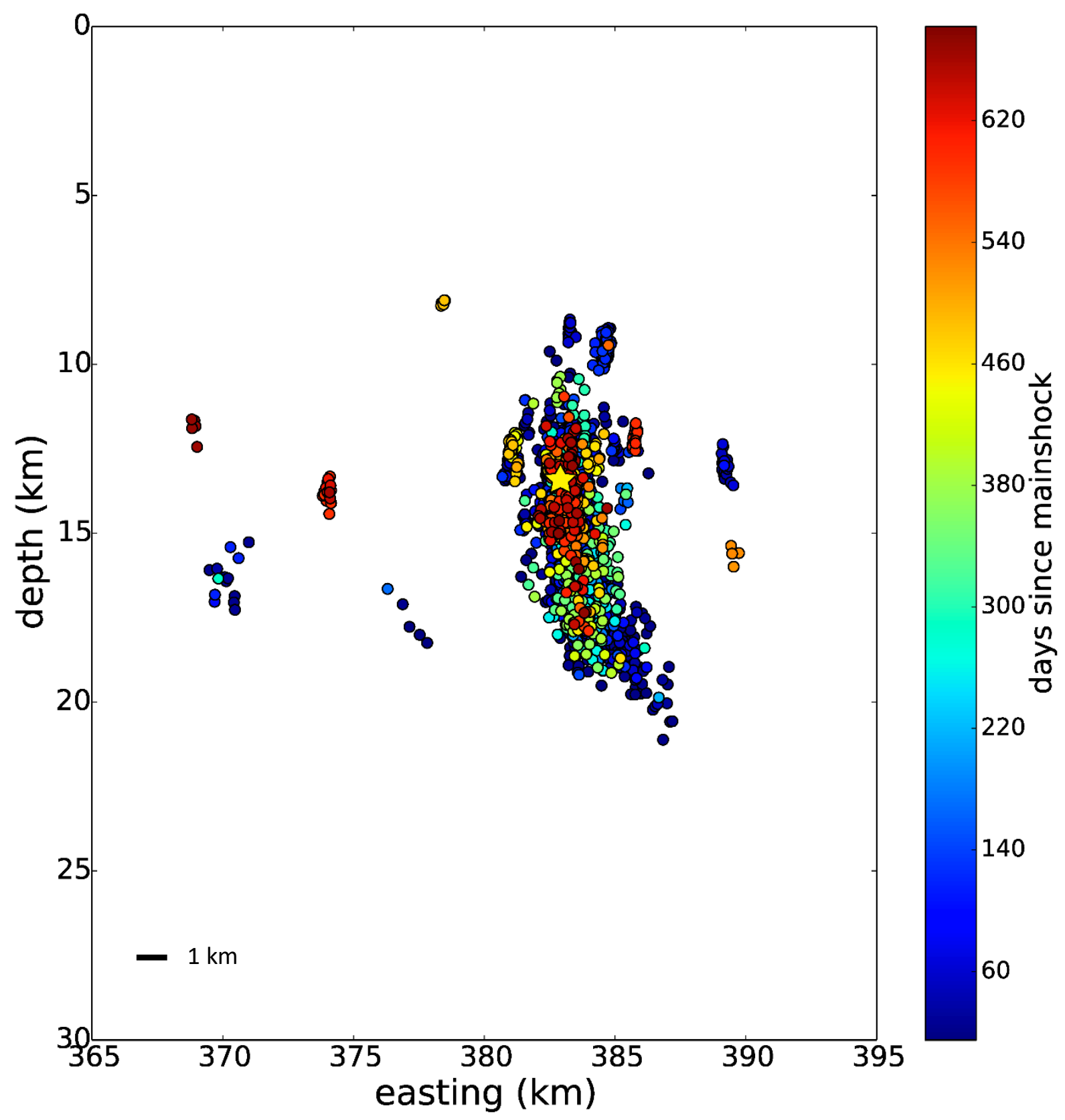

Figure 17. Double difference relocations for all events since the Lincoln M5.8 event until April 28, 2019. Events are color coded by time (days since mainshock) and plotted in UTM coordinates (easting $(\mathrm{km})$ versus depth $(\mathrm{km})$ ). 


\section{HypoDD Clusters (northing vs. depth)}

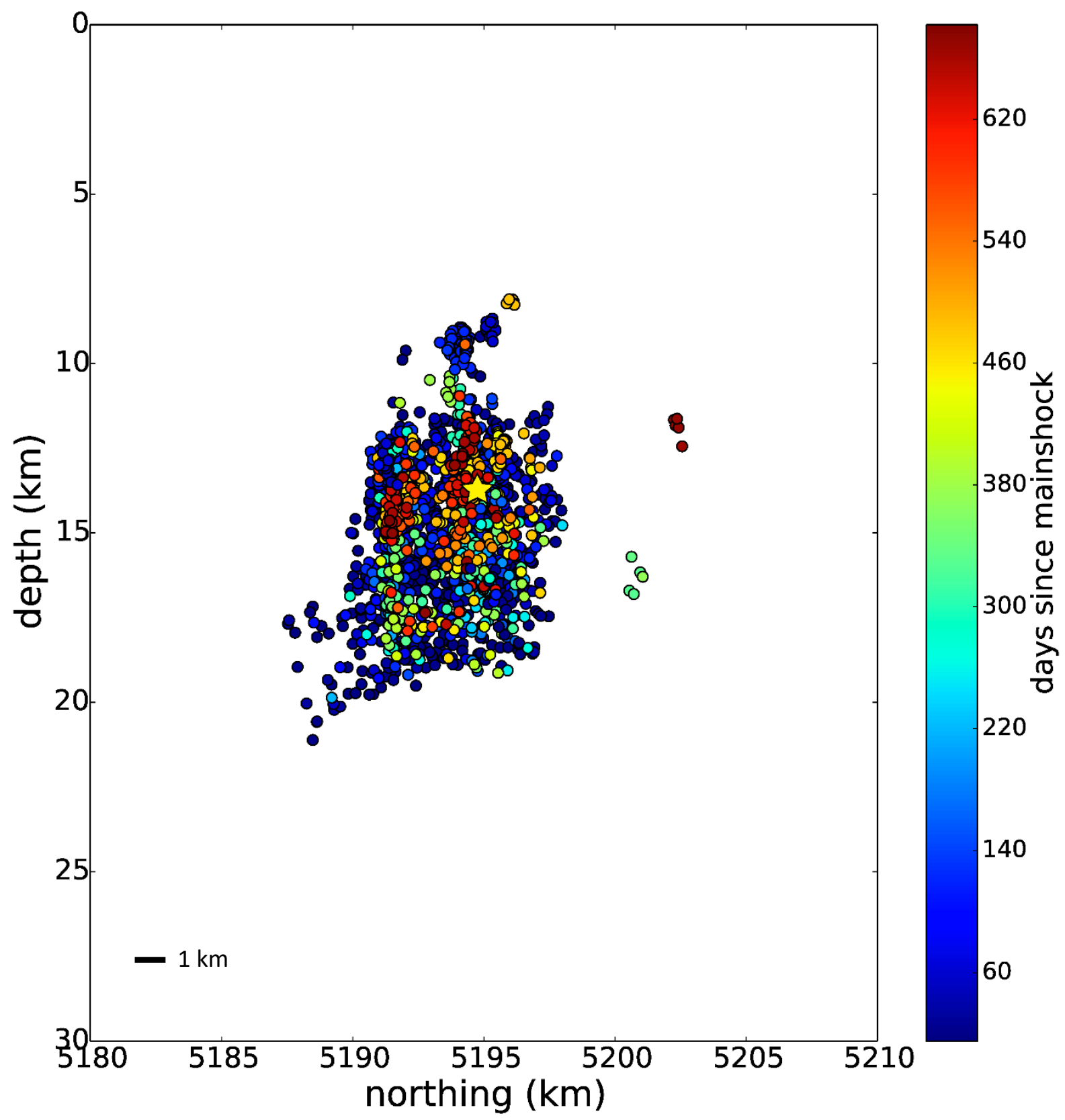

Figure 18. Double difference relocations for all events since the Lincoln M5.8 event until April 28, 2019. Events are color coded by time (days since mainshock) and plotted in UTM coordinates (northing $(\mathrm{km})$ versus depth $(\mathrm{km})$ ). 


\section{Relative Relocations and Focal Mechanisms}

Figure 19 shows a detailed map of each earthquake cluster defined in Fig. 14 to show the spatial alignment of events within each cluster. Focal mechanisms are plotted for all events with at least $12 \mathrm{P}$-wave first motion polarities. Events along the main fault rupture are oriented approximately $\mathrm{N}-\mathrm{S}$ at depths between 10 and $20 \mathrm{~km}$ (Fig. 2); focal mechanism solutions in Cluster 1 show left-lateral movement, inferred from the alignment of aftershock events. Focal mechanism solutions and alignment of aftershock events in Cluster 1 are consistent with results from McMahon et al. (2019). Clusters 2, 7, and 8 are the most consistent with the main aftershock cluster in terms of the alignment of aftershock events. In map view, Cluster 2 is located along the main fault rupture (Figs. 14 and 17), but events in Cluster 2 occurred at a depth of $\sim 8 \mathrm{~km}$. Events in Cluster 2 are oriented approximately N-S or NNE-SSW. Focal mechanism solutions from Cluster 2 show left-lateral movement based on the N-S or NNE-SSW orientation of aftershocks. Events from Cluster 2 primarily occurred from July 23, 2017 until October 31, 2017 (i.e. within 3 months of the mainshock). All 5 events in Cluster 7 show a NNE-SSW, 2-km linear trend which is most similar to the orientation of Cluster 2 as compared to the more N-S orientation of Clusters 1 and 8. Events in Cluster 7 occurred in July 2017 (i.e. within one month following the main shock). The only available fault plane solution for Cluster 7 trends more ENE-WSW than NNE-SSW (assuming left-lateral motion). The orientations of the P- and T-axes for the focal mechanism solution in Cluster 7 differ from most of the other focal mechanism solutions; it shows NW-SE extension instead of NE-SW extension.

Cluster 8 is one of the more robust clusters in terms of the number of events, and the spatial orientation of the events. Events in Cluster 8 are aligned N-S. Focal mechanism solutions are consistent with left-lateral movement based on the N-S alignment of aftershock events. The 
majority of aftershocks in all clusters occurred within the first month of the mainshock. The majority of events in Cluster 8 occurred on February 3, 2019, over a year and a half after the mainshock. The timing of aftershock events in Cluster 8 indicates that the release of energy along the fault ( $\sim 10 \mathrm{~km}$ west of the main fault rupture) occurred a little over 1.5 years after the M5.8 Lincoln event.

Events in individual clusters, except for Cluster 1, occurred within a 2-3 month time period; in several instances, events within clusters occurred on the same day. Clusters 3, 5, 6, 9, 10, and 11 are diffuse spatially. We interpret most of the focal mechanisms to represent leftlateral strike-slip faulting based on the roughly north-south alignment of aftershock events. However, some of the focal mechanisms are inconsistent. For example, in Cluster 9, all of the focal mechanism solutions show oblique-slip movement. Focal mechanism solutions in Clusters 10-12 represent strike slip and oblique-slip faulting. The variation in focal mechanism solutions is likely due to the complex tectonic history of the Lincoln region and uncertainties in the focal mechanism solutions associated primarily with suboptimal station coverage and distribution. 

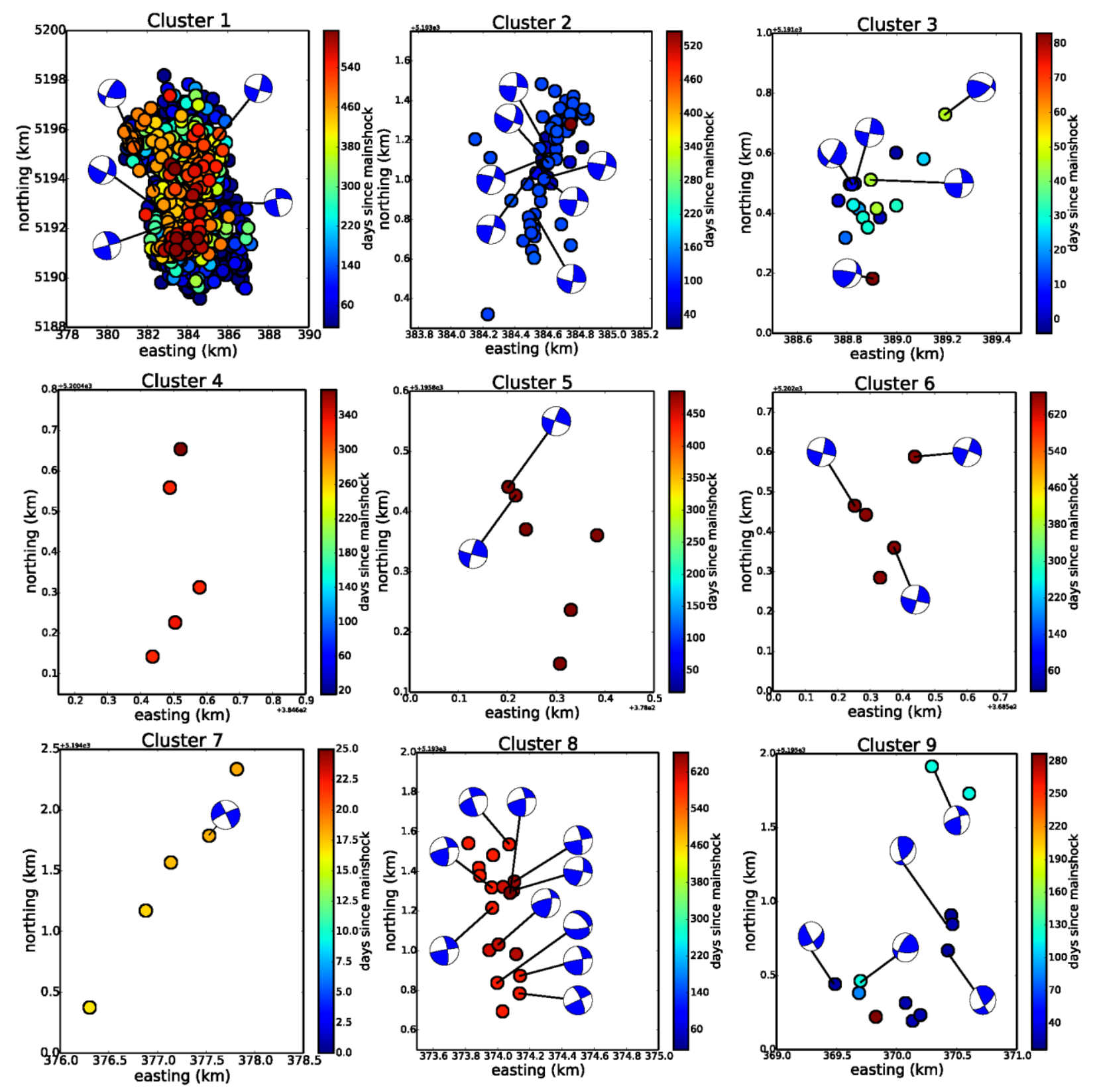

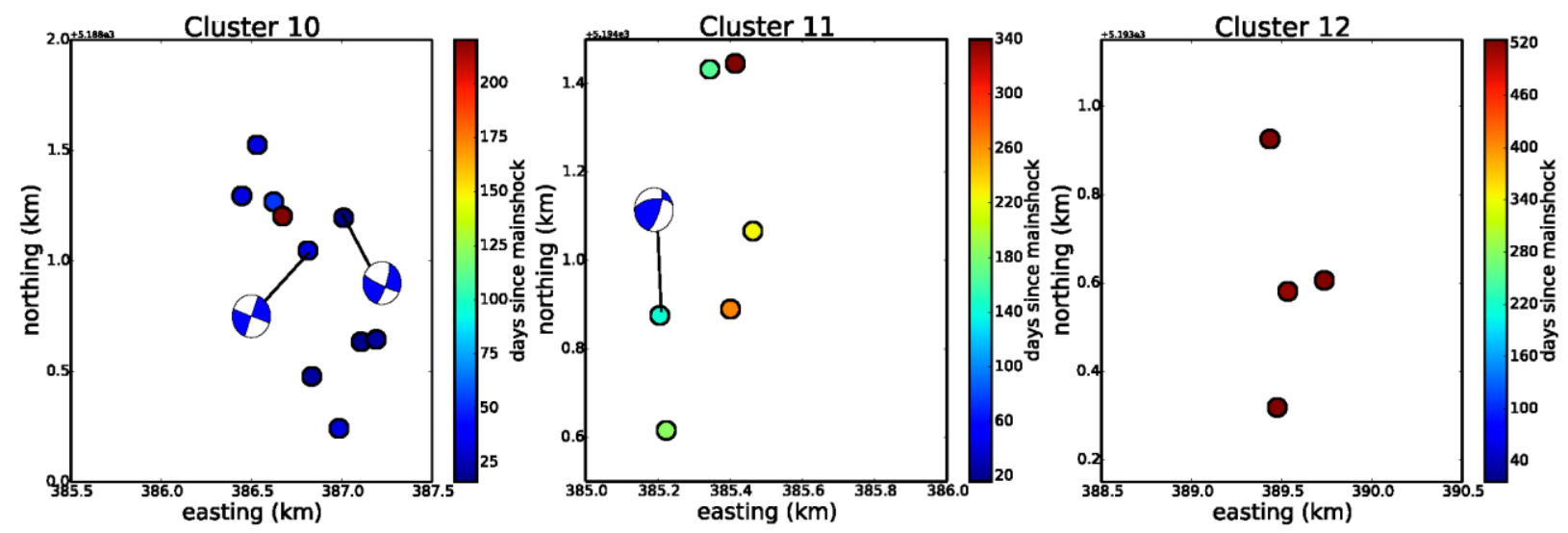

Figure 19. Double difference relocations for Clusters 1-12 color coded by time (days since mainshock until April 28, 2019). Focal mechanism solutions are plotted for all events with at least 12 polarities. Some clusters (i.e. Cluster 7) occurred within a month after the mainshock, which was during a period where we had the least amount of data available. Cluster 1 occurs along the main fault rupture. The focal mechanism solutions for Clusters 2, 7 and 8 are the most consistent. The focal mechanisms for Cluster 2 occurred at a slightly shallower depth than the main cluster, and most of the events align well with the inferred fault plane from the mean fault plane solution. Events in Cluster 7 are aligned NNE-SSW. The interpreted fault plane for the focal mechanism in Cluster 7 is aligned more NE-SW than NNE-SSW. The focal mechanisms for Cluster 8 appear to show that the aftershocks are aligned more N-S or NNW-SSE. Events in all clusters are temporally correlated. Events in Cluster 1 have continued to occur since the mainshock (July 6, 2017) up until April 28, 2019. Overall, the majority of the fault plane solutions show left-lateral strike slip faulting based on the orientation of the aftershock events.

\section{$P$ - and T- Axes Orientations}

We selected 125 fault plane solutions based on number of polarity picks (15+) to determine the distribution of P-and T- axes orientations. Figure 20 illustrates that the dominate style of faulting in the region is strike-slip and consistent with NE-SW extension identified elsewhere along the northern ISB (Stickney, 2015). 


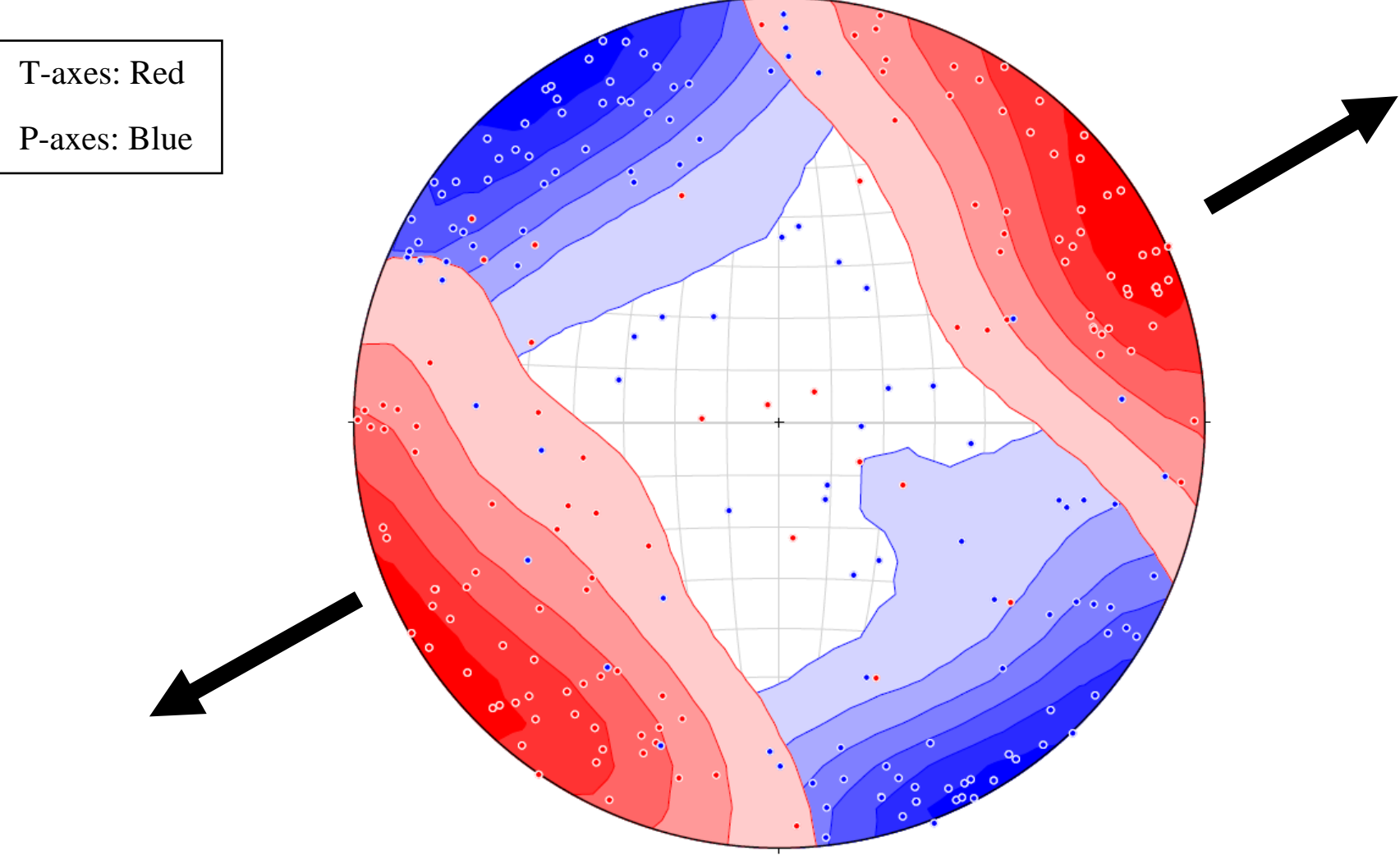

Figure 20. $P$ - and T-axes orientations for events with at least 15 polarities. The T-axes are in red, and the $P$-axes are in blue. The average $T$-axis orientation is $N 60^{\circ} E$. $P$-and $T$-axes indicate the dominate style of faulting in the region is strike-slip, consistent with NE-SW extension identified elsewhere along the northern ISB (Stickney, 2015). The figure was created using the FaultKin software (Allmendinger, 2011).

\section{Magnitude of Completeness}

The magnitude of completeness $\left(M_{c}\right)$ represents the minimum magnitude for which all events are reliably recorded and located by a particular network within a specific region. We used the event frequency-magnitude distribution of the Jiggle catalog to calculate $M_{c}$ (Gutenberg and Richter, 1964). The Jiggle catalog is based on MRSN and other permanent network data; UMSN data are included in magnitude estimates but only for events originally located by 
MRSN. No new events were added to the catalog based on UMSN data, although the quality of data from the additional digital sensors in the UMSN would likely produce additional event identifications. Since the UMSN data are not telemetered, we currently do not have the means to incorporate the additional data into the automated detected algorithms. Figure 21 shows that $M_{c}$ is 1.1 for all events from July 6, 2017 until April 28, 2019. The $M_{c}$ is declared where the values deviate from a straight line. The b-value represents the slope of the curve above $M_{c}$ and it is known as the Gutenberg-Richter relationship (Fiedler et al., 2018).

Figure 21 shows similar results to Fig. 6a from McMahon et al. (2019); Fig. 6a from McMahon et al. (2019) shows a change in slope at M0.7 and at M2.5. Figure 21 exhibits a change in slope at around M2 and again at M3. We calculated a b-value of 0.77 using 1.1 as the value for $M_{c}$ and a b-value of 0.74 using 3.0 as the value for Mc. McMahon et al. (2019) calculated a $M_{c}$ value of 2.5 and a $b$-value of 0.8 for their initial catalogue, which included 303 relatively large events within the first 3 months after the mainshock, and a $M_{c}$ value of 0.7 and a b-value of 0.79 for their final catalog, which included an additional 2706 events discovered by template matching. Our magnitude of completeness results are more comparable to the initial catalog of McMahon et al. (2019) based on methods, but we have considered a much longer time period with thousands more events. The $M_{c}$ for the MRSN catalog is likely higher than the final $M_{c}$ value (0.7) reported in McMahon et al. (2019) because we did not use a matched filter technique to detect lower magnitude events not reported in the MRSN catalog. A b-value of 0.77 is consistent with results from McMahon et al. (2019) and intraplate settings (Okal and Sweet, 2007). The MRSN catalog is complete above magnitude 1.1; events above this magnitude are reliably being recorded and located by the seismic stations within the Lincoln region. Events $\leq$ M1.1 occurred within the Lincoln region but likely have signal-to-noise ratios that are too small 
to be located by the MRSN. The UMSN data was used to improve the estimate of magnitude and location, but not to create the event catalog. The UMSN data are not telemetered, and therefore not included in initial catalog processing.

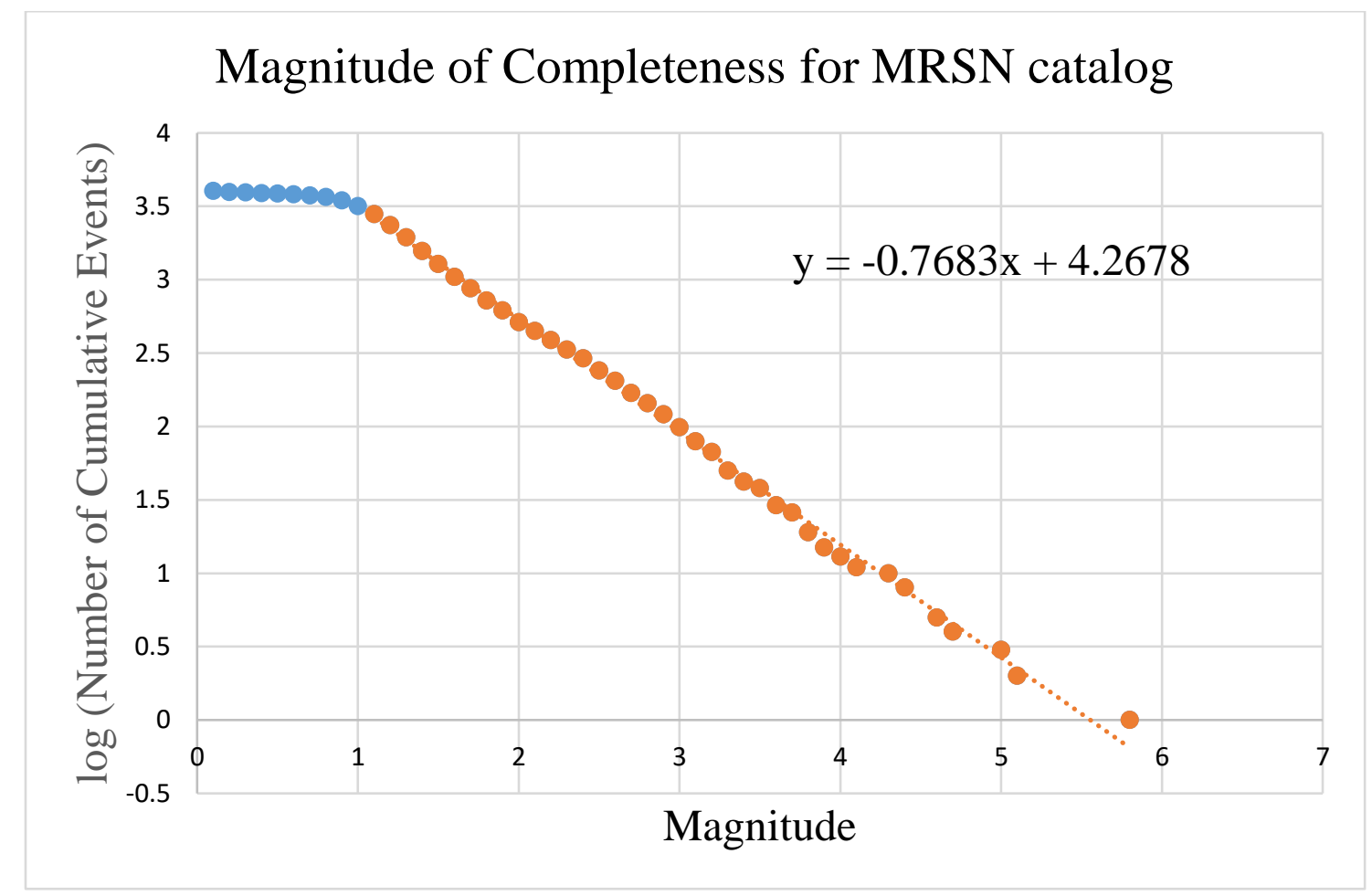

Figure 21. Magnitude of completeness for aftershock events from July 6, 2017 - April 28, 2019. The magnitude of completeness for the MRSN catalog is 1.1. The x-axis is the magnitude and the $y$ axis is the log of the cumulative number of events. The UMSN data was used to improve the estimate of magnitude, but not to initially identify all events. 


\section{Coulomb Stress Changes}

We investigated static stress changes to determine if the main shock triggered events and modified the local stress field. We calculated the Coulomb stress changes on nearby faults and investigated how faults interact by the transfer of stress. We used the focal mechanism for the main shock as the geometry for the source fault. The main shock had a strike, dip, and rake of $\mathrm{N} 13^{\circ} \mathrm{E}, 83^{\circ}$, and $-11^{\circ}$ (U.S. Geological Survey, 2017). We used a magnitude of 5.8, a slip area of $7 \mathrm{~km}$ horizontal by $9 \mathrm{~km}$ vertical, and a displacement of 35 centimeters of slip for the source fault. We specified the depth of the source fault to be between 11 and $20 \mathrm{~km}$ (Fig. 2). We used the aftershocks in Cluster 1 to define the total area or rupture. We used one representative receiver fault to define receiver fault geometry. The majority of the aftershock events are located near the source fault, which we define to be the fault that ruptured during the mainshock.

Coulomb stress change, $\Delta \sigma_{\mathrm{f}}$, is given by:

$\Delta \sigma_{\mathrm{f}}=\Delta \tau_{\mathrm{s}}+\mu^{\prime} \Delta \sigma_{\mathrm{n}}$,

Eq. 1

where $\Delta \sigma_{\mathrm{n}}$ describes the change in normal stress and $\Delta \tau_{\mathrm{s}}$ describes the change in shear stress imposed on the receiver fault due to slip on the source fault. The normal-stress coefficient, $\mu$ ', represents the effective coefficient of friction for the receiver fault. We adopt a standard value of 0.4 for the effective coefficient of friction. A positive change in normal stress indicates reduced compression on the receiver fault. A positive change in shear stress indicates additional shear stress in the direction of defined receiver fault slip (Reasenberg and Simpson 1992; Toda et al. 2005). A positive coulomb stress change $\left(\Delta \sigma_{f}>0\right)$ indicates seismic failure is promoted on the receiver fault (Toda et al. 2011). Figures 22-24 show Coulomb stress changes. We calculated Coulomb stress changes for one representative receiver fault with a strike, dip, and rake of 
$\mathrm{N} 15^{\circ} \mathrm{E}, 85^{\circ}$, and $10^{\circ}$, which is based on a single focal mechanism solution with $20+$ polarities from Cluster 2. Although we only used data from one focal mechanism solution to define the receiver fault geometry, focal mechanism solutions from Cluster 2 are similar. The average inferred fault plane solution aligns well with the orientation of aftershock events, which is consistent with left-lateral strike slip faulting. This is why we used a focal mechanism solution from Cluster 2 to specify receiver fault geometry. Cluster 2 is located at a latitude and longitude of $\sim 46.9,-112.7$, and an average depth of $\sim 8 \mathrm{~km}$. Cluster 2 occurred within 3 months following the main shock. Figure 22 shows calculated Coulomb stress changes in map view at a depth of $12 \mathrm{~km}$, which is the depth at which most aftershocks occurred (Fig. 2). Figure 23 shows calculated Coulomb stress changes with depth along dip direction of the source fault. Figure 24 shows calculated Coulomb stress changes with depth along strike of the source fault. Figures 2224 show positive Coulomb stress changes for events occurring $\sim 8-12 \mathrm{~km}$ in depth. We confirmed that the relatively shallow clusters lie in zones of positive Coulomb stress change of $\sim$ 3-4 bars by specifying the receiver fault geometry to match the faulting mechanisms in the shallow cluster (Cluster 2). Clusters 3, 7, and 9 differ by up to about 20 degrees in strike, but still yield similar results. We therefore infer that static stress changes from the main shock likely triggered aftershocks in the clusters directly above the main aftershock sequence, as well as to the west of the mainshock. Figure 23 shows that events to the east of the mainshock are located in zones of negative Coulomb stress changes. The other clusters to the west of the mainshock have similar receiver fault geometries and exhibit similar patterns of Coulomb stress change but are not shown here. 


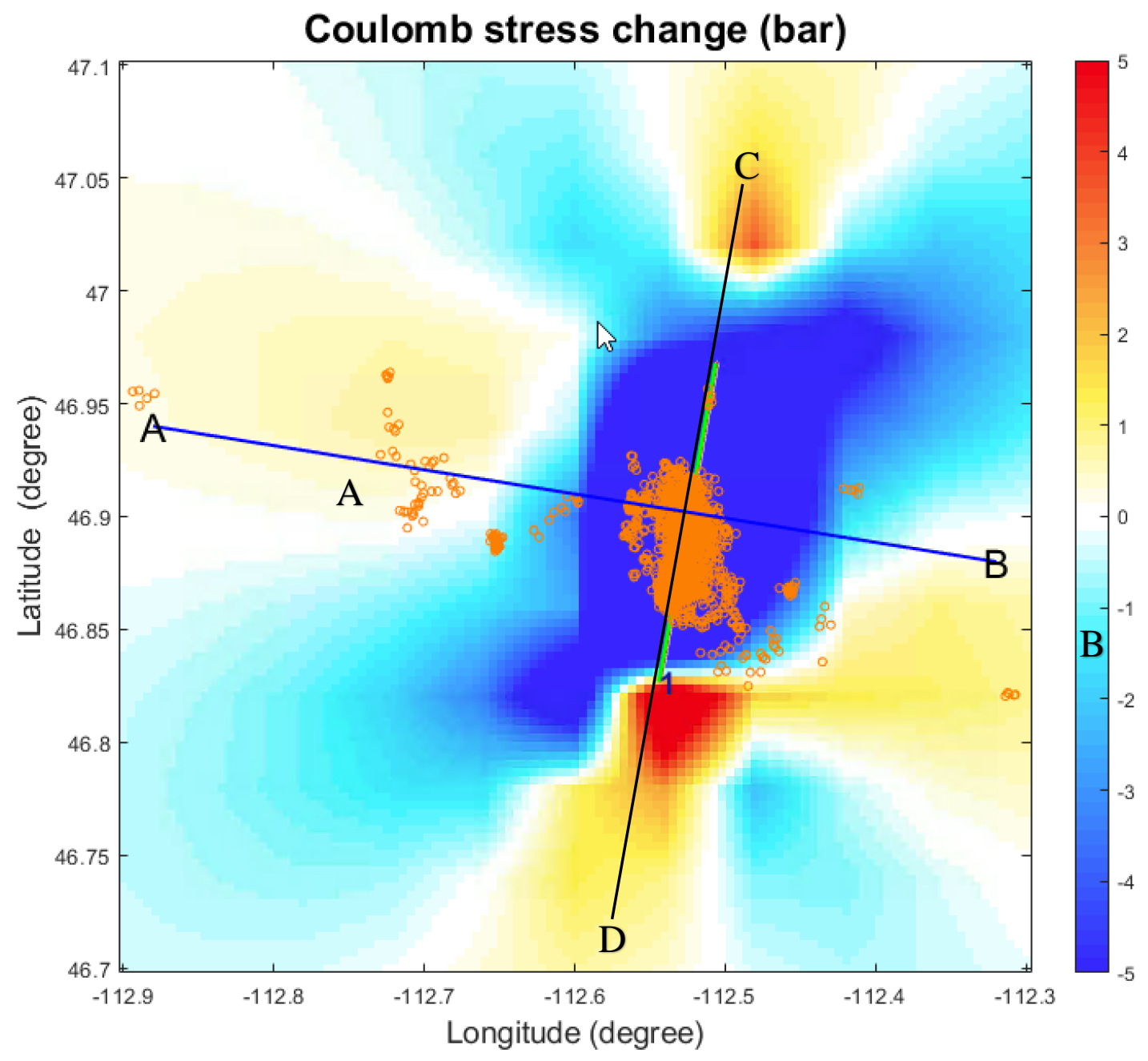

Figure 22. Source fault is the M5.8 Lincoln event. The receiver fault has a strike, dip, and rake of $\mathrm{N} 15^{\circ} \mathrm{E}, 85^{\circ}$, and $10^{\circ}$, which is based on a focal mechanism solution in Cluster 2 with $20+$ polarities. We calculated Coulomb stress changes in map view at a depth of $12 \mathrm{~km}$. Relative relocations along the mainshock and to the west and east of the mainshock are in regions of positive Coulomb stress change ( 1-2 bars). Line A-B represents the depth profile shown in Figure 23. Line C-D represents the depth profile shown in Figure 24. 


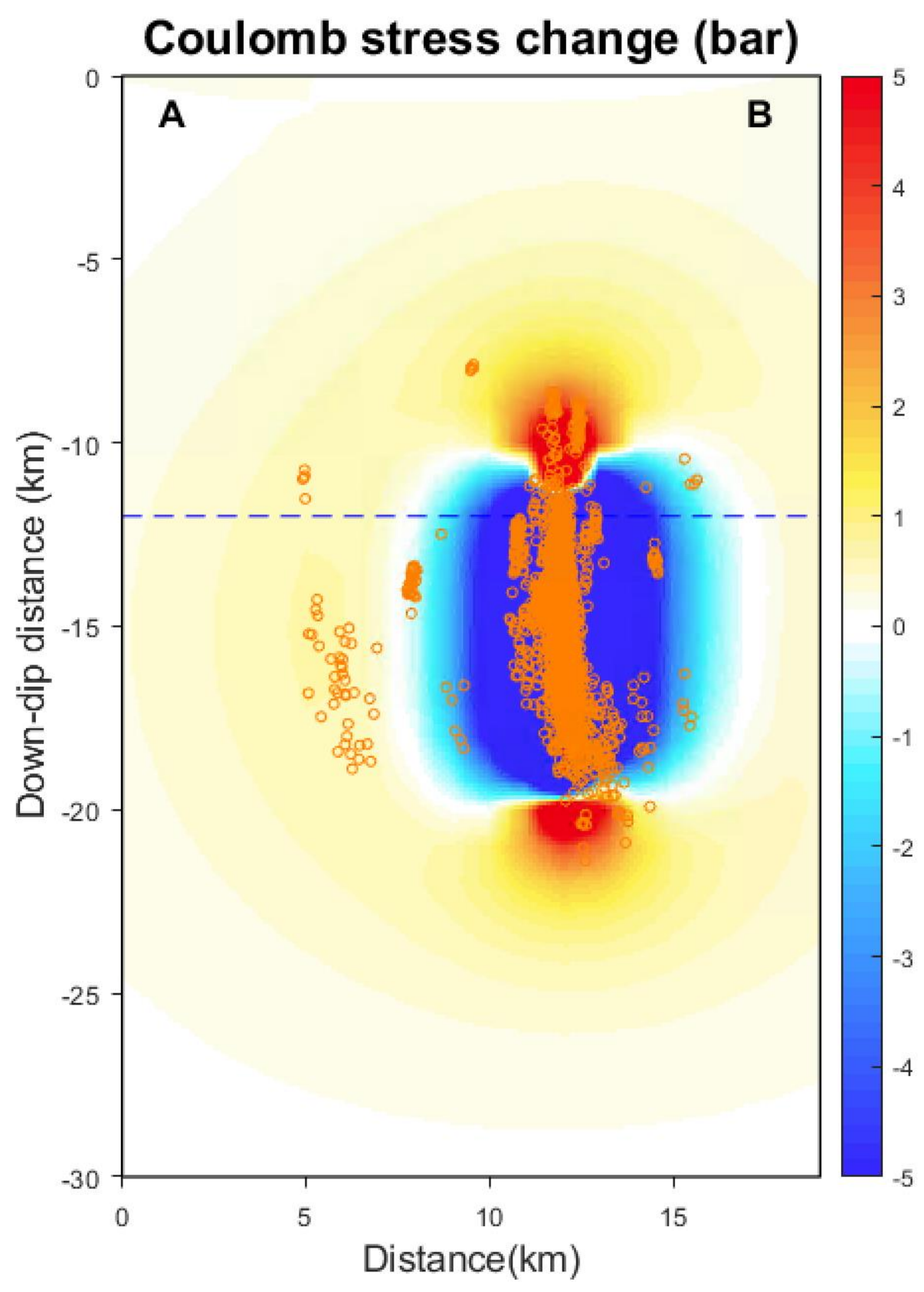

Figure 23. Depth profile showing Coulomb stress changes along dip direction of the source fault. Relative relocations are at a depth of $\sim 8-20 \mathrm{~km}$ below sea level. Some events are located in regions of positive Coulomb stress ( 1-3 bars). Events from the mainshock and to the East of the main shock are located in regions of negative Coulomb stress ( 1-3 bars). 


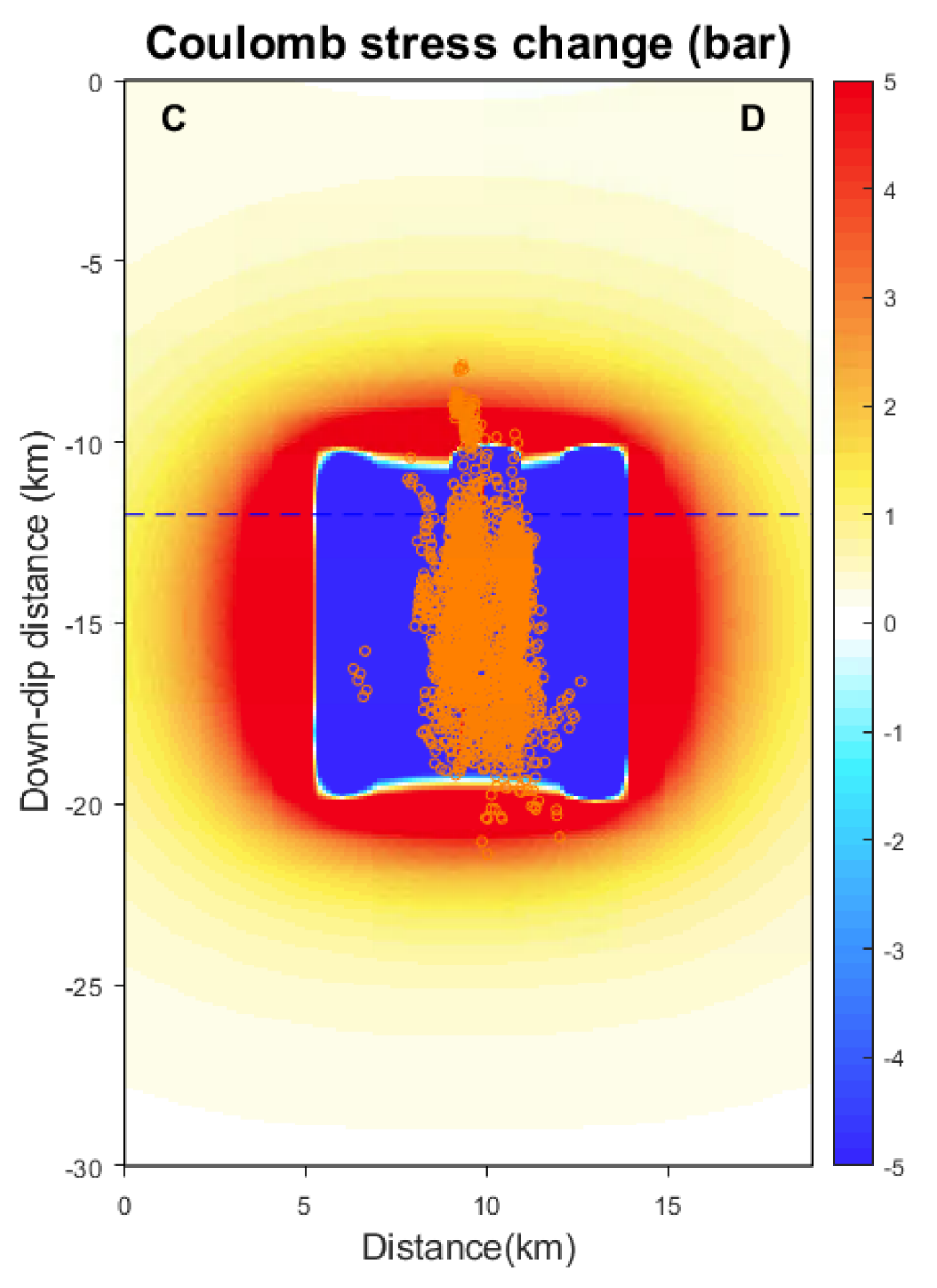

Figure 24. Depth profile showing relative relocations along strike of the source faults. Relative relocations are at a depth of $\sim 8$ to $20 \mathrm{~km}$ below sea level. Mainly the shallow events are located in regions of positive Coulomb stress ( 1-4 bars), and other events are located in regions of negative Coulomb stress (1-4 bars). 


\section{Error Analysis}

Absolute hypocenter locations had an average depth error of $1.04 \mathrm{~km}$, an average horizontal error of $0.34 \mathrm{~km}$, an average of 0.18 seconds for the root-mean-square (RMS) of the travel time residuals, and average azimuthal gap between seismic stations for all events of 74.4 degrees. Double difference relocations had an average east-west error of 43 meters, an average north-south error of 52 meters, and an average depth error of 65 meters. For every fault plane solution, FPFIT reports the uncertainties in the quality of the solution. The $F j$ parameter (minimum of the data-misfit function) describes how well the solution fits to the data. A value of 0 for Fj represents a perfect fit (all observed and theoretical first-motion polarities match), while a value of 1 represents a perfect misfit (all observed and theoretical first-motion polarities are opposite). Misfit describes the difference between the observed data and the predicted data. If the observed data and predicated data are inconsistent, then the model represents a "misfit." If the observed and predicted data are consistent or similar, then the solution is likely well constrained. Misfit also depends on the observation and theoretical weights. Theoretical polarities near the two nodal planes are down-weighted, because first motion polarities may be more ambiguous near nodal planes. Focal mechanism solutions constrained by 10, 12, or 15 polarity picks had a value of 0.05 for Fj. The station distribution ratio (STDR) describes the distribution of first motion polarities on the focal sphere. A low STDR indicates that most of the data lie near the nodal planes in the solution. A high STDR suggests that most of the data lie further away from the nodal planes. A higher STDR (STDR > 0.5) is more robust than a lower STDR. All STDR values from Table 3 are $\geq$ to 0.65 .

$\triangle \mathrm{STR}, \triangle \mathrm{DIP}$, and $\triangle \mathrm{RAK}$ represent uncertainty for the strike, dip, and rake averaged over all of the individual fault plane solutions. We experimented with values of $8,10,12,15$, and 20 
for the number of polarity observations per event. See Table 3 for the average Fj, STDR, $\Delta$ STR, $\triangle \mathrm{DIP}$, and $\triangle \mathrm{RAK}$ for $8,10,12,15$, and 20 polarity picks. The majority of focal mechanisms (Appendix F) show left-lateral strike-slip faulting (based on orientation of aftershock locations). Even though there are 40 stations within $\mathrm{a} \sim 200 \mathrm{~km}$ distance, it is often not possible to make more than 12 polarity picks. Sometimes the data are not clear enough to determine polarities; the waveforms are emergent. The uncertainty in degrees of $\triangle \mathrm{STR}, \triangle \mathrm{DIP}$, and $\triangle \mathrm{RAK}$ is likely a result of the station distribution. Stations might be located near the nodal planes, too close together, or too far away from each other. In general, focal mechanism solutions shown for the individual clusters and in Appendix F are relatively consistent. Figure 25 shows an example focal mechanism for an event from Cluster 6 that occurred on April 15, 2019. The focal mechanism solution is constrained by 15 polarity picks.

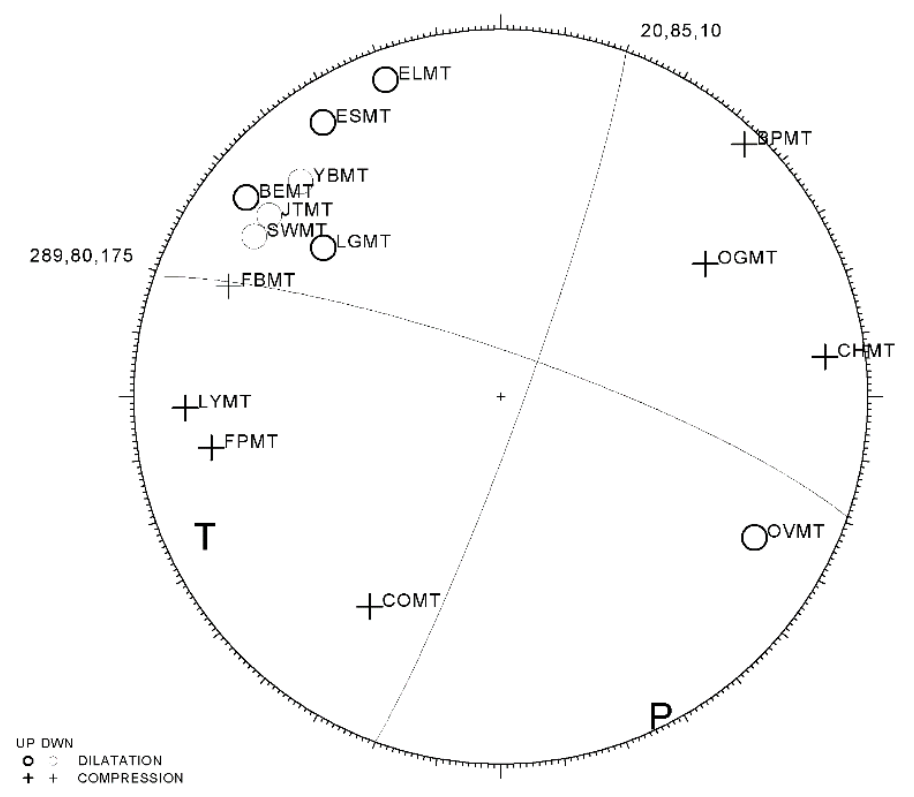

Figure 25. Example focal mechanism solution constrained by 15 polarity picks. This focal mechanism is from a magnitude 2.57 Ml event that occurred on April 15, 2019. The open circles are located in the dilatational quadrant (downward P-wave first motion). The crosses are located in the compressive quadrant (upward P-wave first motion). The total number of polarity picks for this event was 15. 4-letter station codes are plotted next to each first motion observation. Several stations are close to each other in the northwest dilatational quadrant, while many fewer first motion polarities are located in the southeast dilatational quadrant and the northeast and southwest compressive quadrants. This is a lower hemisphere projection. Bold symbols show ray paths that exited the upper hemisphere and were re-projected onto the lower hemisphere. 
Table 4. Uncertainty for fault plane solutions.

\begin{tabular}{|l|l|l|l|l|l|l|}
\hline $\begin{array}{l}\text { Number of } \\
\text { polarity } \\
\text { picks }\end{array}$ & $\begin{array}{l}\text { Number } \\
\text { of } \\
\text { events }\end{array}$ & Fj & STDR & $\Delta$ STR & DDIP & ARAK \\
\hline$\geq 8$ & 1853 & 0.21 & 0.65 & 90.1 & 55.5 & 148.8 \\
\hline$\geq 10$ & 908 & 0.05 & 0.80 & 88.0 & 55.5 & 141.4 \\
\hline$\geq 12$ & 412 & 0.05 & 0.74 & 88.7 & 56.3 & 129.7 \\
\hline$\geq 15$ & 125 & 0.05 & 0.67 & 84.8 & 54.6 & 122.2 \\
\hline$\geq 20$ & 22 & 0.08 & 0.66 & 68.4 & 48.3 & 96.5 \\
\hline
\end{tabular}




\section{Discussion and Interpretation}

Why did the Lincoln Mainshock Rupture as a Left-lateral Strike Slip Fault?

The primary zone of aftershocks following the M5.8 event are oriented approximately N$\mathrm{S}$, which is unexpected due to the WNW-ESE orientation of the mapped LCL faults in the region (Fig. 1). The obliqueness of the aftershock fault planes to the dominant regional fabric is consistent with a bookshelf faulting mechanism (Mandl, 1986; Green et al., 2014; La Femina et al., 2002; Tapponnier et al., 1989). The focal mechanism from USGS (2017) for the M5.8 Lincoln event shows strike-slip faulting, but there is ambiguity in which nodal plane is the fault plane. McMahon et al. (2019) identified the M5.8 Lincoln event as a left-lateral strike-slip fault based on the approximately N-S orientation of aftershocks. However, the study from McMahon et al. (2019) did not provide an explanation for why the Lincoln main shock ruptured as a leftlateral strike slip fault. The mapped LCL faults in the region are right-lateral strike slip faults that accommodate regional crustal extension (Stickney, 2015). Why are aftershock alignments following the 2017 Lincoln mainshock roughly perpendicular to, and therefore apparently contradicting, the orientations of LCL faults? We hypothesize that a bookshelf faulting mechanism, which can accommodate regional extension and/or shear motion via crustal block rotations (Green et al., 2014; Reiser et al., 1993; La Femina et al., 2002; Tapponnier et al., 1990), might explain the unexpected fault orientation of the mainshock and aftershock sequence.

\section{What is Bookshelf Faulting?}

Bookshelf faulting is analogous to a stack of books on a bookshelf that become tilted over time; the row of books extends in length and decreases in height (Mandl, 1987). The outer book covers (planes between books) represent the bookshelf faults and the shelves above and 
below the stack of books represent the "bounding blocks" (Savage et al., 2004). Figure 26 shows a simple illustration of bookshelf faulting. The bookshelf faults exhibit the opposite sense of motion in comparison to the bounding blocks to accommodate the overall strain and shear from the bounding blocks (Freund, 1970; Savage et al., 2004). For example, if the bounding shear zone is right lateral, then the sense of slip on the bookshelf faults would be left lateral to accommodate the shear deformation via crustal block rotations about a vertical axis.

Different methods are used to identify a bookshelf faulting mechanism. One method used to provide evidence for a bookshelf faulting mechanism is to examine the alignment of hypocenter locations and to assess the spatial distribution of hypocenter locations (Mandl et al., 1986; Green et al., 2014). There are small-scale and large-scale examples of bookshelf faulting across the globe. Although bookshelf faulting examples from across the globe differ in appearance, they all share a "common mechanical basis" (Mandl et al., 1986). Bookshelf faulting is represented by a series of en echelon faults, which are parallel or sub-parallel faults, oblique to the overall structural trend in the region (Mandl, 1987). The four main pieces of evidence near Lincoln, MT that are consistent with a bookshelf faulting mechanism are the spacing of the aftershocks, the oblique or roughly perpendicular alignment of aftershocks relative to the primary structural fabric in the region, the presence of extension and shear in the region, and the presence of strike-slip faulting in the region. 


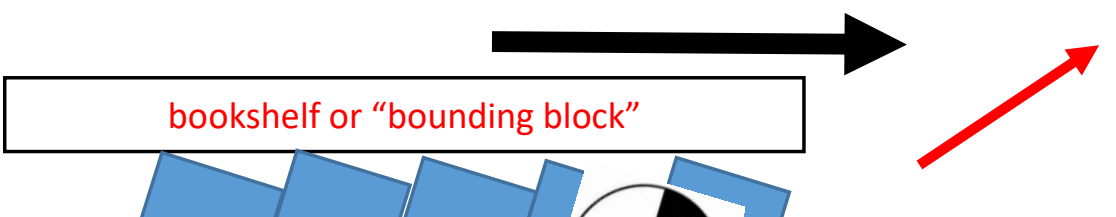

Figure 26. Simple illustration of bookshelf faulting. Bookshelf faulting is analogous to a row of books slipping past each other on a shelf. In this particular example, left-lateral strike slip bookshelffaults are accommodating overall regional extension (red arrows).

bookshelf or "bounding block"

Presence of Extension and Orientation of P-and T-Axes

Figure 27 (reproduced from Stickney, 2015) shows the orientations of P- and T- axes from earthquake fault plane solutions to the north of the LCL and within and south of the LCL. The locations of P- and T- axes show a combination of strike-slip, oblique-slip, and normal faulting. The average T-axis trend for faults just to the north of the LCL is $\mathrm{N} 87^{\circ} \mathrm{E}$. This suggests that the direction of extension is $\mathrm{E}-\mathrm{W}$, which is consistent with the orientation of north trending normal Quaternary faults north of the LCL (Figure 1; Stickney, 2015). E-W extension to the north of the LCL is also consistent with bookshelf faulting because it demonstrates that regional extension is present. T-axis orientations within and south of the LCL and T-axis orientations for the Lincoln region are consistent with NE-SW extension (Figs. 21 and 27). This further indicates that regional extension is present. Fault plane solutions show that regional extension is present to the north of the LCL and within and south of the LCL, which is consistent with bookshelf 
faulting mechanisms (Mandl, 1986; La Femina et al., 2002; Tapponnier et al., 1990; Green et al., 2014).
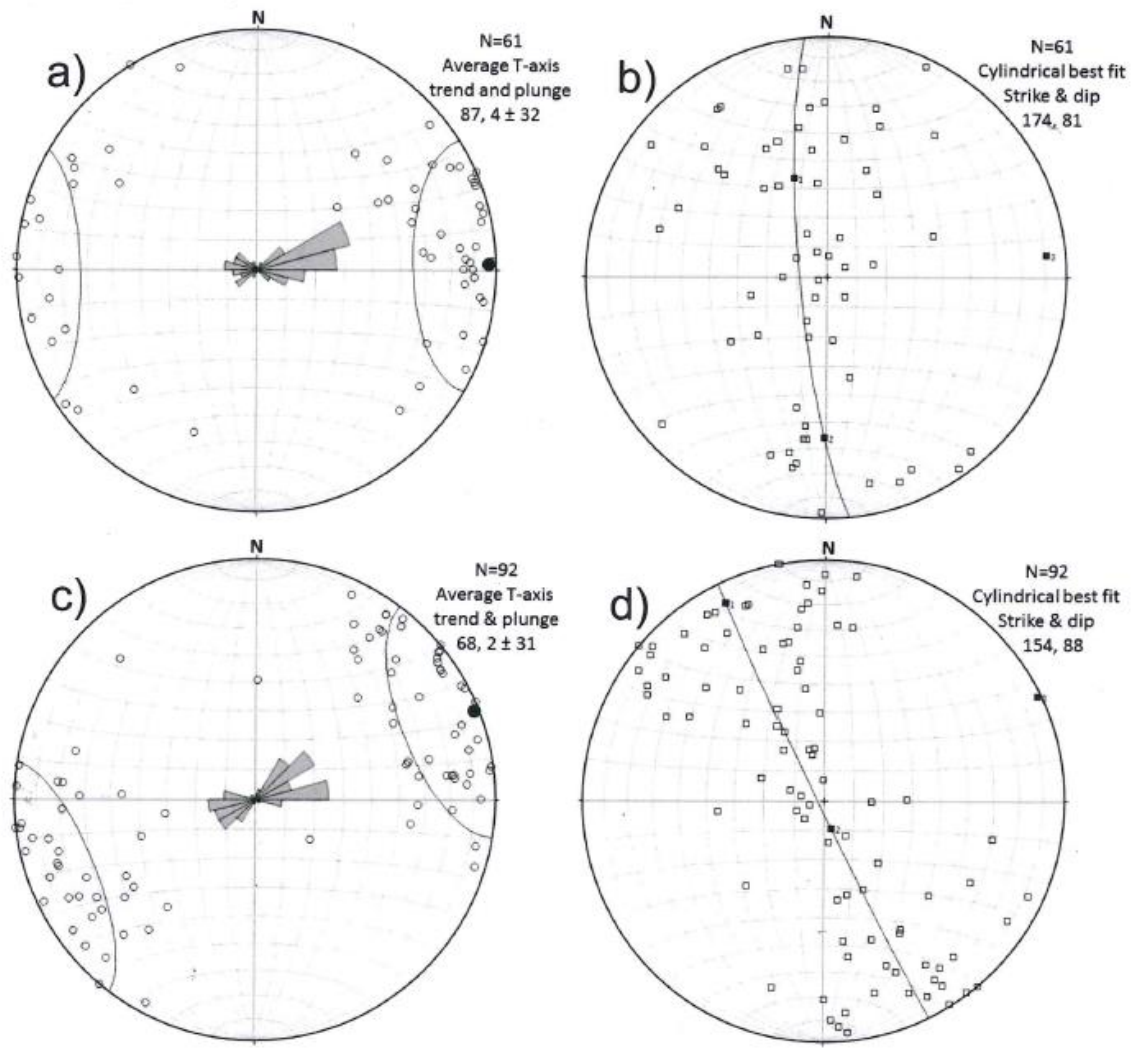

Figure 27. a) and b) show $T$ - and P-axes orientations from 61 earthquakes north of the LCL. $c$ ) and d) show $T$ - and $P$-axes orientations from 92 earthquakes within and south of the LCL. Overall, E-W extension is present to the north of the LCL and NE-SW extension is present within and south of the LCL. (Figure from Stickney, 2015).

Fault plane solutions show that extension is present in the region, and there appears to be two N-S oriented extensional fault segments to the north and south of the bookshelf faulting relay zone near Lincoln, Montana. The approximately N-S oriented extensional fault systems are consistent with E-W extension (Fig. 1), which can result in spatially variable extension and shear zones. The extensional fault segment to the north of the LCL is offset to the west relative to the segment to the south (Fig 1). The presence of extension observed in Montana is consistent with a bookshelf faulting mechanism. Extension is also present in bookshelf faulting mechanisms 
observed in Iceland, Nicaragua, and Ethiopia (Mandl, 1986; La Femina et al., 2002; Tapponnier et al., 1990; Green et al., 2014).

\section{GPS Surface Velocities, Extension, and Right Lateral Motion}

Additional supporting evidence for a bookshelf faulting mechanism is GPS surface velocities throughout the Northern Rocky Mountains. Figure 2 from Schmeelk et al. (2017) shows the direction of regional GPS velocities relative to stable North America; at $44^{\circ} \mathrm{N}$ latitude, GPS velocities are directed to the west at a rate of $4-5 \mathrm{~mm} / \mathrm{yr}$, and at $47^{\circ} \mathrm{N}$ latitude, GPS velocities are directed eastward at a rate of $2-3 \mathrm{~mm} / \mathrm{yr}$ (Schmeelk et al., 2017). This may suggest that a bookshelf faulting mechanism in Northwestern Montana is occurring due to differences in the rate of extension to the south and to the north of the Lincoln region, which set up shear forces in the crust. Extension to the south of the Lincoln region is occurring at a faster rate than extension to the north of the Lincoln region. Extension and strain are inferred based on how the GPS velocities differ spatially.

The varying rates of extension to the north and south of the Lincoln region are similar to bookshelf faulting scenarios observed in Iceland, Ethiopia, and Nicaragua. In Iceland, bookshelf faults are accommodating overall extension and right lateral shear due to differential extension occurring to the north and south of the bookshelf faulting relay zone (Green et al., 2014). In Ethiopia, bookshelf faults are accommodating overall extension and right lateral shear due to differential motion between the Arabia and Somalia Plates ((Tapponnier et al., 1990). In Nicaragua, bookshelf faults are accommodating overall extension and right lateral motion due to the movement of the Central American volcanic arc toward the Middle America trench (La Femina et al., 2002). 
Each of these examples is located in a region dominated by differential extension and shear. Iceland is located in a mid-ocean ridge setting. Ethiopia is an example of a continental rift zone, and part of Nicaragua is located in a forearc basin. Each of these localized shear zones is a consequence of overall regional extension, and in each region, the rate of extension exhibits spatial variations.

\section{Fault Plane Solutions and Aftershock Alignment}

Computed focal mechanisms for events in the Lincoln region primarily show strike slip faulting. However, there is ambiguity in which nodal plane is the fault plane. Based on the approximately N-S orientation of aftershock events, the inferred style of faulting in the Lincoln region is left-lateral strike slip faulting, consistent with the study from McMahon et al. (2019). The unexpected approximately N-S alignment of aftershocks, oriented oblique to the main mapped LCL faults in the region, and the inferred style of left-lateral strike slip faulting in the Lincoln region is consistent with a bookshelf faulting mechanism (Mandl, 1986; La Femina et al., 2002; Tapponnier et al., 1990; Green et al., 2014).

In Iceland, microseismic events are mapped sub-parallel to the orientation of the rift fabric and are located between the Askja rift segment to the NW and the Kverkfjöll segment to the SE (Green et al., 2014). Based on the orientation of well-located microearthquakes, and wellconstrained focal mechanism solutions, Green et al. (2014) inferred left-lateral strike slip faulting. The left-lateral strike slip faults oriented oblique to the rift fabric provide evidence for a bookshelf faulting mechanism. In Nicaragua, La Femina et al. (2002) uses a combination of hypocenter locations, previously mapped faults in the region, and surface rupture data to show that strike slip faults are oriented to the NE and normal to the main mapped NW striking faults in the region. Based on the NE orientation of the strike-slip faults, the authors inferred left-lateral strike slip faulting (La Femina et al., 2002). In Ethiopia, surface fractures and scarps show that 
strike slip faults are mapped oblique to the rift fabric. Based on geological field observations and focal mechanism solutions, Tapponnier et al. (1990) inferred the style of faulting to be left-lateral strike slip faulting. It is a coincidence that in Montana, Iceland, Nicaragua, and Ethiopia that the bookshelf faults are left-lateral strike-slip faults accommodating overall regional extension and right lateral transform motion. It is possible to have right-lateral bookshelf faults accommodating overall left-lateral transform motion. It is important that in each bookshelf faulting scenario, bookshelf faults are oriented oblique, or roughly perpendicular, to the main structural fabric in the region.

\section{The Temporal Evolution of the Lincoln Aftershock Sequence}

If books on a bookshelf move in a right or left lateral sense, then the slip on individual books would occur simultaneously. We investigate the following question: how rapid would we expect individual faults to rupture if these aftershock clusters are indicative of a bookshelf faulting mechanism? If a bookshelf faulting mechanism is occurring in the Lincoln region, then we might expect that all faults would rupture concurrently (e.g. in the time span of a day). This study takes place from July 6, 2017 until May 1, 2019, and individual faults are rupturing within an approximately two-year period. Some earthquake clusters occurred within one month following the mainshock, while other earthquake clusters occurred within several months following the mainshock. Faults in the Lincoln region are not rupturing within a day, but geologically speaking, two years is rapid in time.

The temporal evolution of the M5.8 Lincoln aftershock sequence is consistent with the temporal aspect of bookshelf faulting mechanisms observed in Iceland and Nicaragua. In Iceland, the study took place from 2009 to 2012 and events are spatially and temporally clustered (Green et al., 2014). Events within individual earthquake swarms lasted between one week and 
one month. Green et al. (2014) focuses on earthquakes occurring from 2009 to 2012, but the authors mention that seismic stations within this region have detected events within the past 2-4 decades. In Nicaragua, earthquakes are rupturing along bookshelf faults throughout the $20^{\text {th }}$ century (La Femina et al., 2002). In Ethiopia, no time evolution is discussed in the paper, so there is no basis for comparison (Tapponnier et al., 1990). In Montana, Iceland, and Nicaragua, the temporal aspect of bookshelf faulting is similar, and in each scenario, bookshelf faulting is occurring on a time scale of years, which is considered rapid on a geologic time scale.

\section{Coulomb Stress Changes}

We explored the changes in the local stress field and the possible triggering of aftershocks by computing Coulomb stress changes. The timing and duration of individual earthquake clusters and Coulomb stress changes provide information on when and where stress is being relieved and transferred. Aftershock events are primarily temporally clustered and events within individual clusters last from one week to three months. Coulomb stress changes indicate where faults might rupture based on receiver and source fault geometry and on the amount and sense of slip. Because we used a focal mechanism from Cluster 2 to define receiver fault geometry and sense of slip, this suggests that this specific receiver fault was brought closer to failure due to the main fault rupture. Additionally, Cluster 2 was in a region of positive Coulomb stress changes of $\sim 2-4$ bars, while some other clusters were located in regions of positive Coulomb stress changes of 1-2 bars, so a stress change of 1-2 bars was likely sufficient to trigger events to the west of the mainshock. It is probable that the other clusters were also triggered by the main shock, but it took a longer amount of time for stress to build up on these faults; perhaps they were initially further from failure or the faults have different frictional properties. It is unlikely that the faults have different frictional properties given that all 
events are occurring within a relatively small region. Static stress changes from the main shock likely triggered additional events and promoted failure along a series of parallel, left-lateral strike slip faults located to the west of the source fault. Coulomb stress changes also depend on the regional stress field. Static stress changes indicate how this one event perturbed the regional stress field. Both static stress changes and the regional stress field likely contribute to the spatial distribution of aftershock events. Because there is ambiguity between the two nodal planes, the Coulomb stress changes would also be applicable to two parallel right-lateral strike slip faults, consistent with the orientation of the LCL faults.

\section{Spacing of Bookshelf Faulting Mechanisms}

Bookshelf faulting can occur on large and small scales and in various tectonic environments. We compare the overall scale of bookshelf faulting and the spacing between individual bookshelf faults in Montana to the scale and spacing at which bookshelf faulting is occurring in Iceland, Nicaragua, and Ethiopia. In Montana, clusters are primarily separated from each other by $\sim 1$ to $5 \mathrm{~km}$ and are confined to a region of $\sim 15$ by $10 \mathrm{~km}$. In Iceland, crustal blocks are $\sim 15$ by $2 \mathrm{~km}$ in size (Green et al., 2014). Figure 2 from Green et al (2014) shows that five left lateral strike-slip faults are $\sim$ two km apart from each other; however, the faults are not evenly spaced. In Nicaragua, bookshelf faults are confined to a region of $25 \mathrm{~km}$, and Figure 1 from La Femina et al. (2002) shows that slip is occurring on multiple fault planes. In Ethiopia, bookshelf faults are confined to a narrow zone that is $\sim 10 \mathrm{~km}$ wide, and each bookshelf fault is offset from one another by $\sim 3 \mathrm{~km}$ (Tapponnier et al., 1989). The scale and spacing of bookshelf faults in Montana is similar to examples of bookshelf faulting occurring in Iceland, Nicaragua, and Ethiopia. When bookshelf faulting occurs on a smaller scale, it is common to observe multiple, discrete fault planes (Mandl, 1986). 


\section{Presence of Parallel Faults}

In bookshelf faulting mechanisms, bookshelf faults are arrays of parallel faults that are oblique to the direction of the external shear (Mandl, 1986). Figure 26 shows bookshelf faults parallel to one another and roughly perpendicular to the direction of external shear. In Montana, individual clusters are not precisely parallel. Montana has had a long and complex tectonic history, and it is likely that faults in the Lincoln region may be rupturing along pre-existing planes of weakness because it is more energetically favorable for faults to rupture along preexisting planes of weakness than to rupture intact rock. We hypothesize that the variation in the orientation of pre-existing planes of weakness in the Lincoln region might explain why earthquake clusters are not precisely parallel. The bookshelf faulting mechanisms observed in

Iceland, Nicaragua, and Ethiopia all use hypocenter locations and focal mechanism solutions to show the presence of multiple, parallel strike slip faults mapped oblique to the main structural trends in the region (Green et al., 2014; La Femina et al., 2002; Tapponnier et al., 1989).

\section{Summary of Bookshelf Faulting Observed in Montana, Iceland, Ethiopia, and Nicaragua}

Figure 28 shows a simplified version of different bookshelf faulting mechanisms observed in Northwestern Montana, Iceland, Ethiopia, and Nicaragua. 


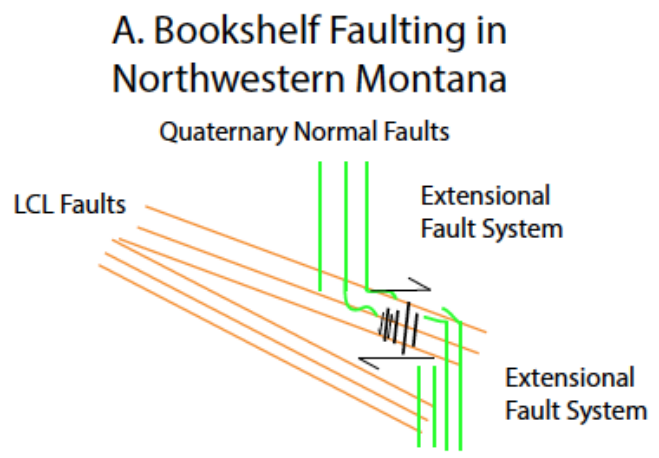

\section{B. Bookshelf Faulting} in Iceland

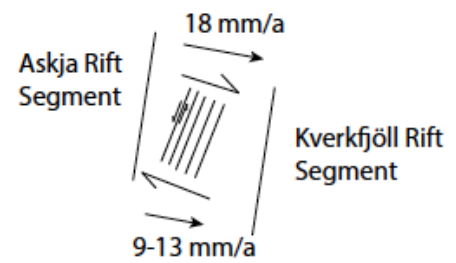

\section{Bookshelf Faulting in Ethiopia}
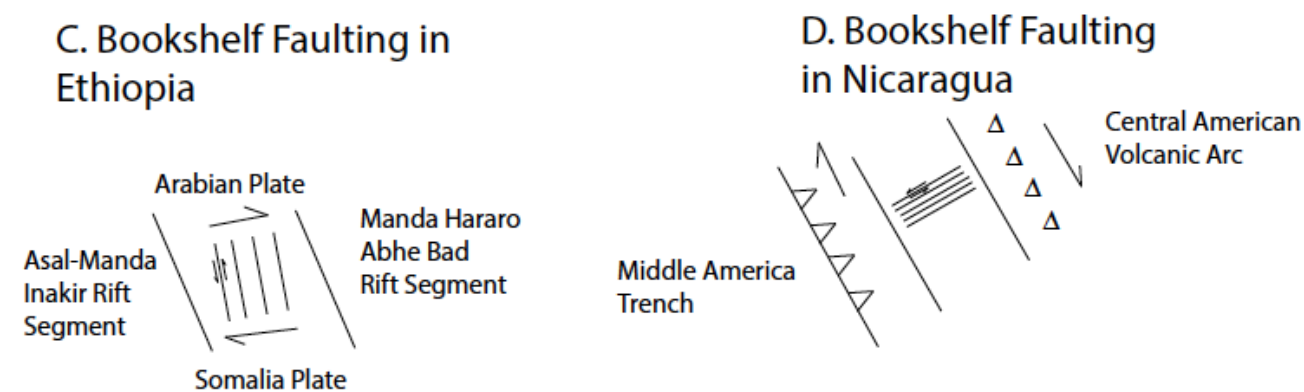

Figure 28. a), b), c), and d) represent a simplified version of bookshelf faulting in northwestern Montana, Iceland, Ethiopia, and Nicaragua. a) Green lines represent $\sim N-S$ trending Quaternary faults located to the north and south of the LCL faults (orange lines). The Quaternary faults resemble two extensional fault systems. The extensional fault system to the north is offset to the west relative to the extensional fault system to the south by the LCL faults. Left-lateral strike slip faults, in black, are mapped oblique to the WNW-ESE trending LCL transform faults. These left lateral faults are likely accommodating differential motion between the two extensional fault systems. b) represents bookshelf faulting in Iceland. Left-lateral strike slip faults are accommodating extensional motion between the two rift segments and right lateral motion due to differential motion to the north and south of the rift relay zone. Left-lateral strike slip faults are sub-parallel to the overall rift fabric (figure modified from Green et al., 2014). c) Left lateral strike slip faults mapped subparallel to the rift fabric in Ethiopia are accommodating extensional motion and right lateral motion due to differential plate motion to the north and south of the rift zone (figure modified from Tapponnier et al., 1990). d) In Nicaragua, left-lateral strike slip faults are mapped perpendicular to the orientation of the Central American Volcanic Arc and the Middle America Trench. Left lateral strike slip faults are accommodating extensional and right lateral motion due to differential motion between the Central American Volcanic Arc and the Middle America Trench (figure modified from La Femina et al., 2002). Note that figures are not drawn to scale. 
Is Shear or Extension the primary form of Deformation in Montana?

There is strong evidence that bookshelf faults are accommodating regional extension in the Lincoln area. P- and T-axes show that the mean direction of extension is NE-SW, and focal mechanism solutions show a combination of normal and strike slip faulting. Regional GPS velocities and associated strain rates in the Northern Rocky Mountains show extension occurring at different rates to the south and north of the Lincoln region. Therefore, we suggest that the presence of differential extension, which can set up shear forces in the crust, is driving overall deformation in this region. An alternative explanation is that bookshelf faults are accommodating localized right lateral shear due to the presence of the LCL faults in the region. We conclude the latter scenario to be unlikely due to the presence of regional extension and the lack of evidence that LCL faults are currently active in the region (Stickney, 2015). 


\section{Conclusions}

We deployed a modern seismic network (UMSN) to complement the USGS temporary stations and the MRSN. The UMSN allows us to use the best set of data for an aftershock sequence in the state of Montana to date. We have picked P- and S- wave arrival times, and plotted Wadati diagrams for each event to test phase pick quality and to determine the average $v_{\mathrm{P}} / v_{\mathrm{S}}$ ratio (1.76). We computed hypocenter locations, double difference relocations, and generated focal mechanisms for hundreds of aftershocks from July 6, 2017 until April 28, 2019. Double difference relocations delineate additional faults in the region that are oblique to the main mapped faults in the region. We observe a series of approximately parallel left-lateral strike slip faults located to the west and east of the M5.8 main fault rupture. Most of the earthquake clusters are occurring to the west of the main shock, and events within most of the individual clusters are occurring within a 2-3 month period; in several instances, events within individual clusters are occurring within the same day. Some aftershock events occur in regions of positive Coulomb stress change ( 1-2 bars) at a depth of $\sim 12-16 \mathrm{~km}$. Static stress changes from the mainshock likely triggered additional aftershocks.

The spatial and temporal distribution of aftershocks near Lincoln, Montana is consistent with other examples of bookshelf faulting around the world. The spatial and temporal distribution of aftershock events suggests that faults are being rotated clockwise into their current orientation. Left-lateral strike slip faults appear to be accommodating differential extension between two rift segments located to the north and south of the LCL. Despite some variation in the orientation of aftershock events due to the region's complex tectonic history, the spatial and temporal evolution of the aftershock sequence following the Lincoln M5.8 event provides evidence for a bookshelf faulting mechanism occurring in an intraplate setting. 


\section{References}

Allmendinger, R. W., N. Cardozo, and D. M. Fisher (2011). Structural Geology Algorithms : Vectors and Tensors, Cambridge University Press, Cambridge.

Beyreuther, M., R. Barsch, L. Krischer, T. Megies, Y. Behr, and J. Wassermann (2010). ObsPy: A Python Toolbox for Seismology, 81, no. 3, 530-533, doi: 10.1785/gssrl.81.3.530.

Catchings, R (1999). Regional Vp, Vs, Vp / Vs, and Poisson's Ratios across Earthquake Source Zones from Memphis, Tennessee, to St. Louis, Missouri, Bull. Seismol. Soc. Am. 89, no. 6, 1591-1605.

Christensen, N. I., 1996, Poisson's ratio and crustal seismology: Journal of Geophysical Research: Solid Earth, 101, B2, 3139-3156, doi: 10.1029/95JB03446.

Ekström, G., M. Nettles, and A. M. Dziewoński (2012), The global CMT project: Centroidmoment tensors for 13,017 earthquakes, Phys. Earth Planet. Inter., 200,1-9.

Fiedler, B., Hainzl, S., Zöller, G., \& Holschneider, M. (2018). Detection of Gutenberg-Richter b-Value Changes in Earthquake Time Series. Bulletin of the Seismological Society of America, 108(5A), 2778-2787. doi:10.1785/0120180091

FPFIT, FPPLOT and FPPAGE: Fortran computer programs for calculating and displaying earthquake fault-plane solutions (n.d.), doi: 10.3133/ofr85739.

Green, R. G., R. S. White, and T. Greenfield (2014). Motion in the north Iceland volcanic rift zone accommodated by bookshelf faulting, 7, no. 1, 29-33, doi: 10.1038/ngeo2012.

Gutenberg, B., and C. F. Richter (1944). Frequency of earthquakes in California, Bull. Seismol. Soc. Am. 34, no. 4, 185-188.

Jo, Eunyoung, and Tae-Kyung Hong (2013). V (sub P) /V (sub S) Ratios in the Upper Crust of the Southern Korean Peninsula and Their Correlations with Seismic and Geophysical Properties. Journal of Asian Earth Sciences 66, 204-214.

Johnston, J. E., \& Christensen, N. I. (1992). Shear wave reflectivity, anisotropies, Poisson's ratios, and densities of a southern Appalachian Paleozoic sedimentary sequence. Tectonophysics, 210(1), 1-20. doi:10.1016/0040-1951(92)90124-O.

Klein, F. (2014). User's Guide to HYPOINVERSE-2000, a Fortran Program to Solve for Earthquake Locations and Magnitudes, Version 1.40, June 2014, Unpublished, doi: 10.13140/2.1.4859.3602.

Krischer, L., T. Megies, R. Barsch, M. Beyreuther, T. Lecocq, C. Caudron, and J. Wassermann (2015). ObsPy: a bridge for seismology into the scientific Python ecosystem, 8, no. 1, 14003, doi: 10.1088/1749-4699/8/1/014003.

La Femina, P. C., T. . Dixon, and W. Strauch (2002). Bookshelf faulting in Nicaragua, 30, no. 8, 751, doi: $\mathrm{BFIN}>2.0 . \mathrm{CO} ; 2$. 
Lee, M. W. (2003). Velocity ratio and its application to predicting velocities (Version 1.0. ed.). Reston, Va.: U.S. Dept. of the Interior, U.S. Geological Survey.

Lin, J., and R. S. Stein (2004). Stress triggering in thrust and subduction earthquakes and stress interaction between the southern San Andreas and nearby thrust and strike-slip faults, 109, no. B2, B02303-n/a, doi: 10.1029/2003JB002607.

Mandl, G. (1987). Tectonic deformation by rotating parallel faults: the "bookshelf" mechanism, 141, no. 4, 277,289-285,316, doi: 10.1016/0040-1951(87)90205-8.

Marrett, R., and R. W. Allmendinger (1990). Kinematic analysis of fault-slip data, 12, no. 8, 973-986, doi: 10.1016/0191-8141(90)90093-E.

R. Mjelde, R. Aurvøag, S. Kodaira, H. Shimamura, K. Gunnarsson, A. Nakanishi, H. Shiobara. $\mathrm{V}_{\mathrm{P}} / \mathrm{V}_{\mathrm{S}}$-ratios from the central Kolbeinsey ridge to the Jan Mayen basin, north Atlantic; implications for lithology, porosity and present-day stress field. Marine Geophysical Researches, 23 (2002), pp. 125-145

Okal, E. A., and J. R. Sweet (2007). Frequency-size distributions for intraplate earthquakes, in Continental Intraplate Earthquakes: Science, Hazard, and Policy Issues, S. Stein and S. Mazzotti (Editors), Geol. Soc. Am. Spec. Pap. 425, 59-71, doi: 10.1130/2007.2425(05).

Payne, S. ., R. McCaffrey, R. . King, and S. Kattenhorn (2012). A new interpretation of deformation rates in the Snake River Plain and adjacent basin and range regions based on GPS measurements, 189, no. 1, 101-122, doi: 10.1111/j.1365-246X.2012.05370.x.

Pierce, K. L., and L. A. Morgan (2009). Is the track of the Yellowstone hotspot driven by a deep mantle plume? - Review of volcanism, faulting, and uplift in light of new data, 188, no. 1, 1-25, doi: 10.1016/j.jvolgeores.2009.07.009.

REASENBERG, P. A., and R. W. SIMPSON (1992). Response of Regional Seismicity to the Static Stress Change Produced by the Loma Prieta Earthquake, 255, no. 5052, 16871690, doi: 10.1126/science.255.5052.1687.

Laura Reiser Wetzel, Douglas A. Wiens, and Martin C. Kleinrock. Evidence from Earthquakes for Bookshelf Faulting at Large Non-transform Ridge Offsets. Nature 362.6417 (1993): 235-237.

Peng, Zhigang., Vidale, John., \& Houston, Heidi. (2006). Anomalous early aftershock decay rate of the 2004 Mw6.0 Parkfield, California, earthquake. Geophysical Research Letters, 33, L17307, doi: 10.1029/2006GL026744.

Reynolds, M. W. (1979). Character and extent of Basin-Range faulting, western Montana and east central Idaho, in Basin and Range Symposium and Great Basin Field Conference, G. W. Newman and H. D. Goode (Editors), Rocky Mountain Association of Geologists/Utah Geological Association, Salt Lake City, Utah/Denver, Colorado, 185-193. 
Schmeelk, D., Bendick, R., Stickney, M., \& Bomberger, C. (2017). Kinematic evidence for the effect of changing plate boundary conditions on the tectonics of the northern U.S. Rockies. Tectonics, 36, 1090-1102, doi: 10.1002/2016TC004427

Sears, J. W., and M. Hendrix (2004). Lewis and Clark line and the rotational origin of the Alberta and Helena salient, North American Cordillera, in Orogenic Curvature: Integrating Paleomagnetic and Structural Analysis, A. J. Susan and A. B. Weil (Editors), Geol. Soc. Am. Special Paper 383, 173-186, doi: 10.1130/0-8137-2383-3 (2004)383[173:LACLAT]2.0.CO;2.

Stein, S., and M. Wysession (2003). An Introduction to Seismology, Earthquakes, and Earth Structure, Wiley-Blackwell, GB.

Stickney, M. (2015). Seismicity within and adjacent to the Eastern Lewis and Clark Line, Westcentral Montana, 44, 19-36.

Stickney, M. C., and M. J. Bartholomew (1987). Seismicity and quaternary faulting of the northern basin and range province, Montana and Idaho, 77, no. 5, 1602-1625.

Tapponnier, P., R. Armijo, I. Manighetti, and V. Courtillot (1990). Bookshelf faulting and horizontal block rotations between overlapping rifts in southern Afar, 17, no. 1, 1-4, doi: 10.1029/GL017i001p00001.

Toda, S., R. S. Stein, K. Richards-Dinger, and S. B. Bozkurt (2005). Forecasting the evolution of seismicity in southern California: Animations built on earthquake stress transfer, 110, no. B5, B05S16, doi: 10.1029/2004JB003415.

USGS (n.d.). M 5.8 - 11km SE of Lincoln, Montana, <https://earthquake.usgs.gov/earthquakes/eventpage/us10009757/moment-tensor> (accessed June 11, 2019).

USGS (n.d.) Earthquake Glossary, https://earthquake.usgs.gov/learn/glossary/?term=aftershocks (accessed January 16, 2020).

Wadati, K. 1933. On the travel time of earthquake waves, Part II, Geophys. Mag., 7 : 101-111.

Waldhauser, F. (2000). A Double-Difference Earthquake Location Algorithm: Method and Application to the Northern Hayward Fault, California, 90, no. 6, 1353-1368, doi: $10.1785 / 0120000006$.

Waldhauser, F. (2001). HypoDD -- A Program to Compute Double-Difference Hypocenter Locations, Columbia University, doi: 10.7916/D8SN072H.

Wallace, C. A., D. J. Lidke, and R. G. Schmidt (1990). Faults of the central part of the Lewis and Clark line and fragmentation of the Late Cretaceous foreland basin in west-central Montana, Geol. Soc. Am. Bull. 102, no. 8, 1021-1037, doi: 10.1130/0016-7606(1990) 102<1021:FOTCPO>2.3.CO;2. 
Wassermann, J., L. Krischer, R. Barsch, M. Beyreuther, and T. Megies (2011). ObsPy-What can it do for data centers and observatories? 54, no. 1, 47-58, doi: 10.4401/ag-4838.

Wessel, P., W. H. F. Smith, R. Scharroo, J. Luis, and F. Wobbe (2013). Generic Mapping Tools: Improved Version Released, 94, no. 45, 409-410, doi: 10.1002/2013EO450001.

Zeiler, C. P., M. C. Stickney, and M. A. Speece (2005). Revised Velocity Structure of Western Montana, 95, no. 2, 759-762, doi: 10.1785/0120040088. 


\section{Appendices}

Appendix A. Loading Data, Picking Phases, and Exporting Picks/catalogs from Jiggle

This section explains how to load data, pick phases, and export picks/locations in Jiggle. Because the UMSN data are not telemetered, after manually retrieving data from the stations, we archive the data with IRIS at the following website: https://ds.iris.edu/mda/UM. We then have the ability to view waveforms for the MRSN, USGS, and UMSN networks. We select the events in the Lincoln region, and only make $\mathrm{P}$ - and $\mathrm{S}$ - wave picks for events in the Lincoln region. Once Pand S- wave picks are made for each station for a given event, Jiggle invokes Hypoinverse to locate the events and updates information such as hypocenter location, vertical and horizontal error, RMS error, azimuthal gap, and local magnitude for each analyzed event. We export the event parameters by logging into the University of Utah database. We specify the file type (i.e. archive or summary file, date range, and region of interest. We additionally include finalized, intermediate, and human reviewed events). We only exclude events that have been automatically located by the software (i.e. not human reviewed). We then relocate the events using HypoInverse-2000.

Appendix B. Emergent and Impulsive Phase Arrivals

Emergent $P$-wave arrival. Note the + symbol indicates a weaker polarity pick than the $U$ symbol.

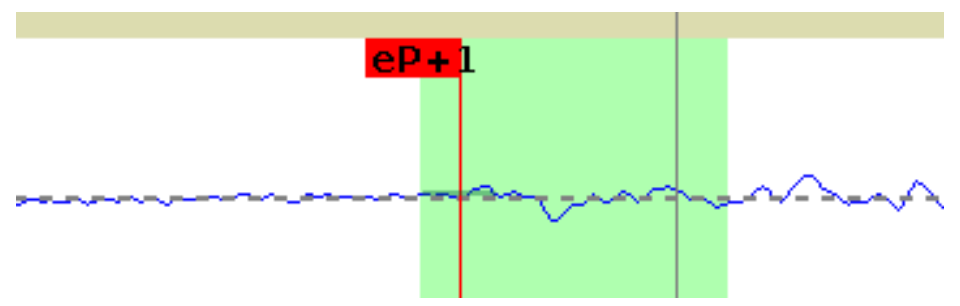

Impulsive P-wave arrival:

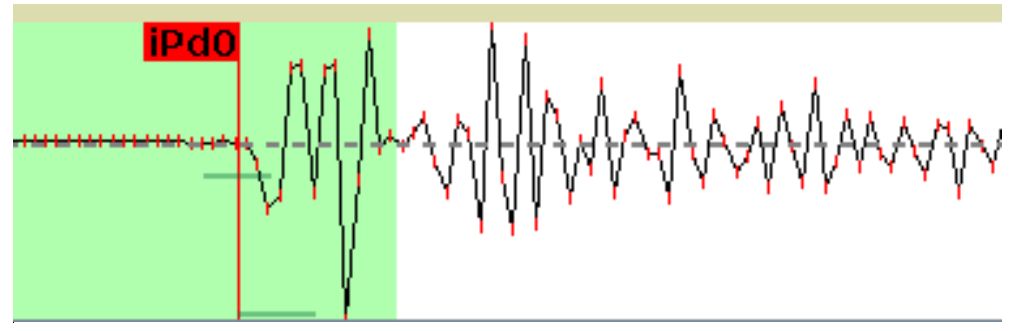


HypoDD built in programs:

Ncsn2pha: converts hypoinverse-2000 archive file to a file containing phase travel time information (see p. 23 of HypoDD manual).

Ph2dt: Converts phase data from the output of ncsn2pha to travel times differences for event pairs recorded at the same station.

We used valued in bold (i.e. $0.2,200,2,8,8,5,80$ ) as the parameters to calculate the difference in travel time residuals for events recorded at the same station. This helped compute the doubledifference relocations show in Figs. 14-20. Note that values in brackets after each parameter are the default values in HypoDD. The values we used for this specific study are in bold at the bottom of the example ph2dt input file.

* ph2dt.inp - input control file for program ph2dt

* Input station file:

/home/es126387/hypoDD-files/MT-stations.txt

* Input phase file:

lincoln-all.pha

*MINWGHT: min. pick weight allowed [0]

*MAXDIST: max. distance in $\mathrm{km}$ between event pair and stations [200]

*MAXSEP: max. hypocentral separation in $\mathrm{km}$ [10]

*MAXNGH: max. number of neighbors per event [10]

*MINLNK: min. number of links required to define a neighbor [8]

*MINOBS: min. number of links per pair saved [8]

*MAXOBS: max. number of links per pair saved [20]

*MINWGHT MAXDIST MAXSEP MAXNGH MINLNK MINOBS MAXOBS

$\begin{array}{lllllll}0.2 & 200 & 2 & 8 & 8 & 5 & 80\end{array}$

HypoDD: Identifies earthquake clusters.

HypoDD example input file (see a full description of hypoDD parameters in the hypoDD manual on pages 17-20).

* RELOC.INP:

*--- input file selection

* cross correlation diff times:

$*$

$*_{\text {catalog P diff times: }}$

/home/es126387/hypoDD-files/17-19-files/dt.ct

*

* event file:

/home/es126387/hypoDD-files/17-19-files/event.dat

*

* station file:

/home/es126387/hypoDD-files/MT-stations.txt 
*--- output file selection

* original locations:

./ph2dt-maxsep-5/all.loc

* relocations:

./ph2dt-maxsep-5/all.reloc

* station information:

./ph2dt-maxsep-5/all.sta

* residual information:

$*$ ph2dt-maxsep-5.res

* source parameter information:

* ph2dt-maxsep-5.src

$*$

*--- data type selection:

*IDAT: $0=$ synthetics; $1=$ cross corr; $2=$ catalog; $3=$ cross $\&$ cat

* IPHA: $1=$ P; $2=\mathrm{S} ; 3=\mathrm{P} \& \mathrm{~S}$

* DIST:max dist [km] between cluster centroid and station

* IDAT IPHA DIST

23200

$*$

*--- event clustering:

* OBSCC: $\min \#$ of obs/pair for crosstime data $(0=$ no clustering)

* OBSCT: $\min \#$ of obs/pair for network data $(0=$ no clustering $)$

* OBSCC OBSCT

$0 \quad 8$

*

*--- solution control:

* ISTART: $\quad 1=$ from single source; 2 = from network sources

* ISOLV: $\quad 1=$ SVD, $2=$ lsqr

* NSET: $\quad$ number of sets of iteration with specifications following

* ISTART ISOLV NSET

$\begin{array}{lll}2 & 1 & 2\end{array}$

$*$

*--- data weighting and re-weighting:

* NITER: last iteration to use the following weights

* WTCCP, WTCCS: weight cross P, S

* WTCTP, WTCTS: weight catalog P, S

* WRCC, WRCT: $\quad$ residual threshold in sec for cross, catalog data

* WDCC, WDCT: $\quad$ max dist $[\mathrm{km}]$ between cross, catalog linked pairs

* DAMP: damping (for lsqr only)

* --- CROSS DATA ---- ----CATALOG DATA ----

* NITER WTCCP WTCCS WRCC WDCC WTCTP WTCTS WRCT WDCT DAMP $\begin{array}{llllllllll}5 & -9 & -9 & -9 & -9 & 1.0 & 0.3 & 5 & 1 & 80\end{array}$

$\begin{array}{lllllllllll}5 & -9 & -9 & -9 & -9 & 1.0 & 0.5 & 5 & 1 & 80\end{array}$

$*$ 
*--- 1D model:

* NLAY: number of model layers

* RATIO: $\quad$ vp/vs ratio

* TOP: $\quad$ depths of top of layer $(\mathrm{km})$

* VEL: layer velocities $(\mathrm{km} / \mathrm{s})$

* NLAY RATIO

$5 \quad 1.76$

*UPT MODEL

* TOP

$\begin{array}{lllll}0.0 & 1.90 & 5.80 & 18.60 & 38.50\end{array}$

* VEL

$\begin{array}{lllll}4.58 & 5.70 & 6.12 & 6.53 \quad 8.00\end{array}$

$*$

*--- event selection:

* CID: cluster to be relocated $(0=$ all $)$

* ID: cuspids of event to be relocated (8 per line)

* CID

18

* ID

This shows example relocated hypocenter output from HypoDD. The event ID, location, change in location, error for each relative relocation, time, and cluster id number is reported in the hypoDD output. This file shows output for events in Cluster 2 identified in Figs. 14-16 and 20.

\begin{tabular}{|c|c|c|c|c|c|c|c|c|c|c|c|c|c|c|c|c|}
\hline Event ID & latitude & longitude & depth & E-W change & $\mathrm{N}-\mathrm{S}$ change & depth change & E-W error & $\mathrm{N}-\mathrm{S}$ error & depth error & year & month & day & hour & minute & second & clusterid \\
\hline 80235569 & 46.89035 & -112.515 & 9.674 & -31.9 & -22.8 & 210.4 & 25.8 & 38.9 & 71.3 & 2017 & 7 & 23 & 22 & 29 & 59.56 & 2 \\
\hline 80235579 & 46.89055 & -112.515 & 9.51 & -31 & -0.4 & 46 & 26.7 & 38.8 & 73.5 & 2017 & 7 & 23 & 22 & 36 & 1.6 & 2 \\
\hline 80235624 & 46.88897 & -112.511 & 8.834 & 237.7 & -175.7 & -629.5 & 38 & 45.1 & 70.5 & 2017 & 7 & 24 & 0 & 8 & 42.09 & 2 \\
\hline 80235679 & 46.89039 & -112.515 & 9.567 & -39.4 & -17.7 & 103.4 & 21.1 & 32.6 & 52 & 2017 & 7 & 24 & 0 & 32 & 30.75 & 2 \\
\hline 80235794 & 46.89085 & -112.515 & 9.139 & -28.6 & 32.8 & -324.1 & 21.4 & 32.6 & 50 & 2017 & 7 & 24 & 7 & 20 & 26.84 & 2 \\
\hline 80235804 & 46.89076 & -112.512 & 9.003 & 195.4 & 22.9 & -460.9 & 28.3 & 43 & 60.5 & 2017 & 7 & 24 & 7 & 47 & 21.96 & 2 \\
\hline 80235834 & 46.89155 & -112.515 & 9.515 & -3.2 & 111 & 51.5 & 28 & 37.3 & 60.6 & 2017 & 7 & 24 & 9 & 53 & 50.05 & 2 \\
\hline 80238104 & 46.89025 & -112.515 & 9.586 & -61.2 & -33.4 & 122.5 & 25.8 & 46.4 & 62.8 & 2017 & 8 & 1 & 16 & 29 & 39.14 & 2 \\
\hline 80238109 & 46.88994 & -112.515 & 9.5 & -16.8 & -67.6 & 36.9 & 22.3 & 42.3 & 50.9 & 2017 & 8 & 1 & 16 & 31 & 51.2 & 2 \\
\hline
\end{tabular}

\section{Appendix D. Example FPFIT Input File}

Example FPFIT input file (see pages 10-11 from the FPFIT manual for a full description of each command). This shows the commands we used to compute focal mechanisms shown in Appendix E and Fig. 19.

ttl 1 'none'

hyp 'lincoln-all3.arc' out 'lincoln-all3.rep'

sum 'lincoln-all3.sum'

pol 'lincoln-all3-15.pol' 
for 3

mag 0 .

obs 12

dis 200

res 100.0

ain 0.180 .0

amp 0

bst 1

fin 1

rep 1

cmp 0

hdr 0.2290E-01 0.7570E-01 0.22850 .3395

mcr 0.20001 .0001 .0001 .000

dir 90.00250 .020 .005 .000

dip 10.0090 .0020 .005 .000

rak -180.0 160.0 20.0010 .00

chn 1 'HHZ'

chn 2 'BH1'

chn 3 'EHE'

chn 4 'HHE'

chn 5 'EHZ'

chn 6 'BHE'

chn 7 'HHN'

hds 1 ' 2 '

mes 1 ''

Example output summary file from FPFIT (see page 13 from the FPFIT manual for a complete description of each value). This output summary file is for the fault plane solutions shown in Appendix E. The first few columns show the time of the event and the location of the event. Other important information in the file includes the dip direction, dip, and rake of the fault plane (i.e 108, 80, -10 in the first row). The other columns report the amount of uncertainty in the fault plane solution (i.e. 0.09 in the first row represents the amount of misfit in the data set and 0.54 is the value for STDR. The last three columns show the values of uncertainty for strike, dip, and rake.

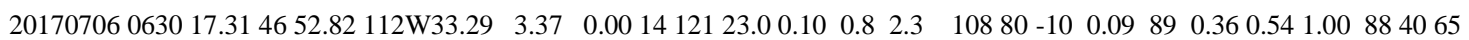

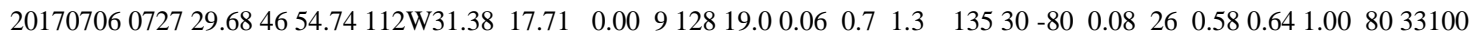

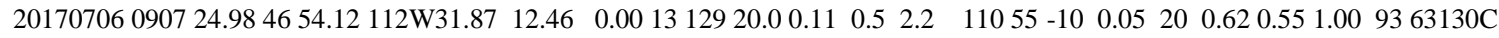

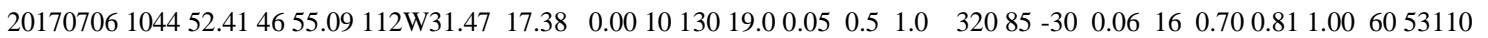

\section{Appendix E. Events Filtered by Magnitude and OBSCT Parameter}

Relocated hypocenters filtered by magnitude and OBSCT (hypoDD) parameter. A comparison of results when the maximum distance between event pairs (MAXSEP parameter), a parameter used to define the number of neighboring events, is set to either $2 \mathrm{~km}$ and $5 \mathrm{~km}$ is also shown. Changing the MAXSEP parameter has only a small effect on the relocated hypocenters (see below). When the OBSCT parameter is set to 10 or 12, fewer events are included because the number of links required to define an event pair has increased, but increasing the OBSCT 
parameter sharpens the spatial distribution and orientation of some of the earthquake clusters. We experimented with setting the OBSCT parameter to a higher threshold to see if it would decrease the scatter in some of the earthquake clusters, but some of the smaller earthquake clusters were lost because it was a time when we had a smaller data set to work with. Filtering events by magnitude also decreased the scatter in earthquake clusters, but some of the clusters were lost. 
Magnitude 0.5, OBSCT 8, 10, and 12
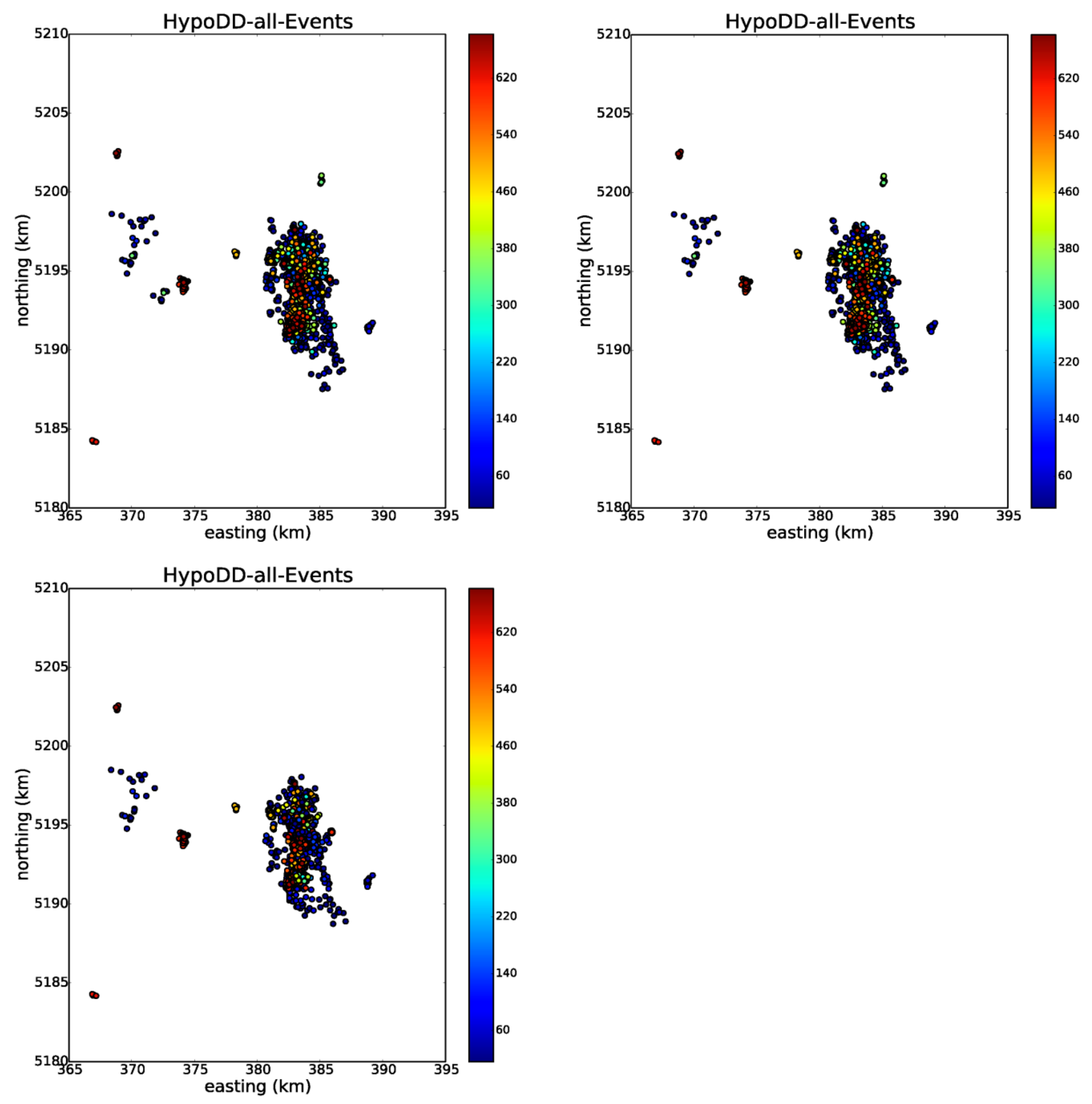
Magnitude 1, OBSCT 8, 10, and 12
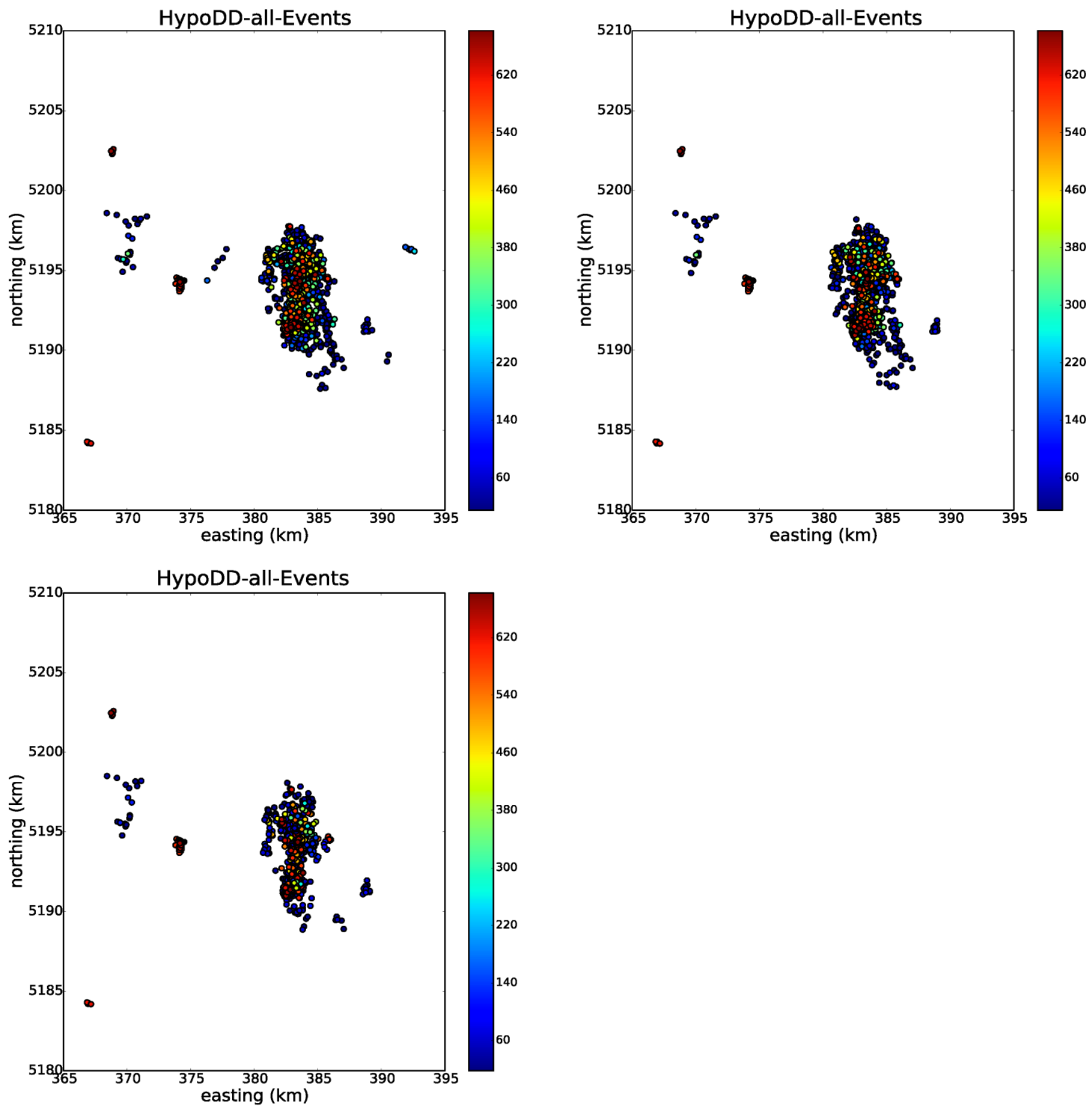
Magnitude 1.5, OBSCT 8, 10, and 12
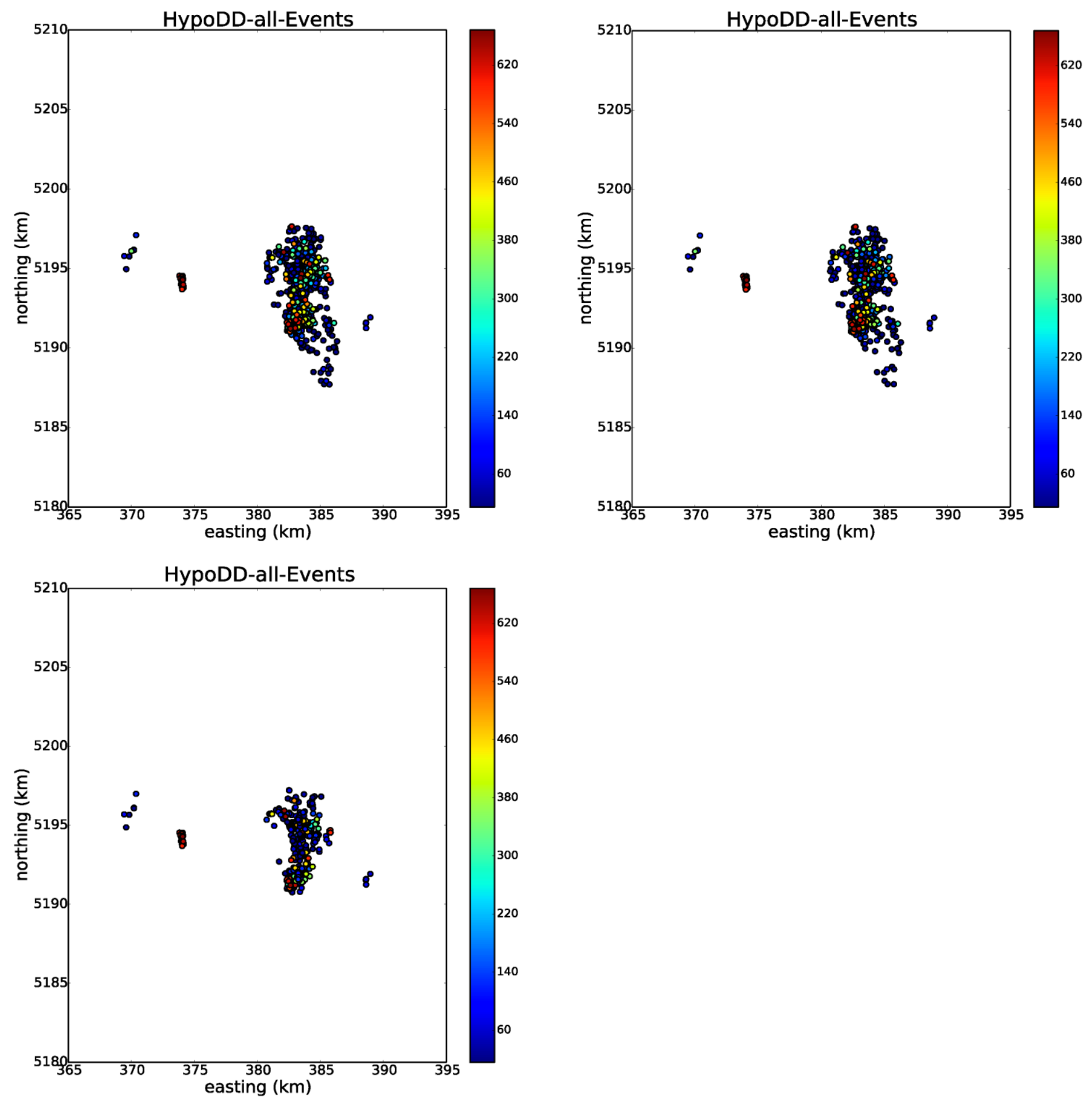
MAXSEP 2, OBSCT 8 and 12; MAXSEP 5, OBSCT 8 and 12
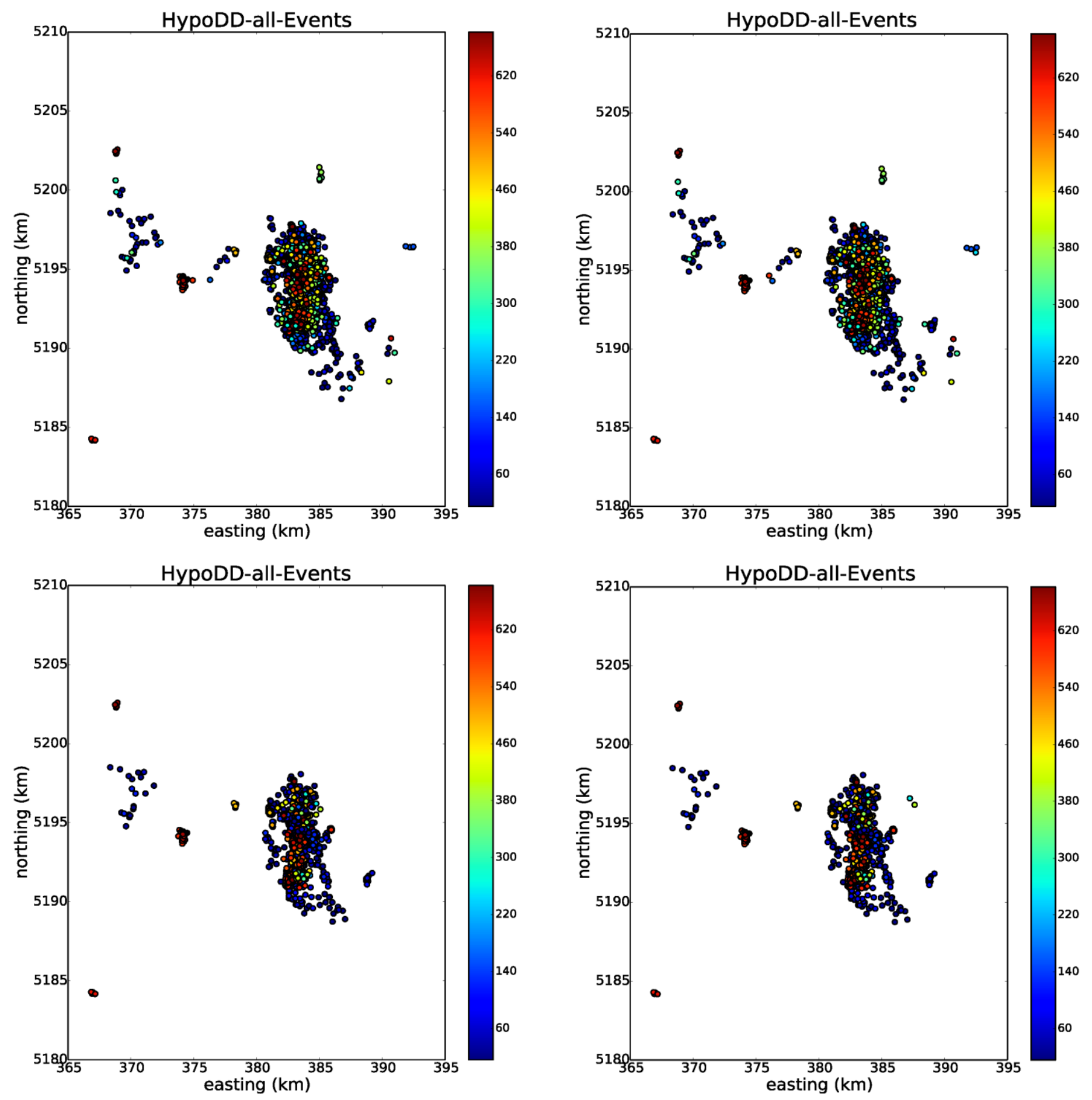
All FPFIT focal mechanism solutions for events with 12 polarities or more.
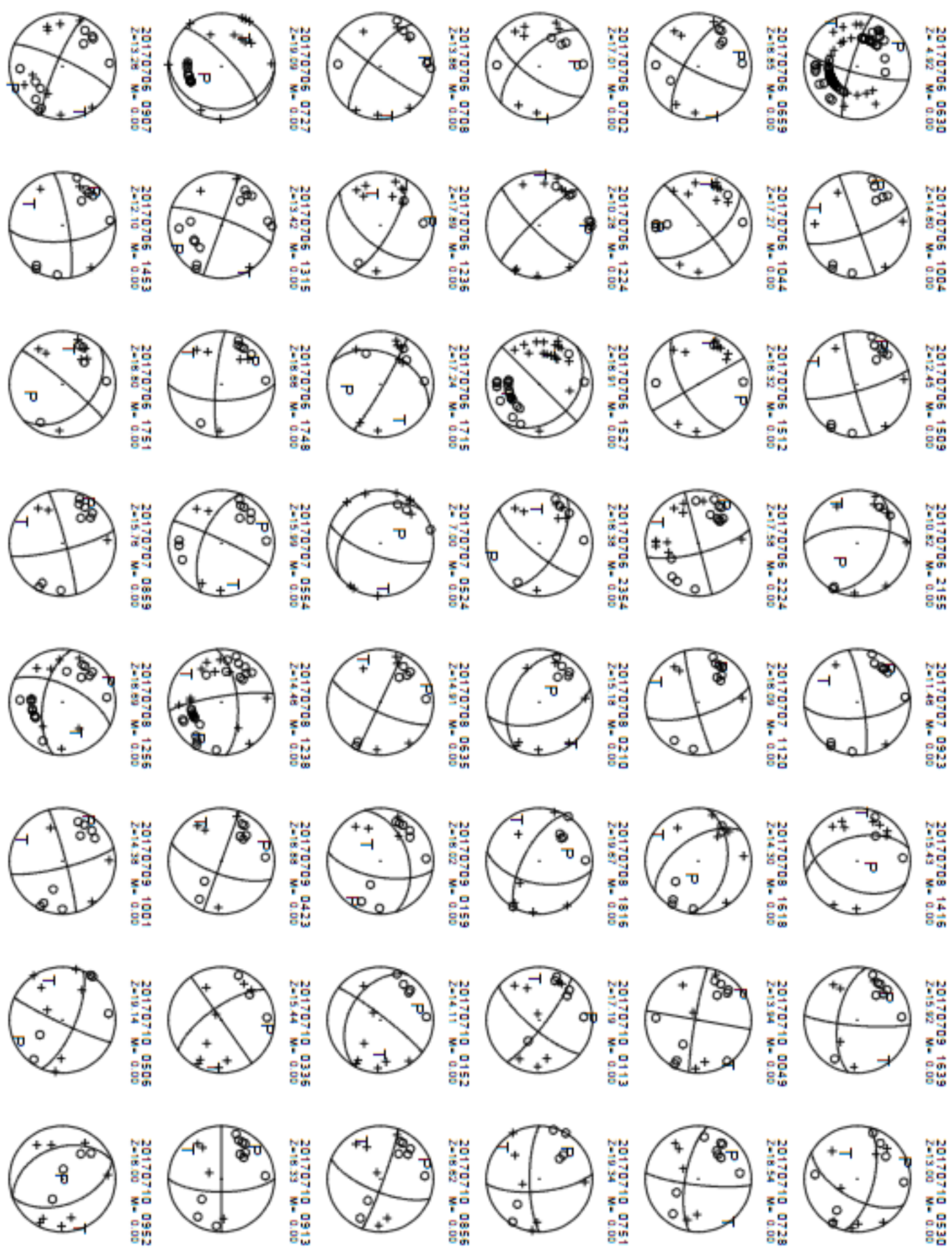
$\left(\begin{array}{r|r|}+4 \\ +20 \\ 0\end{array}\right.$
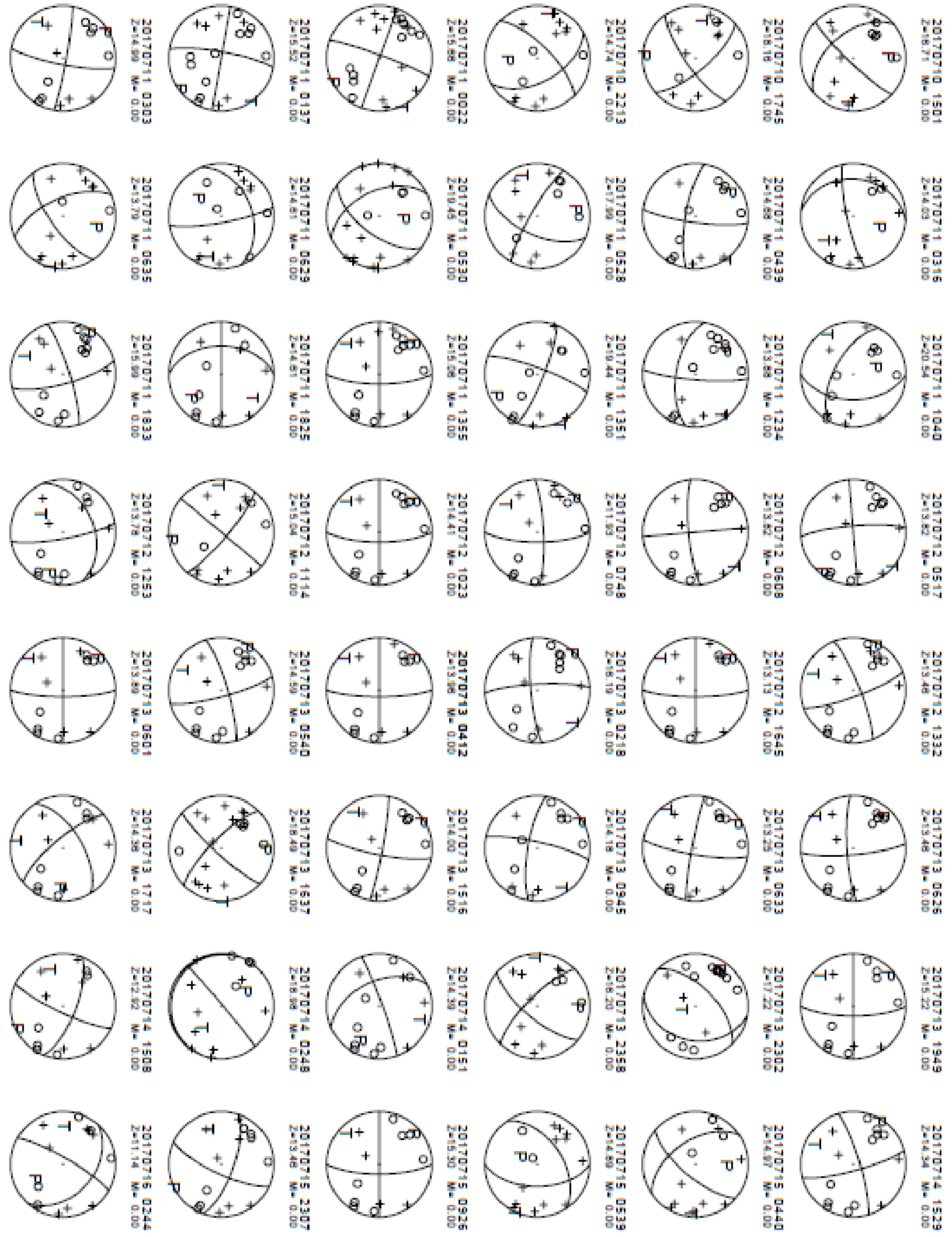

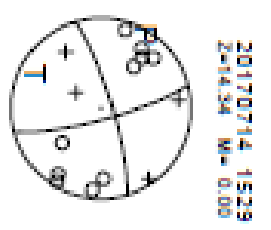



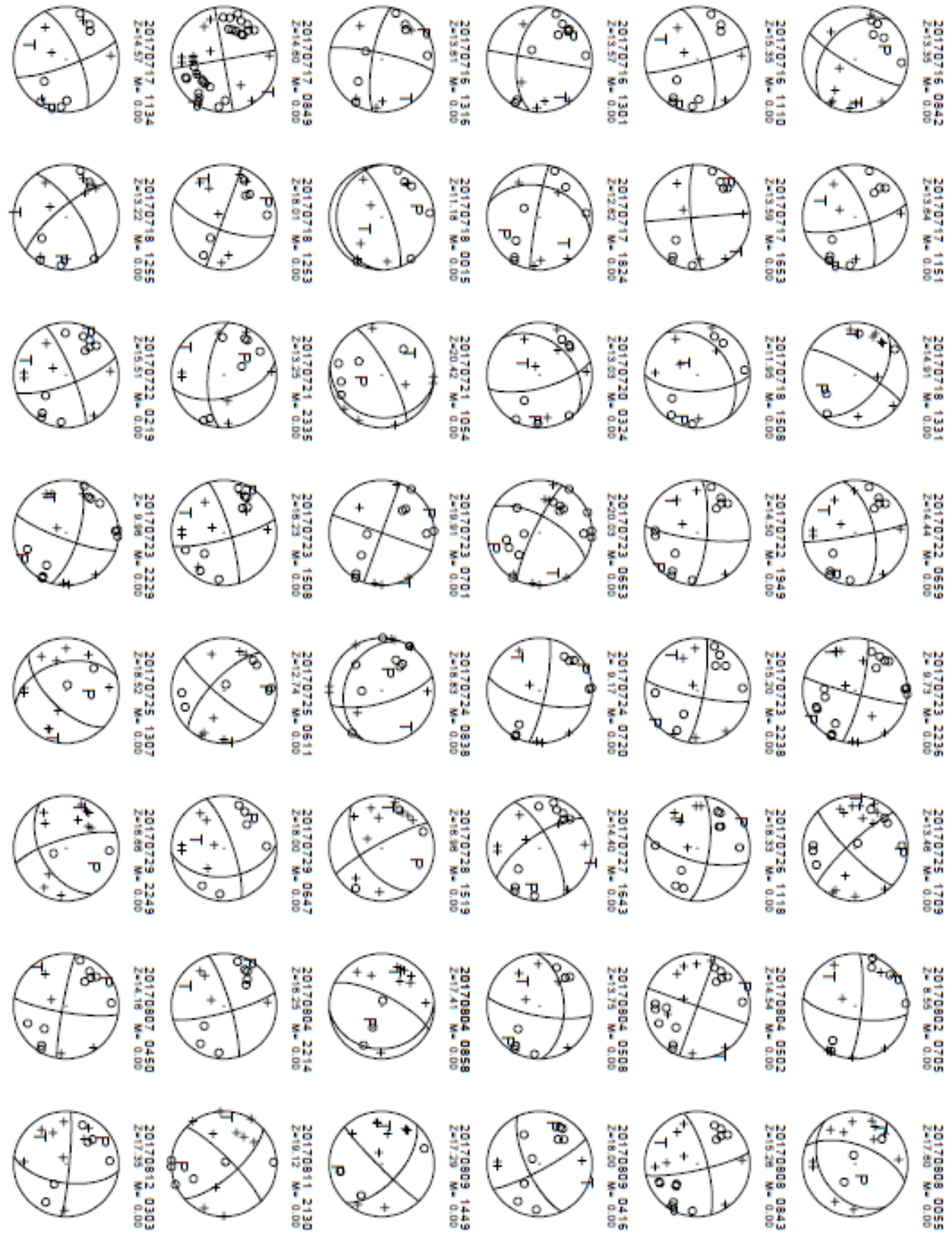

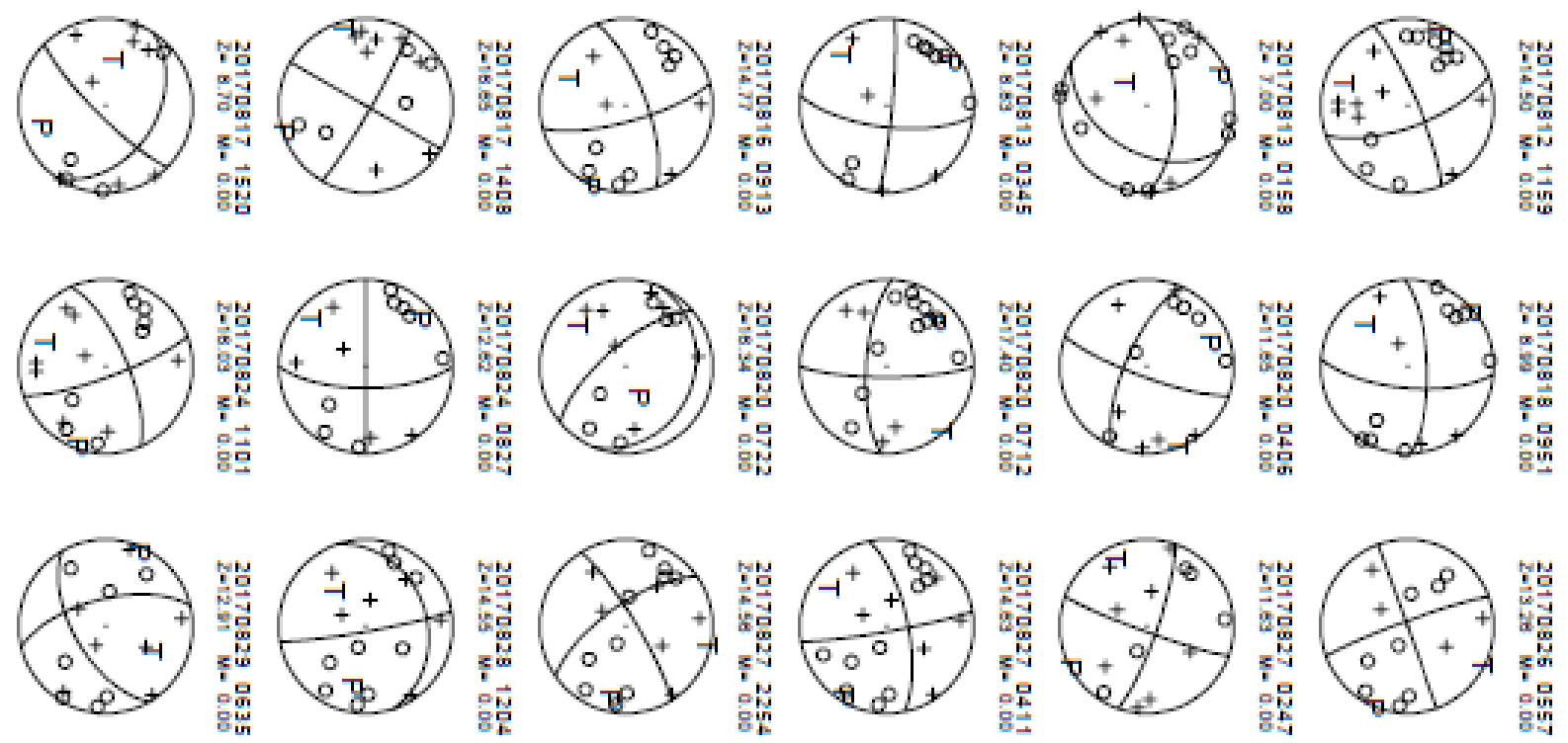

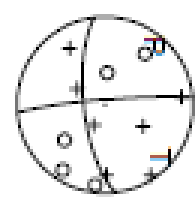
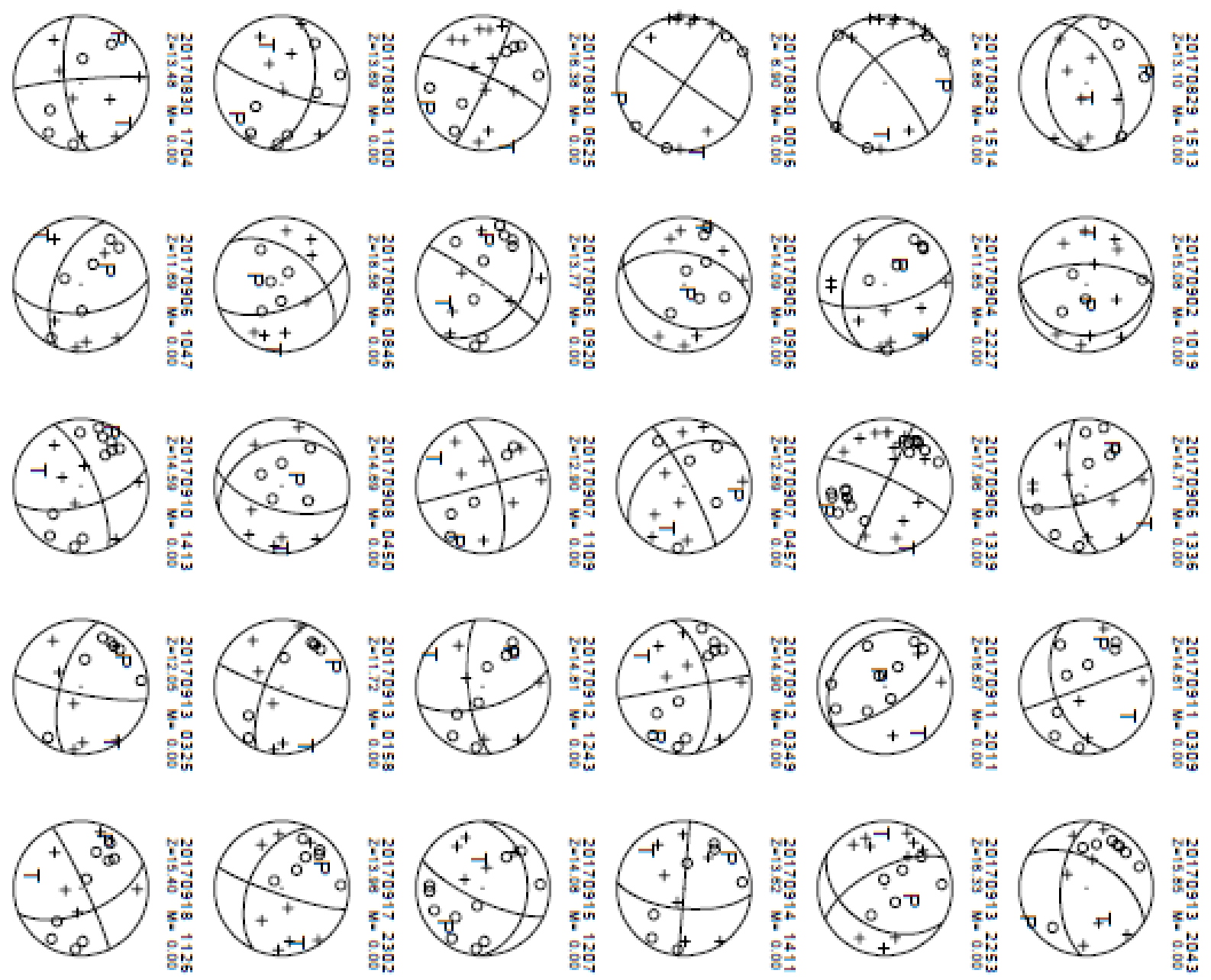

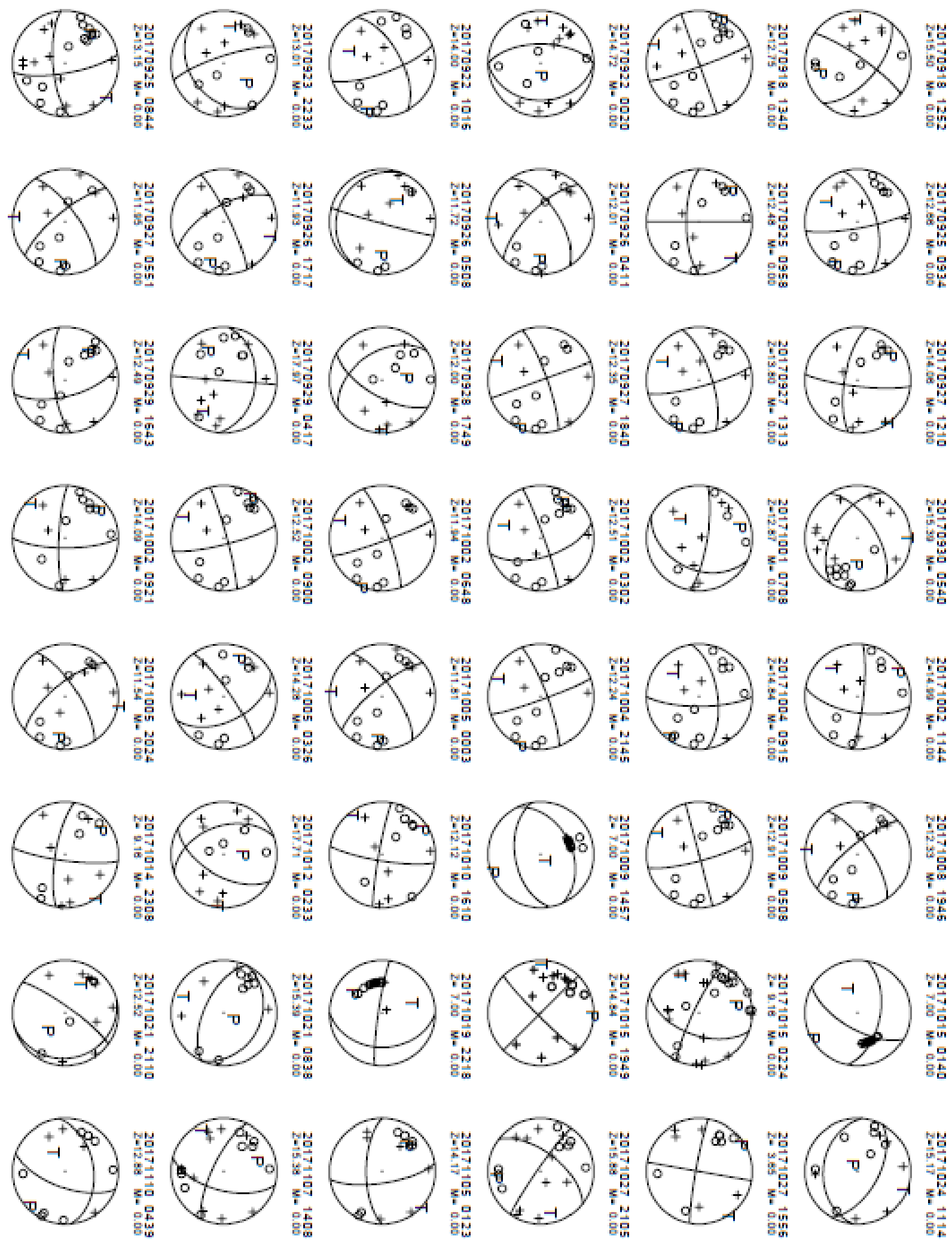

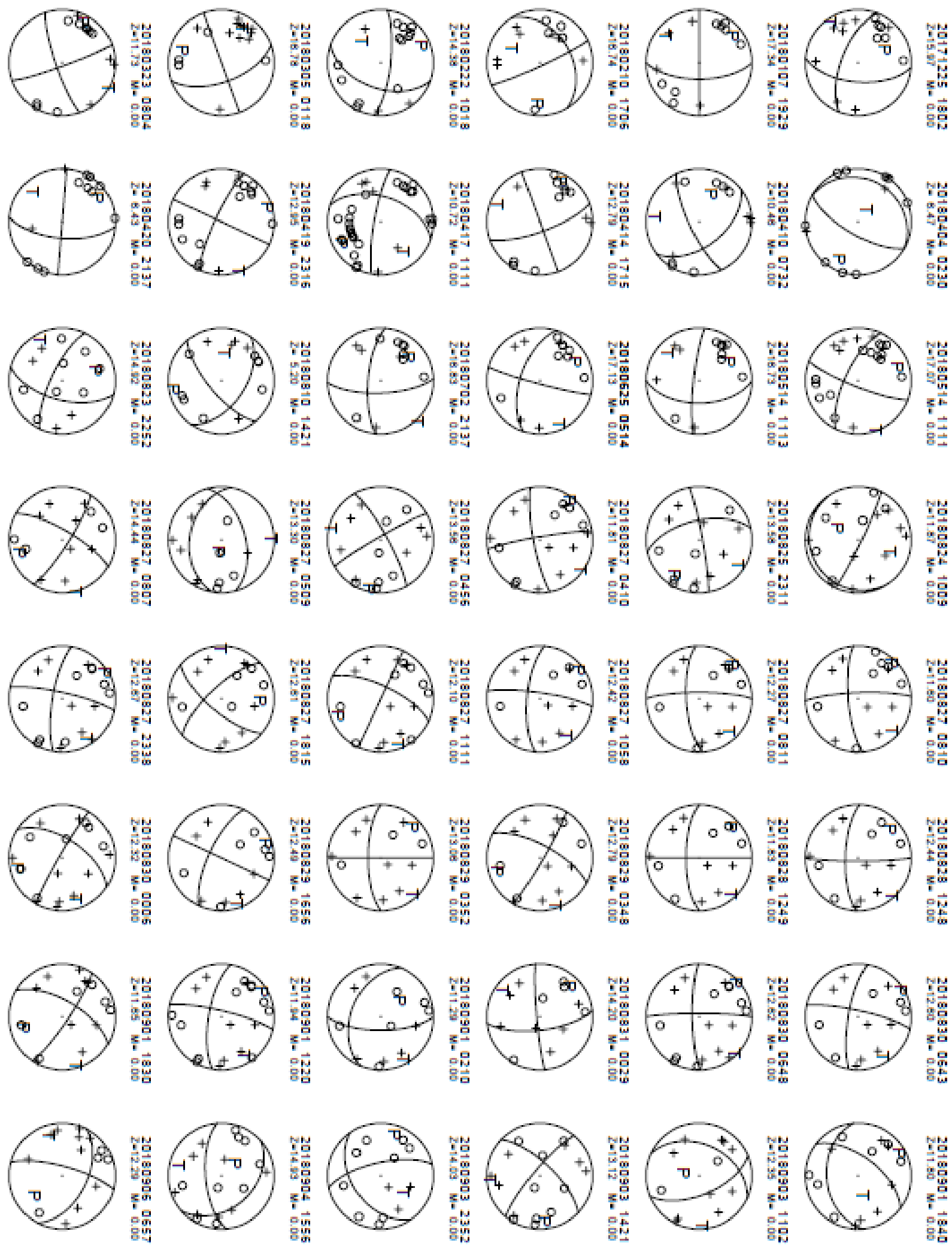


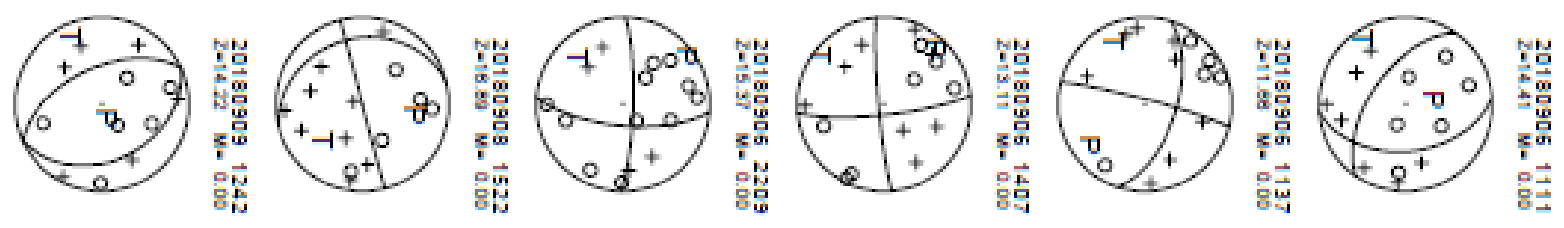

(20.9)

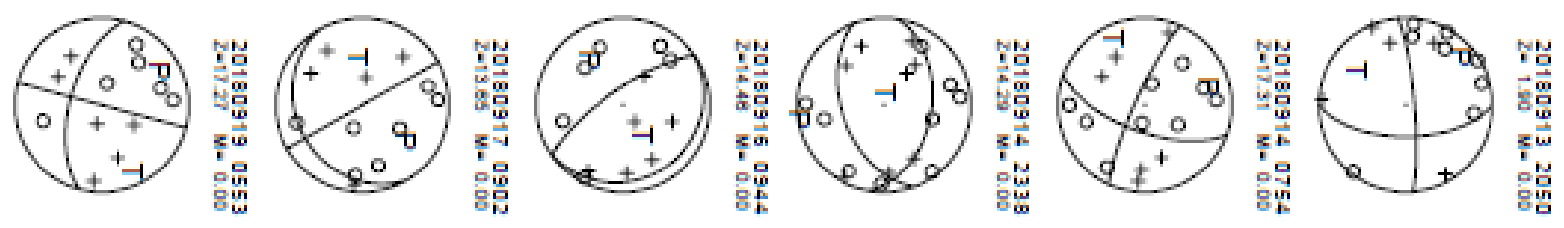

(10.)

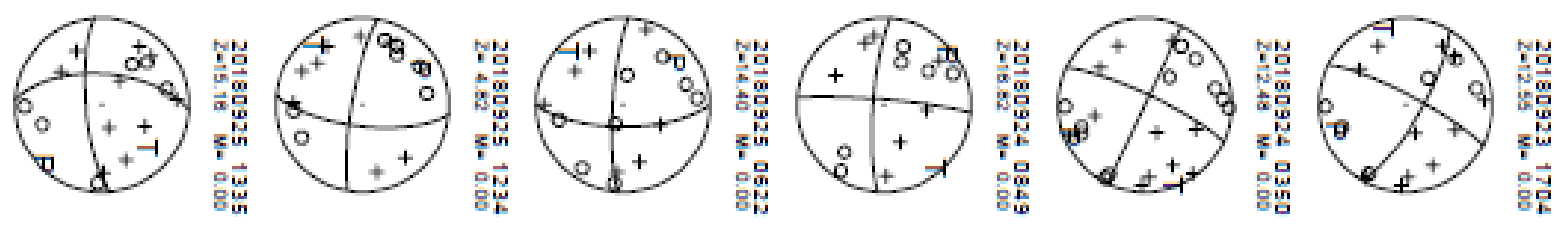

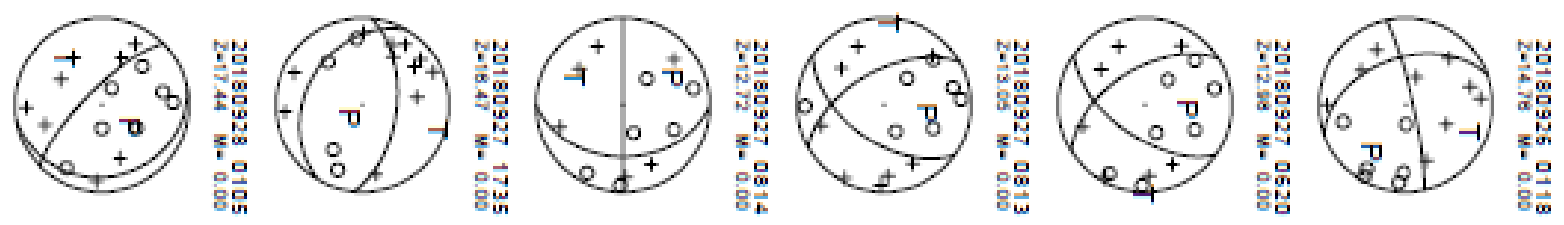

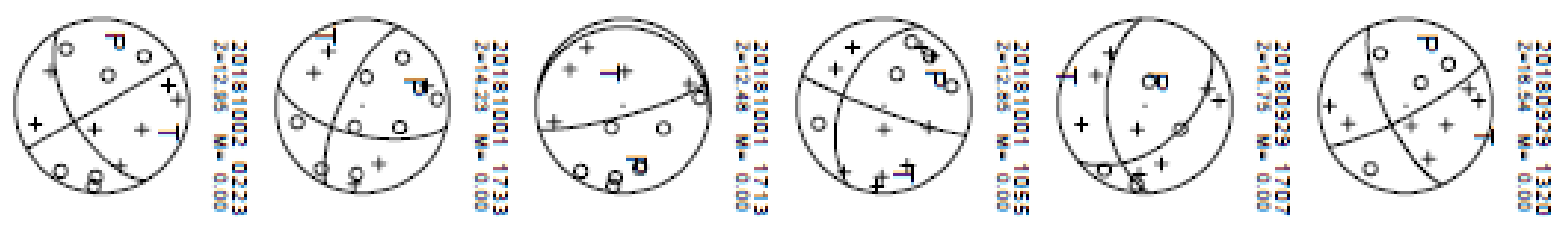

28. 

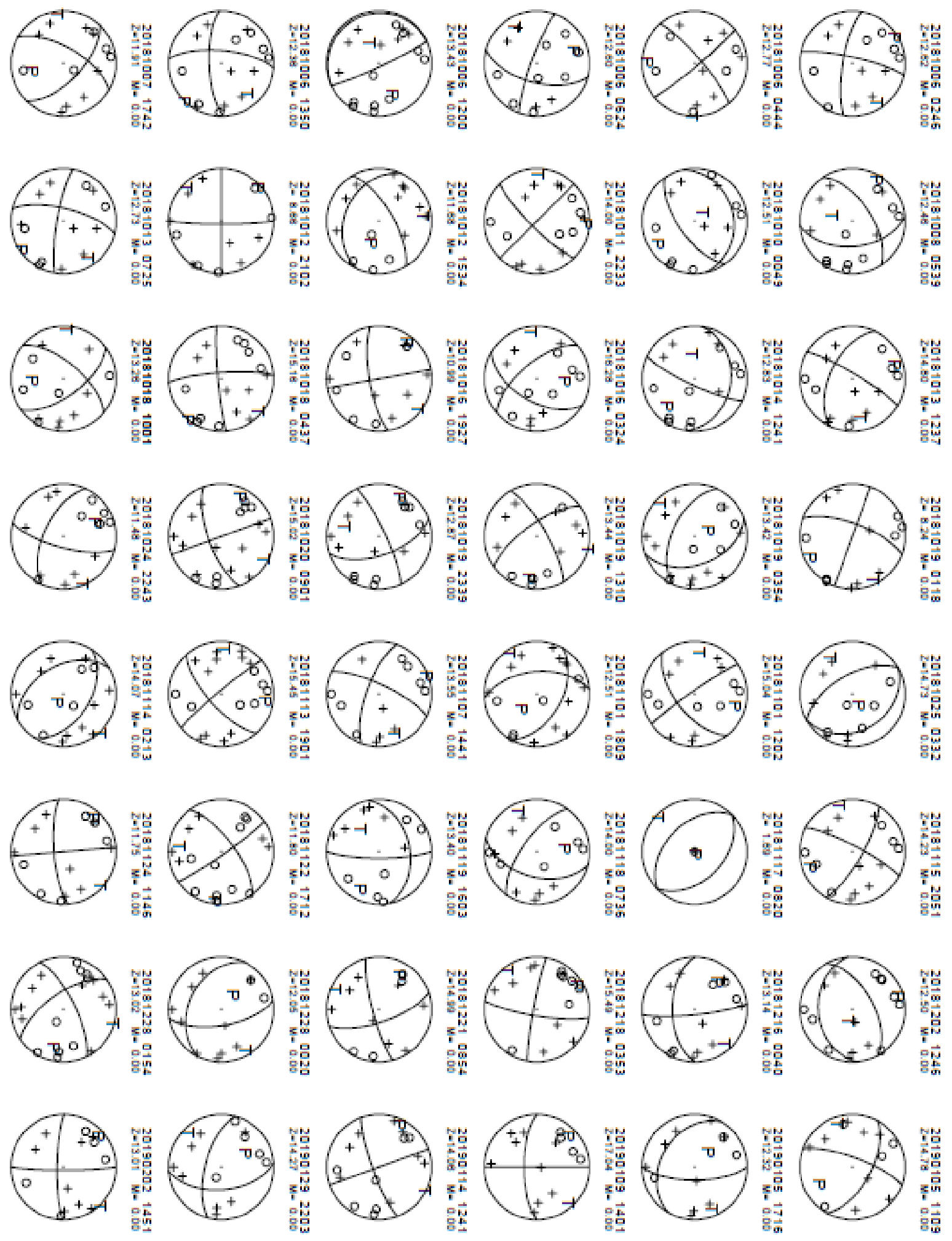

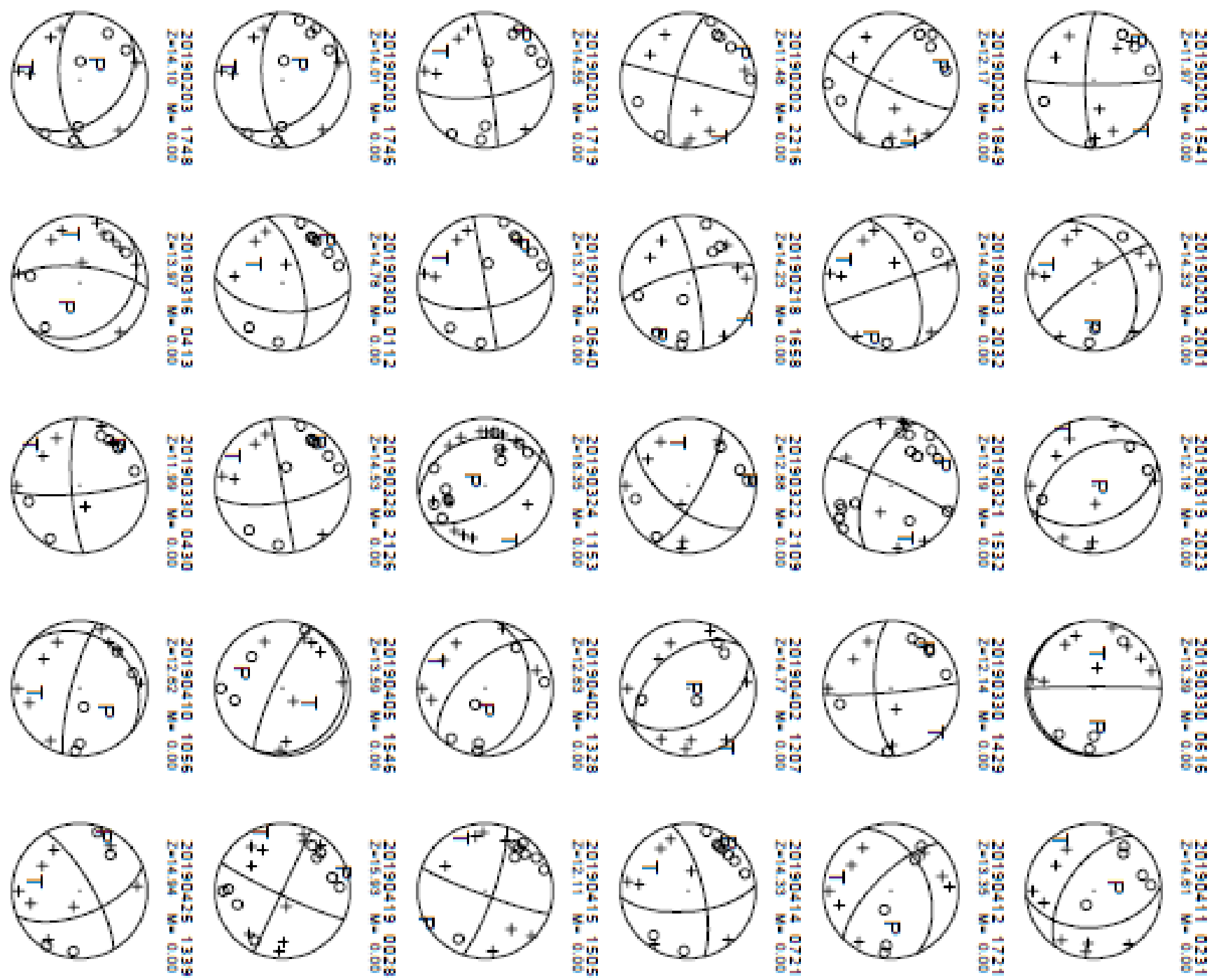
